

\section{TABLE OF CONTENTS}

3 Editorial - Has changed, is changing, will change: Our home the Earth

Boris Vannière, Graciela Gil-Romera and Sarah Eggleston

4 Paleoscience and the UN Sustainable Development Goals

Keely Mills and Matthew Jones

6 Can we tell how climate will change in the future?

Frank Oldfield

$9 \quad$ How green were the oceans in the past?

Iván Hernández-Almeida and Mariem Saavedra-Pellitero

12 From the depths of the Amundsen Sea

Margot Courtillat

16 Why sea level is not level

Juliet Sefton and Fangyi Tan

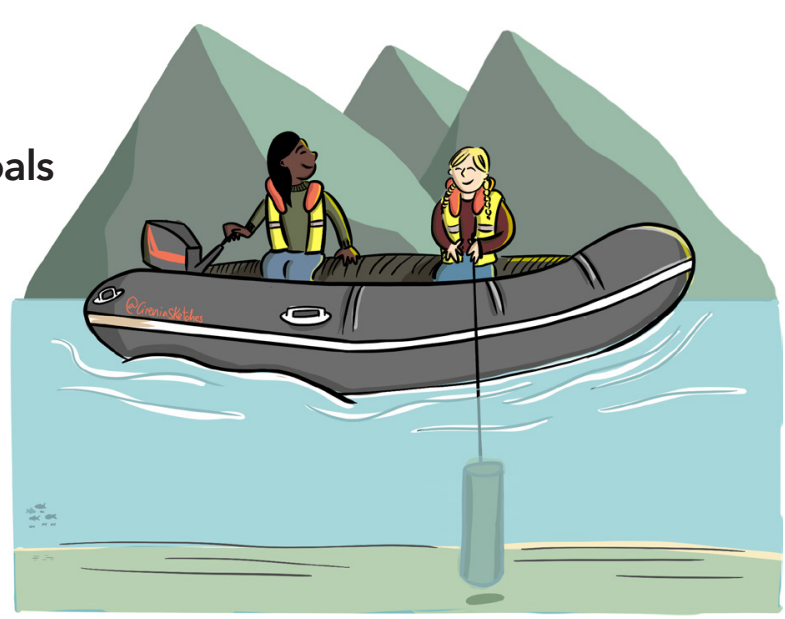

20 A message from the buried past: Deciphering the location of ancient settlements Hadar Elyashiv

23 The stone readers

Jérémie Moreau and Boris Vannière

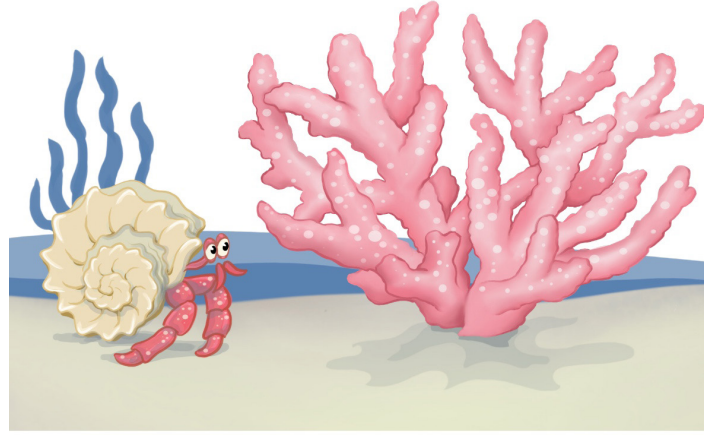

$28 \quad$ Young scientists speak about global change sciences Stella Alexandroff, Alicja Bonk and Tamara Trofimova

30 The South Pacific and climate change Silvia Frisia, Nicole Pierce and Pauline Treble

$34 \quad$ Linking lead pollution in ice cores to ancient history Nathan Chellman and Joe McConnell

$36 \quad$ Lake mud detectives

Laura Hunt, Angela Nankabirwa and Tessa Driessen

38 Pollen reveals the plant world of the past

Andrea Miebach

41 How to record fires that burned thousands of years ago

Emma Rehn

44 Humans and environments in the most arid place of the world

María Eugenia de Porras, Eugenia M. Gayó, Mauricio Uribe and Antonio Maldonado

49 Past farmers and the environment Jerry Olatoyan

52 Paleovirology

Marco Palombelli and Peter Gitau

54 Glossary

Robyn Granger and Graciela Gil-Romera

56 Meet the authors and illustrators

58 Resources and references

59 Acknowledgments

60 Paleotherapy

Boris Vannière and Peb \& Fox

Cover Jérémie Moreau
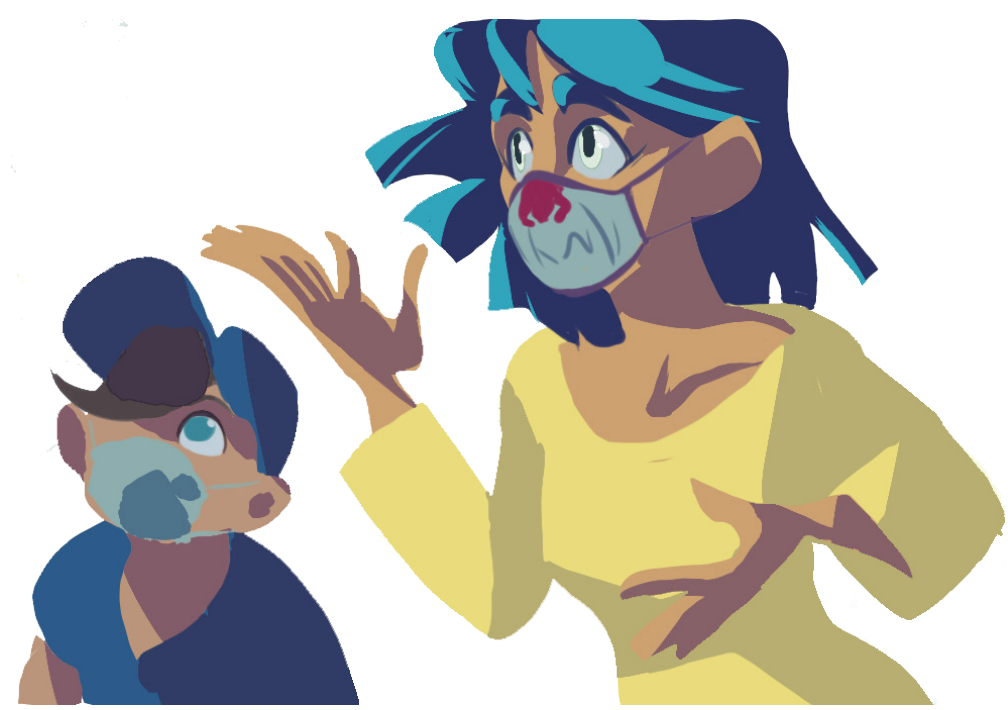

Editors Boris Vannière, Graciela Gil-Romera and Sarah Eggleston 


\title{
HAS CHANGED, IS CHANGING, WILL CHANGE: OUR HOME THE EARTH
}

\author{
Boris Vannière, Graciela Gil-Romera and Sarah Eggleston
}

Generation Z, or C for change? Most of the faces seen at climate strikes and other international political movements for environmental justice have been those of you - the "Post-Millennials", teenagers and young adults. To provide you with a sound scientific basis for issues concerning current environmental and climate change, we have launched a new PAGES publication, Past Global Changes Horizons, where we have asked scientists from all over the world to explain "global change" to the younger generation, and why it is not merely a hypothesis but rather a reality based on facts. This change can be measured, it needs to be highlighted, and we have to face it. You may consider the following pages as a direct source of information that will help you to defend your voice in the ongoing global change debate. You might also consider the time you take to read these articles as your contribution to slowing down the current climate change!

Right now, the Earth is changing a lot, but let's stop to think: how unique is the change that our planet is experiencing compared to changes in the past? Or even more importantly: what is the role of humans in this global change? The only way to find answers to these questions is by looking back in time. That's what paleoscientists do: travel through time! This isn't done with a time machine like Dr. Who's TARDIS, the Back to the Future DeLorean, or the dark matter holes from Dark or Stranger Things. Instead, paleoscientists travel to Antarctica, caves, deserts, or virtually to supercomputing centers, to study ancient societies, explore former landscapes, or look for the reasons for changes in past climate conditions. Their observations allow them to document the long history of the planet that we have inhabited for millennia. All of these observations show that human activities have deeply modified ecosystems and the dynamics of these ecosystems through time.

Like Alice's Adventures in Wonderland, where time runs backwards, and where Alice learns a lot about herself, paleoscientists cross the mirror of time in order to learn from our past to better understand our present and, more importantly, to help inform decisions about how to create a better future. This is one of Past Global Changes' (a.k.a. PAGES) main missions: to understand past changes on Earth and the causes and impacts of these changes in order to explain the present global changes, and to provide the key knowledge to build a sustainable future. By digging into the Earth's surface, it is possible to learn a lot about the history of the planet. For instance, some PAGES scientists drill into the bottoms of lakes to examine microscopic charcoal particles accumulated in the sediments. This can allow them to calculate how many wildfires occurred at a certain location in the past. Understanding the causes and consequences of these long-gone fires helps to better estimate what might happen in the future.

PAGES research includes all topics in environmental science addressing the past: geology, paleoecology, paleoclimatology, paleogeography, archaeology, and history. The articles in this magazine reflect this, and the topics include life in the desert, micro-organisms in the ocean, pollen grains hidden in mud in lakes, and molecular thermometers in caves. The stories come from all over the world: from some of the coldest regions and some of the warmest, from the deepest parts of the ocean and the shores, from the land and the air. They deal with the history of pollution and present-day Sustainable Development Goals identified by the United Nations. They also explore the long history of human adaptation, because of changes in the climate, and human impacts on the Earth. There are comics and stories with illustrations. Some of the diagrams seem complicated at first, but

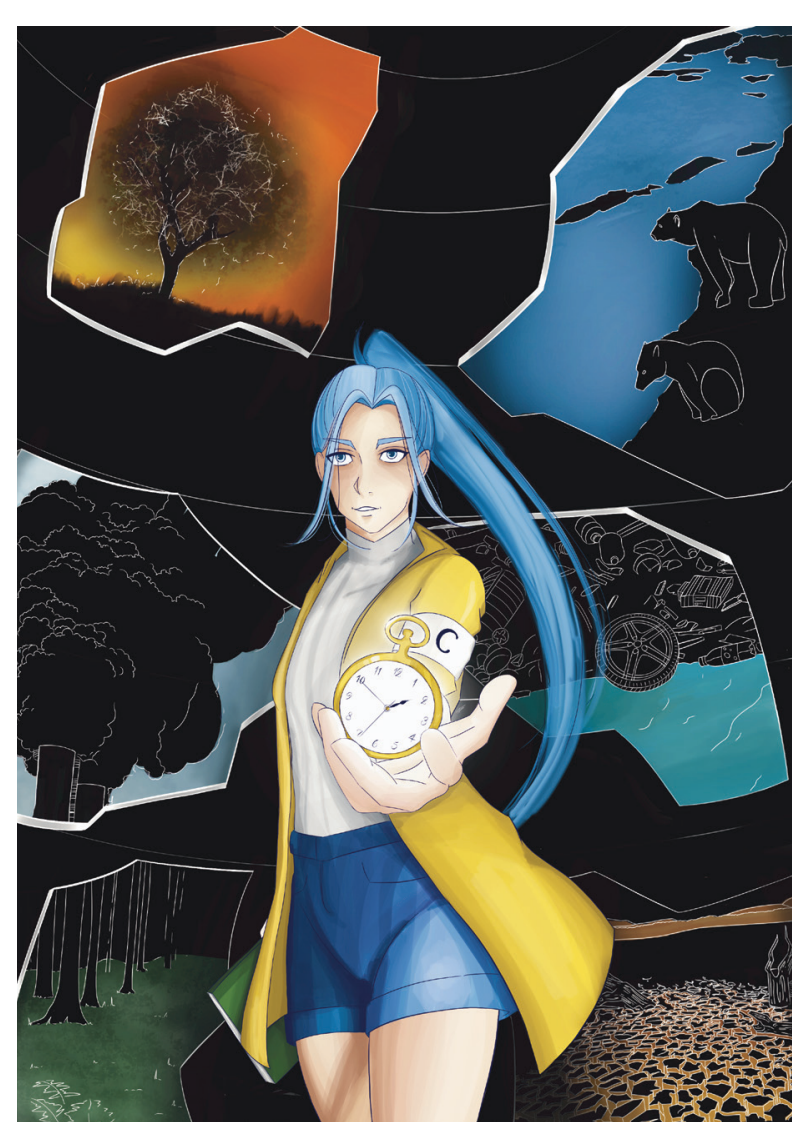
sometimes pictures are worth even more than a thousand words: this is the best way for scientists to show what they have measured and what this tells us about the past. More importantly, this collection of articles will give you the facts to tell apart actual science from fake news or non-expert opinions.

Have fun reading this magazine! We hope you enjoy the adventures narrated by our scientists: these are their time-traveling experiences where they describe what they have learned, how this may help them to envision a better future world, and what might be done to help make those dreams come true. Flip through these PAGES, and change how you think about the world. Step into Alice's shoes for a while as you jump through the mirror and turn back the clock.

Illustration: Alice Favory 


\section{Keely Mills and Matthew Jones}

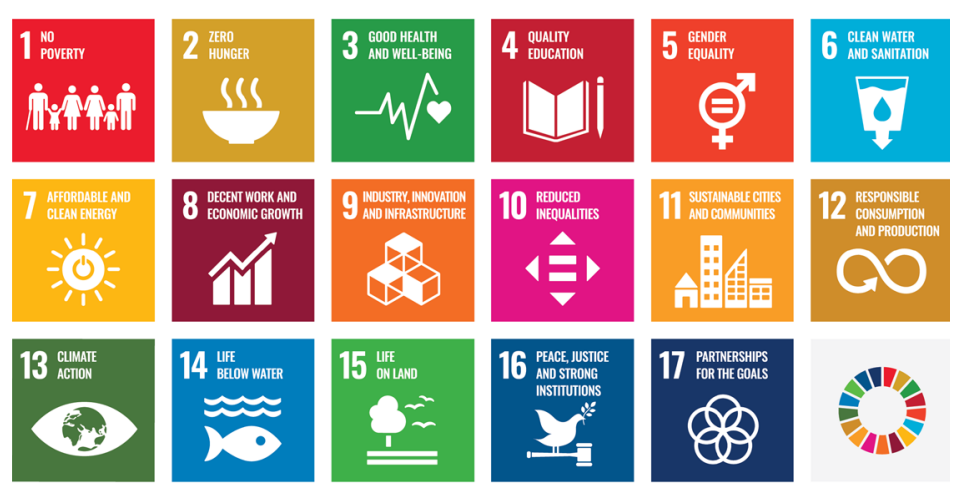

Figure 1: The 17 Sustainable Development Goals as defined by the United Nations.

\section{The Sustainable what ...?}

In 2015 the United Nations called for governments and people across the world to work together to "end poverty, protect the planet and improve the lives of all". They set 17 goals - the Sustainable Development Goals (SDGs) - which have 169 targets! We need to hit all of those targets by 2030 !

\section{A global challenge}

The 17 SDGs can only be reached if everyone - from you and your nextdoor neighbor, to scientists (including PAGES scientists) and government organizations - works together. We also need to bring together different types of research, such as environmental science and social science to really make a lasting change.

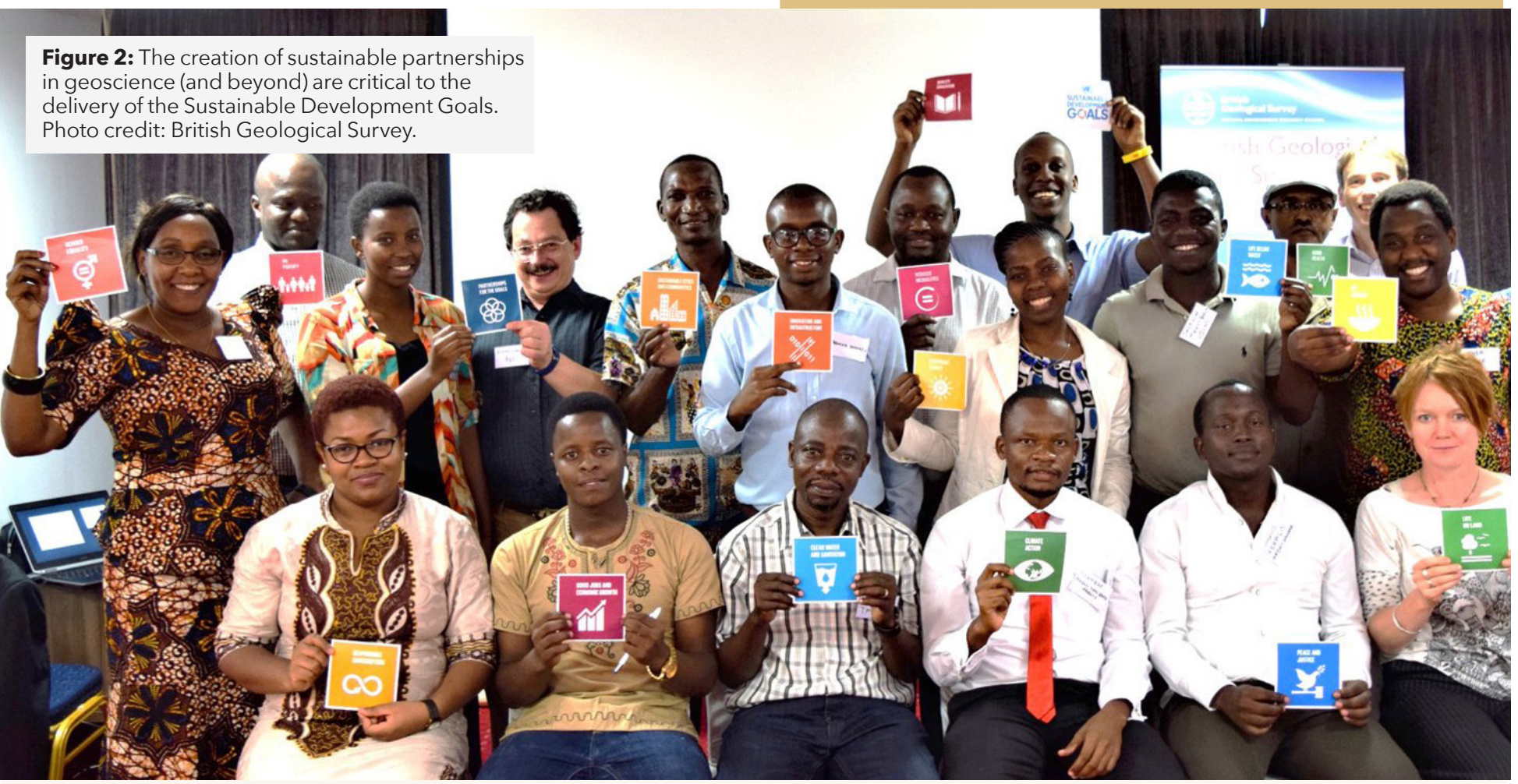

\section{Can studying the past really help achieve the SDGs?}

Geoscientists have many skills that can be used to address these global goals. We take lots of measurements that allow us to understand our planet and how people interact with their environment. We work with scientists and communities all over the world, and we often join the dots between many different science subjects (such as biology, chemistry, and physics) to solve difficult problems.
The research we do looks at the Earth and the environment today and in the past. This is important as we can use this information to work out what will happen to the Earth and the environment in the future. This includes everything from understanding past climate change and modeling future climate, to understanding and predicting changes in water resources, and predicting the impact of environmental hazards like volcanic eruptions and earthquakes. 


\section{GOAL 2: ZERO HUNGER}

\section{End hunger, achieve food security and improved nutrition, and promote} sustainable agriculture

Agriculture was first developed over 10,000 years ago and has been supporting human populations ever since. The archaeological and geological records

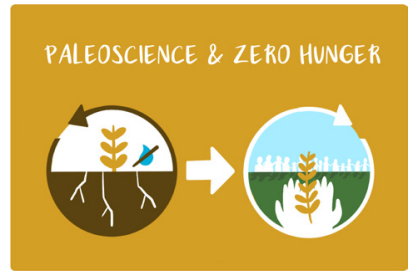
provide examples of how past societies, and their agricultural practices, have been able to cope with changes in the environment and climate. Paleoscience can also measure how agriculture in the past may have caused problems, such as desertification or changes in water availability and quality. We can learn from these examples to ensure that agriculture in the future does not cause additional stress to the environment while still being able to feed a growing human population.

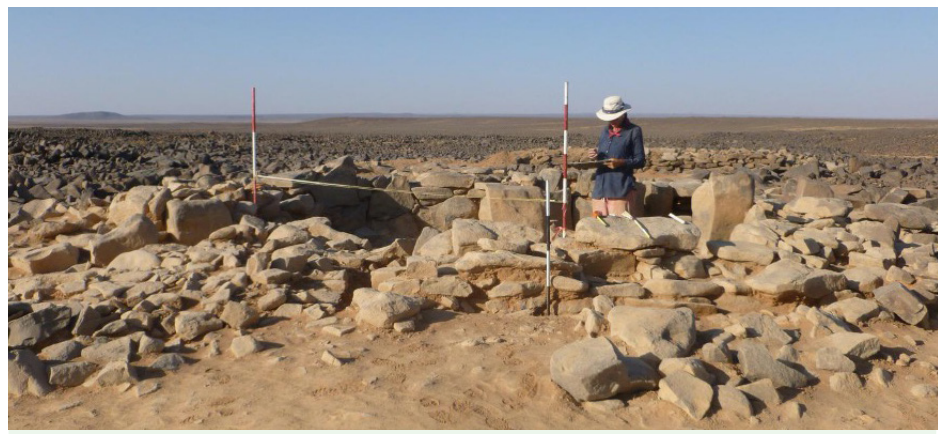

Figure 3: Excavation at the Neolothic site of Wisad Pools, Jordan, as part of the Eastern Badia Archaeological Project. Evidence suggests the region was a lot wetter and greener in the past. Photo credit: Matt Jones.

\section{GOAL 13: CLIMATE ACTION}

\section{Take urgent action to combat climate change} and its impacts

Paleoscientists have and will continue to contribute to the Intergovernmental Panel on Climate Change Assessment Reports. These reports bring

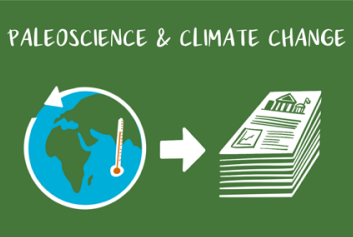
together scientific knowledge

on the impacts of climate change and provide information for governments in over 120 countries. Paleoscientists contribute by providing data on how the climate has changed going back in time for hundreds and thousands of years. The data covers all parts of the Earth, including the atmosphere, oceans, and polar regions.

\section{Find out more:}

UN SDGs: https://sdgs.un.org/goals

Intergovernmental Panel on Climate Change

Assessment Reports: www.ipcc.ch/reports

\section{GOAL 6: CLEAN WATER}

\section{Protect water-related ecosystems including wetlands and lakes}

Tropical regions are home to some of the fastest growing populations and some of the world's poorest people. These regions are also impacted by PALEOSCIENCE \& CLEAN WATER

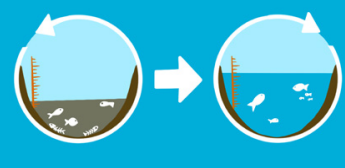

influence how much rain falls, for example. This can cause problems with how much water there is in lakes, and how clean that water is. If there is not enough water, or if it is very dirty, it can make people sick, and it can also make the creatures and fish that live in the lakes die. Paleoscientists can study how the amount of lake water has changed through time and how clean it has been, and work with lake managers to develop guidelines to help look after the lakes into the future.

\section{GOAL 17: PARTNERSHIPS Enhance global partnerships to share knowl- edge to support the achievement of SDGs in all countries}

Perhaps the key to achieving all the SDGs is tied up in Goal 17. Paleoscientists are very good at working as a team to help understand some of the problems that our Earth faces; paleoscience relies on experts from many different subjects. It is important that we continue to work together, at home or overseas, with scientists, government bodies, and our nextdoor neighbors! We must work hard to create new ideas that will have a positive impact on the environment and fellow humans. PAGES engages with groups of people from all over the world, who work together to ensure that we understand Earth's changes in the past, present, and future.
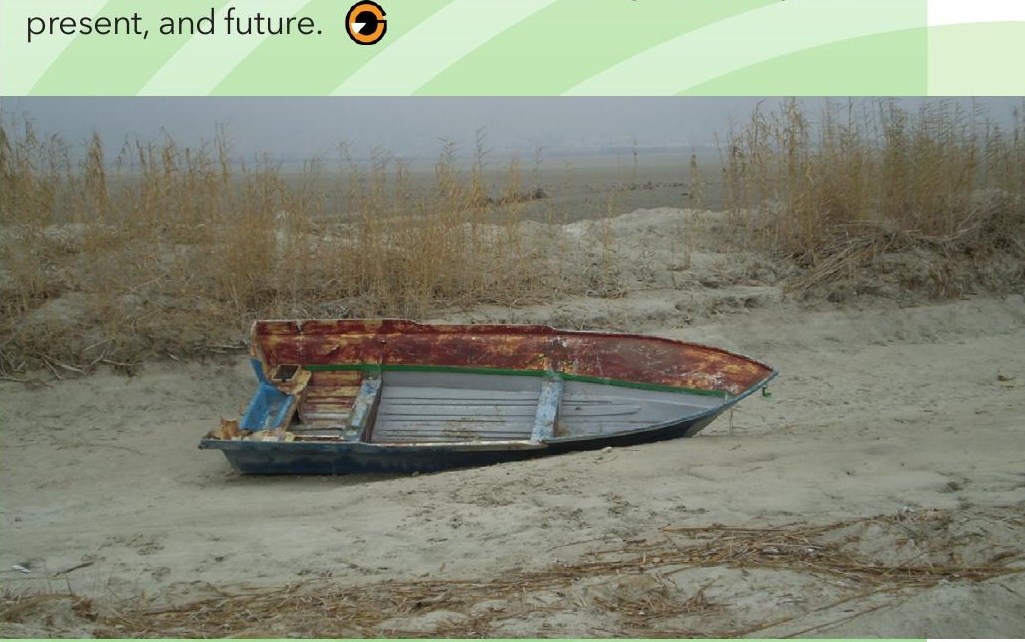

Figure 4: Lake Parishan, Fars, Iran. Photo taken during fieldwork associated with the Mamasani Archaeological Project. Research indicates that lake levels have been sensitive to human activities for thousands of years. Photo credit: Matt Jones. 


\section{Can we tell how climate will change in the future?}

\section{Frank Oldfield}

Working out how climate will change in the future depends on the use of computer-based models. The latest models of future climate change tell us that during your lifetime, global warming and the weather extremes linked to it will pose major challenges for life on Earth unless urgent action is taken now. How reliable are these models and the projections of future climate that they create? Producing them requires a rather new kind of science that is often criticized by those who don't believe in man-made climate change, so it is important to learn more about how climate models, especially those used to project future global warming, are tested for their reliability.

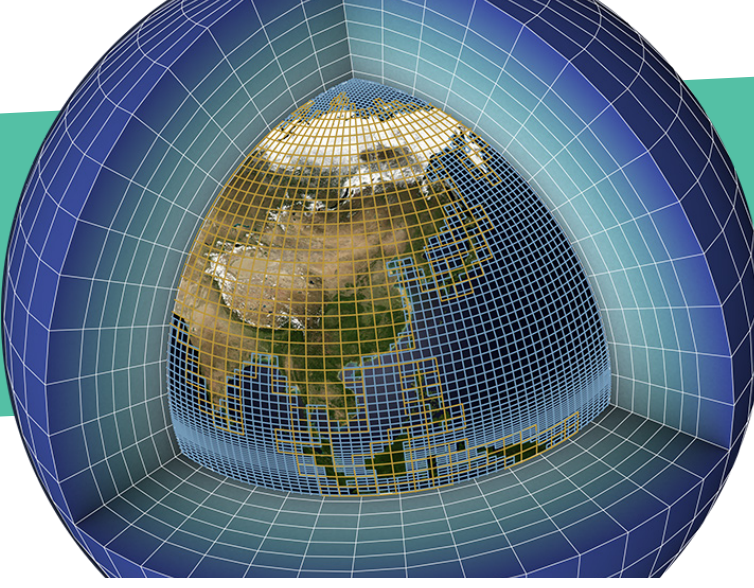

Image credit: IPSL, CEA

A key test is whether they can predict the climate during a period for which we already know what the climate was like: the past! Unlike in modern times, earlier climatic changes were driven by natural processes such as changes in the energy received from the sun, natural variations in atmospheric greenhouse gases such as $\mathrm{CO}_{2}$ and methane, and volcanic activity. Over the last few decades, changes arising from human activities must also be included, mainly increases in atmospheric greenhouse gases and notably $\mathrm{CO}_{2}$ arising largely from the use of fossil fuels. Only if the results produced by the models for the past compare well with the actual record of past climate changes can we rely on the models to give reliable projections for the future. The model-based results are usually referred to as simulations.
HOW WILL CLIMATE CHANGE THE FUTURE?

(2) NOCRYSTAL $\rightarrow$ BALL BUT acrianiachiones

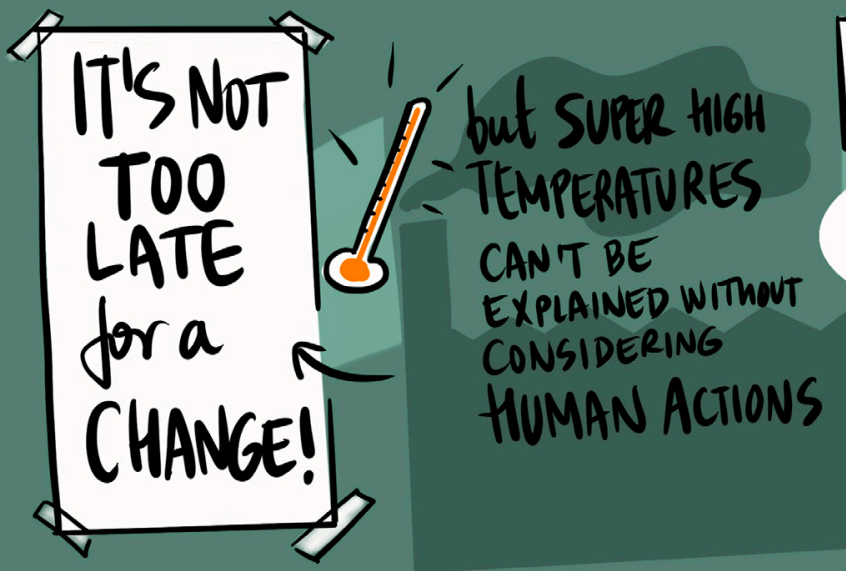

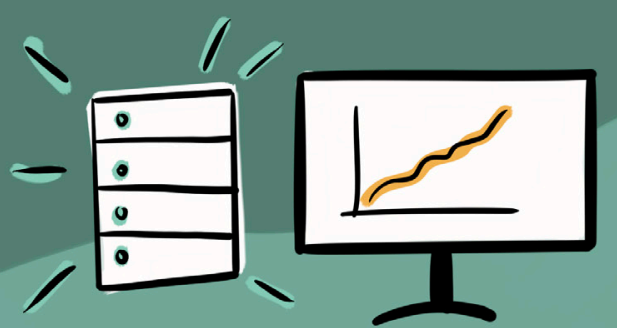

FAMADITER-BASED MODELS USed to make PREDICTIONS =
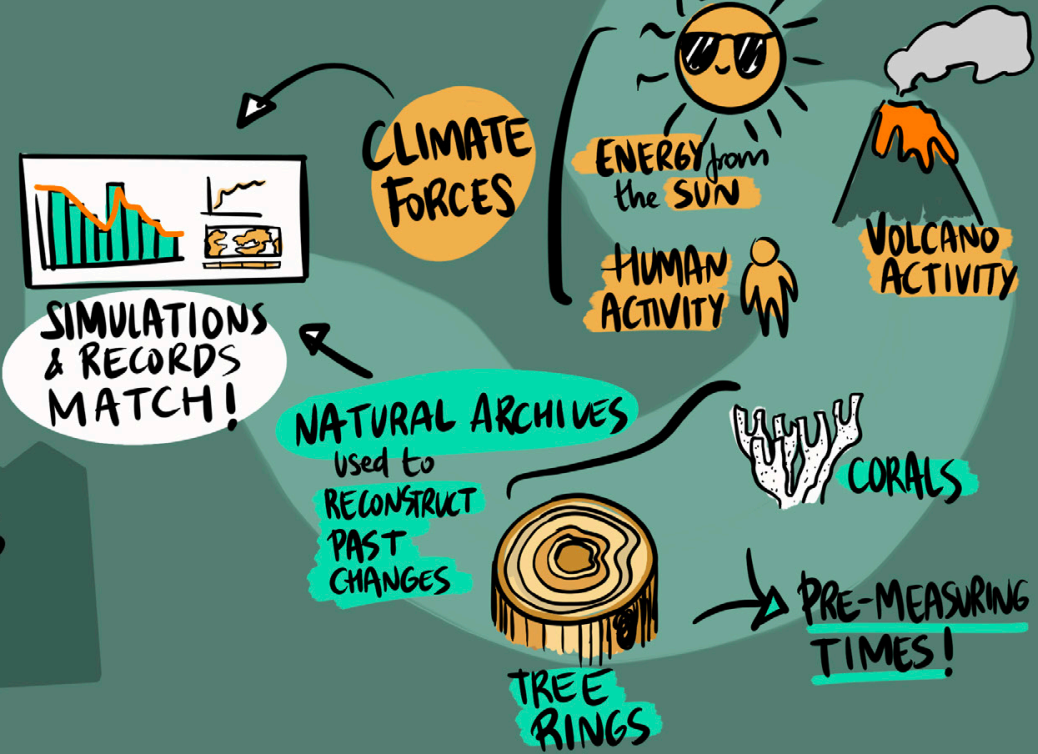
Wait but... DO THEY $>$ WORK? $\sqrt{5}$ TEST TUE PAST FIRST 
We know mainly from meteorological and written records how climate has changed over the last 170 years or so. Models can therefore be tested by comparing the simulations for this period with the actual record of climate change.

But climate has varied on much longer timescales, so it is also important to be able to make similar comparisons for a longer period in the past. For pre-measurement times, past global temperatures have to be reconstructed from other lines of evidence, for example tree rings, sediments, and corals. We may think of these as natural archives of information about the climate. First, we need to work out, through a process of calibration, how well they have recorded past climate change.

Take tree rings as one example. Accurately dated features like annual ring width for a group of trees can be established for each year that the trees grew. The sequence obtained can then be compared with the temperature records spanning the same period from nearby weather stations. By comparing the sequence of tree-ring measurements with the sequence of temperature values, the tree-ring record can be translated into past temperature changes. Then, by measuring ring widths in dated older wood, beyond the timespan of direct observations, the values derived from the calibration can be used to reconstruct a longer record of annual temperature changes. The next step is to combine records from long-lived trees with those from fossil wood. These can then provide temperature records spanning many centuries. The methods for calibrating other natural archives may be different, but the goal remains the same, to derive records of past climate change for the period before the 1850 s.
Now we come to the key question: how well do the model-based simulations of past temperature compare with the records derived from measurements and from natural archive-based reconstructions? Figure 1 shows a reconstruction of global temperatures for the period 1200 to $1850 \mathrm{CE}$ compared with the results from a range of the most recent computer-based global temperature simulations for the same period. The graph shows that there is good agreement between the model-based simulations and the grey envelope of natural archive-based reconstructions. So far so good, but what about the recent past, during which time human activities have affected the climate?

Figure 2 shows the record for the most recent period, the one during which the key question of human-induced global warming arises. The graph provides a comparison between the past changes in global temperature over the last 170 years and the calculated effects of the various processes, both natural and human-induced, that are used to generate computer-based climate models. Until the middle of the 20th century, the changes in global temperature mainly reflect the influence of natural processes, but since then those natural processes on their own fail to generate changes that match the actual, rapid temperature increase recorded

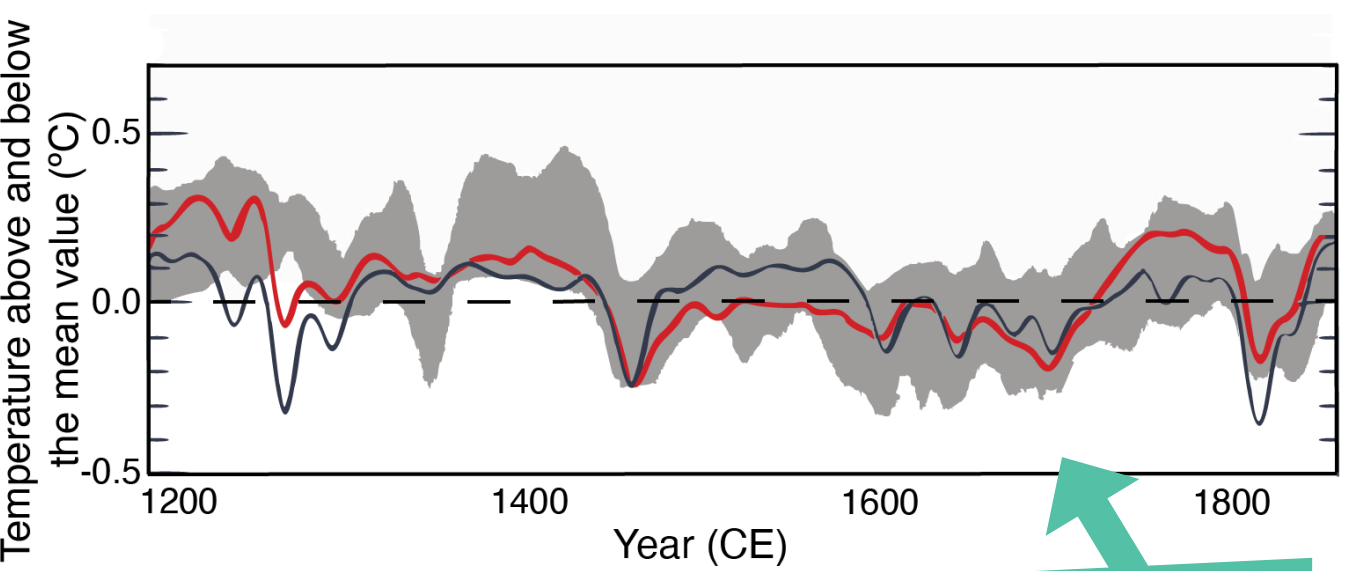
Figure 1: The graph compares computer-simulated results with natural archive-based reconstructions of global temperatur for multiple model1850 CE. The red and blue lines plot mean values for multiple mariations in based simulations. The red line uses maximum values for values. The grey shing the sun's influence, the blue line uses mes by several independent research spans the range of reconstructed values by selions above and below groups. The temperature scale shows variations abo 1500-1850 (dashed line). reconstructed mean temperature for the per in the Fifth Assessment Report The graph is based on Figure 5.8 shown
of the Intergovernmental Panel on Climate Change. 


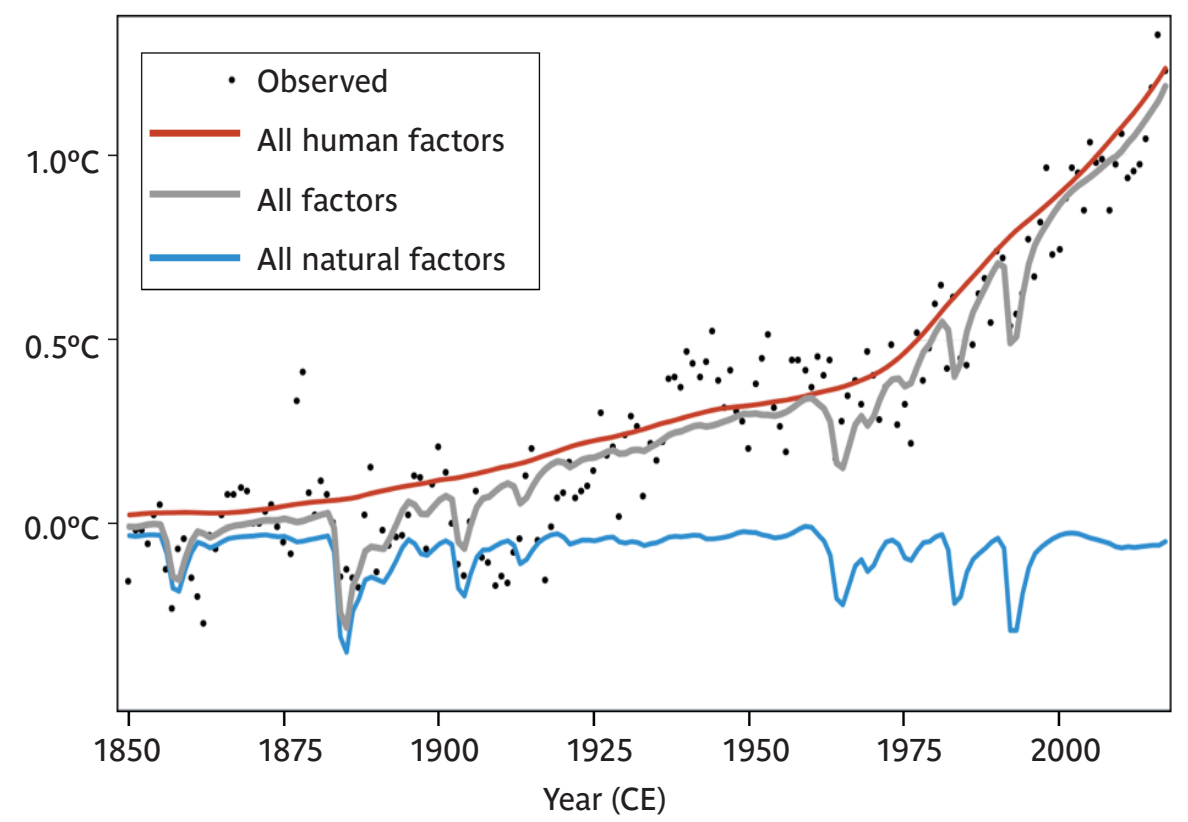

Figure 2: The graph compares computer-simulated results with the actual observed record of global temperature for the period since 1850 CE. The black dots represent annual values and the lines plot the results of alternative simulations, both with and without the impact of human activities. Adapted from Global Warming Index.

by recent measurements. Only by factoring in the rise in greenhouse gas concentrations resulting largely from fossil

fuel use is it possible to account for this increase. From these graphs, we see that models can reproduce the past record of climate change extremely well; moreover, the second graph confirms that the main cause of the recent increase in temperature is human activity. These results strengthen confidence in the projections of future global temperature

\section{Alternative simulated global temperature trends to 2100}

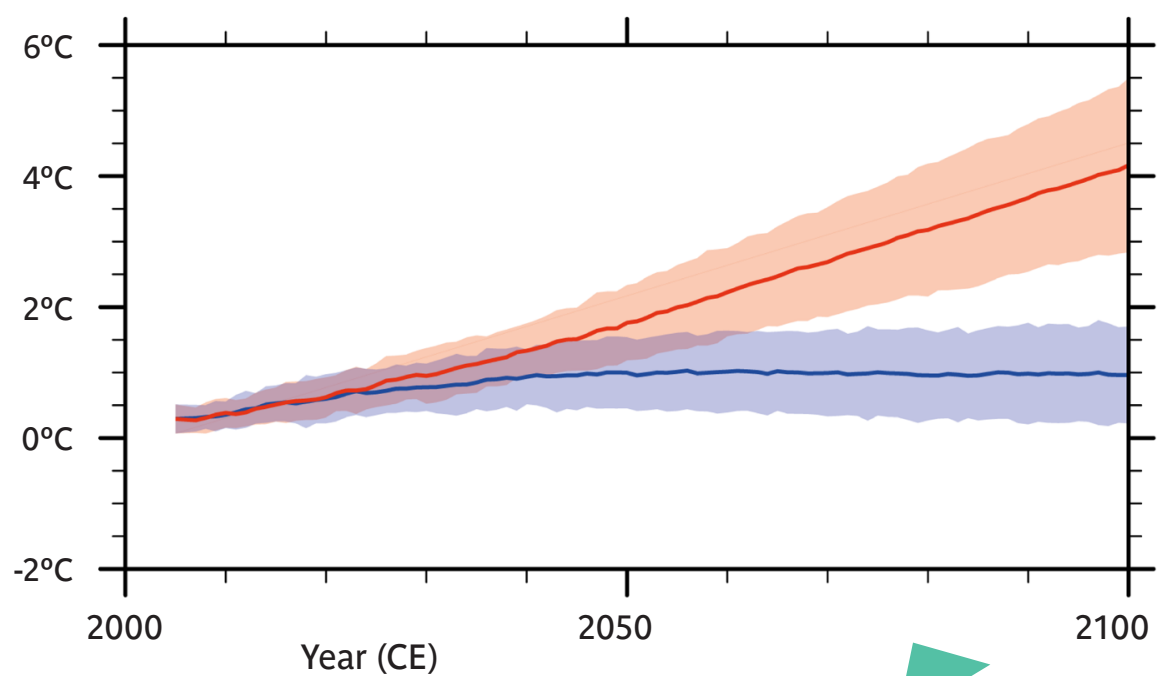

Figure 3: The graph shows one of many attempts to highlight the likely impact of alternative human responses on the future continued of global temperature changes. The red line line assumes urgent and high greenhouse gas emissions; the bling shows the uncertainty optimum reduction and control. Shapted from Figure SPM.6. attached to each projection. that models provide. How can anyone doubt their value as a basis for action?

Enough about the science used to validate future global temperature projections - the actual course of climate change during your lifetime and beyond will depend, above all, on human behavior. Projecting the likely impact on climate change of different combinations of human activities calls for models that go beyond the strictly scientific. They inevitably include additional uncertainties. Figure 3 is one of many attempts to show the crucial importance of human behavior. The two lines are shaded to indicate the level of uncertainty for each projection. If there is an urgent, optimum reduction in emissions we would expect to follow the blue line. If there is continued, rapid growth in atmospheric concentrations of greenhouse gases the climate models suggest that we will follow the red line. The future therefore depends on human policy and responses.

Look at the graph and ask yourself: what needs to happen to bring further increases in greenhouse gases to levels that minimize future environmental damage and human hardship? (3) 


\section{HOW GREEN WERE THE OCEANS IN THE PAST?}

\section{Get the answer from an awesome "bug" buried in the mud}

Iván Hernández-Almeida and Mariem Saavedra-Pellitero

When we look beyond the clouds, at the starry night, there are eyes looking back at us. Sentinels in space, able to see colors in the blue abyss of the sea.
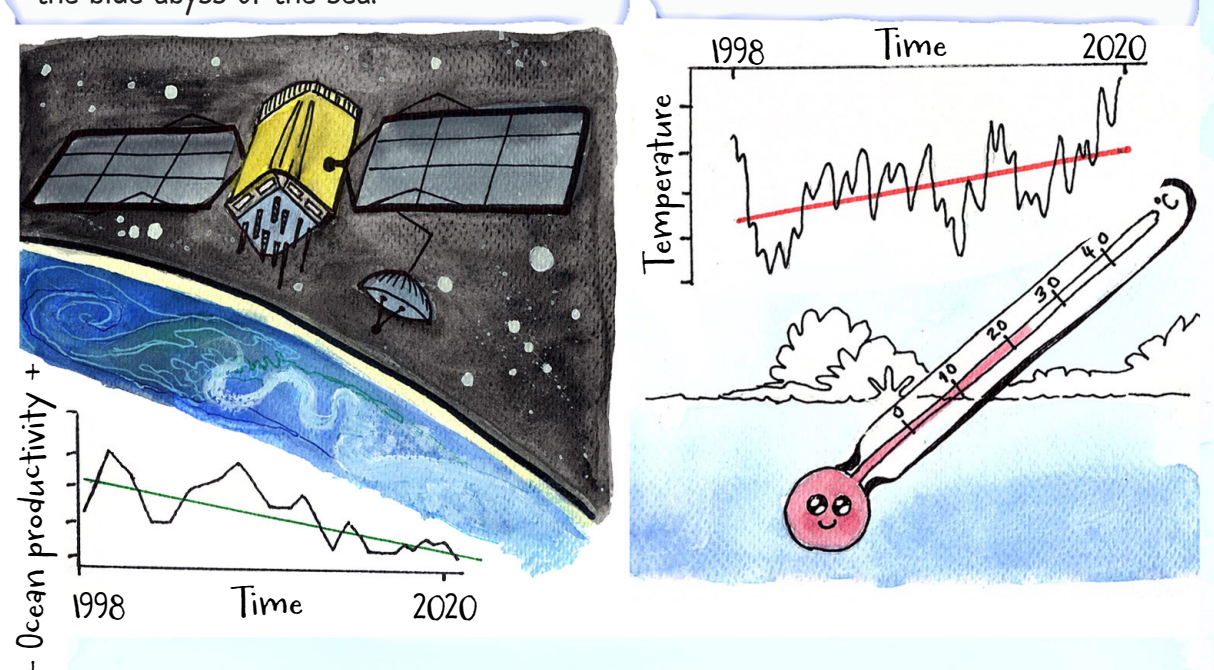

But their memory is short, going back not much further than the year you were born.

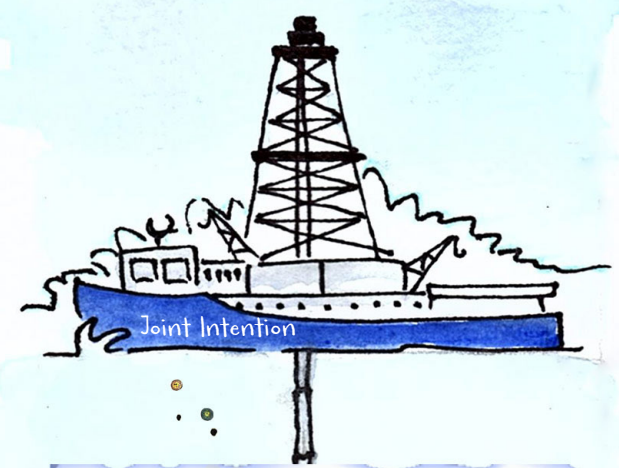

To have a peek beyond, further into the past, we must dig into the mud. Fine layers of sand and clay, alternating like a chocolate cake, are like pages of a book. Each slice, a grasp of time, traps the remains of "bugs" that lived,

bloomed and died.

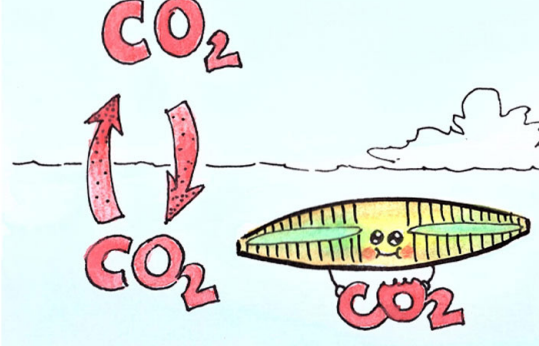

You may have heard that tiny algae creatures, invisible to the naked eye, are the trees of the ocean. You may have been told that these algae might hold the key to combat GLOBAL WARMING.

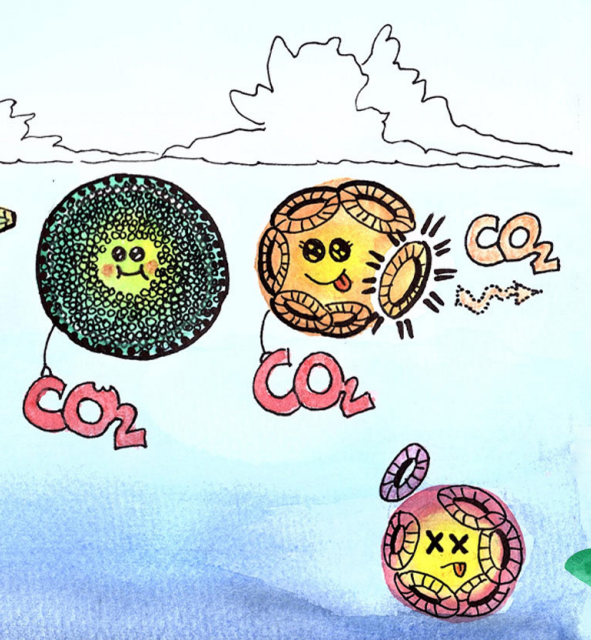

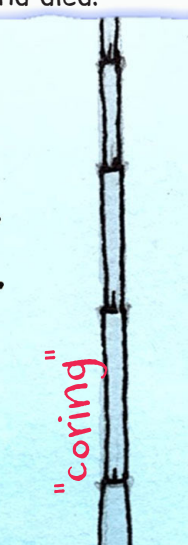

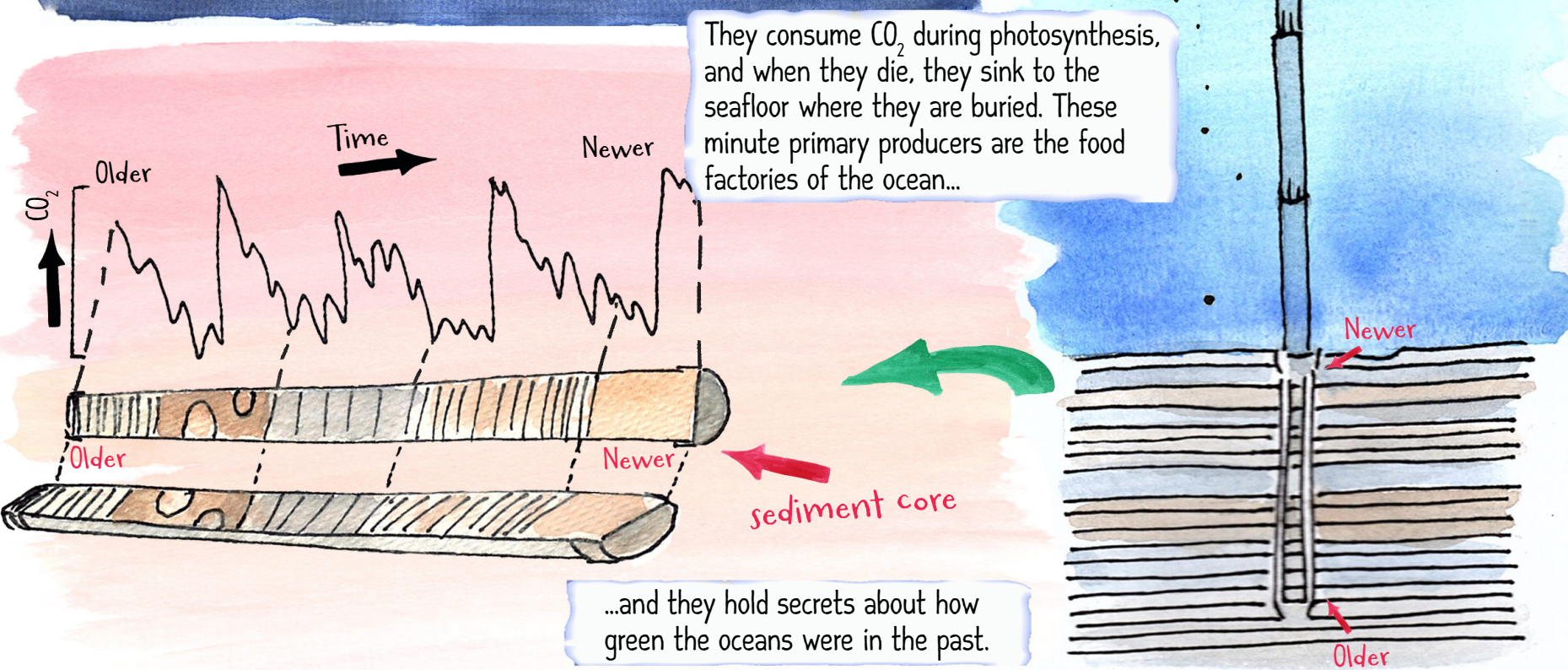



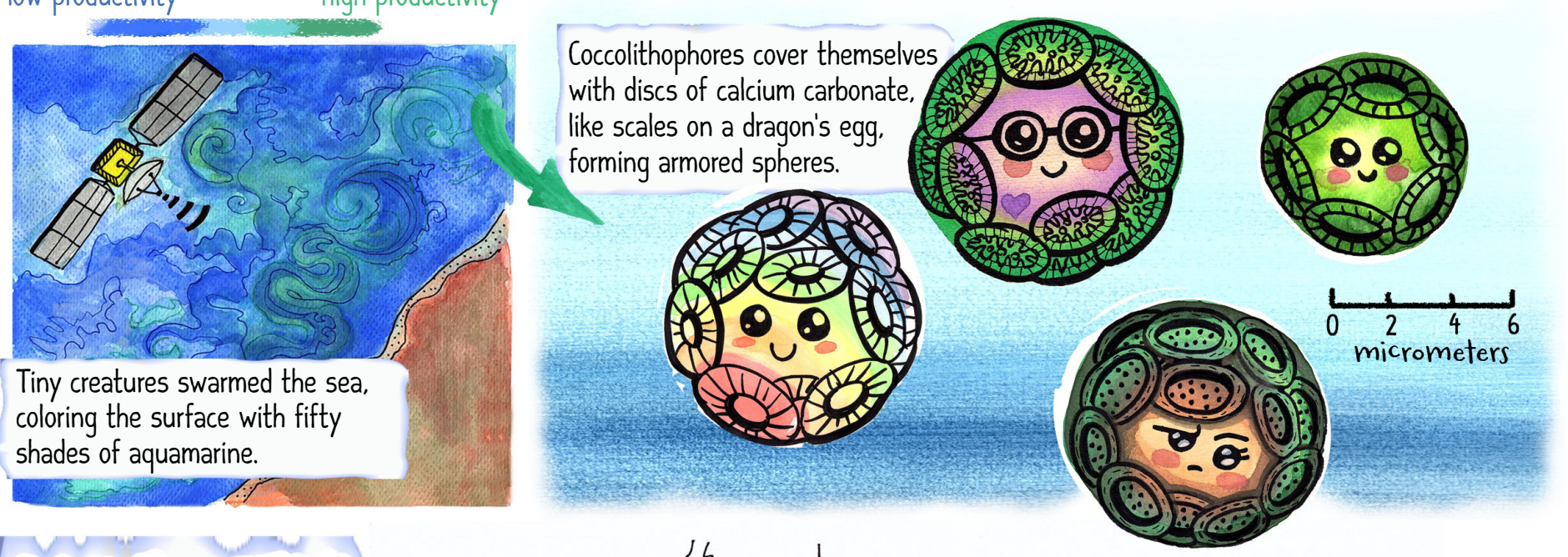

You may have been told that these algae thrive everywhere in the ocean. But this is not entirely true. There are vast areas of the ocean that are like deserts for life.

The tropical oceans are heated throughout most of the year. They turn into a warm soup that rarely mixes. Although sunlight is not a problem, nutrients are rare and lie deeper in the ocean.

One of these coccolithophore algae, called Florisphaera profunda, loves living deep, in this warm soup, and it is rarely found in cold waters.

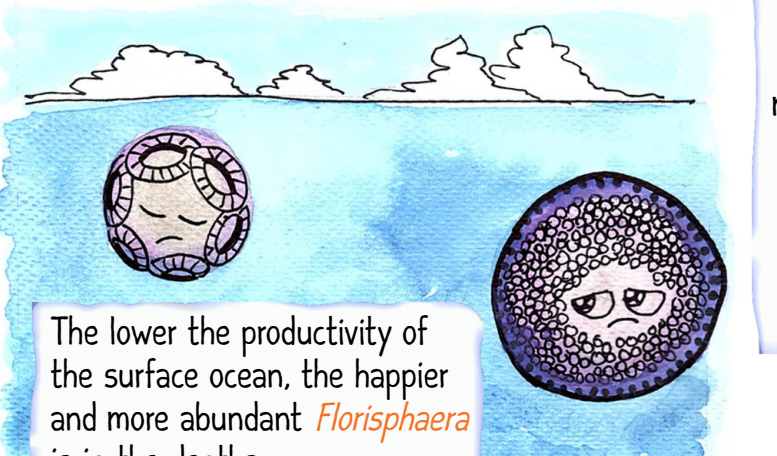

is in the depths.

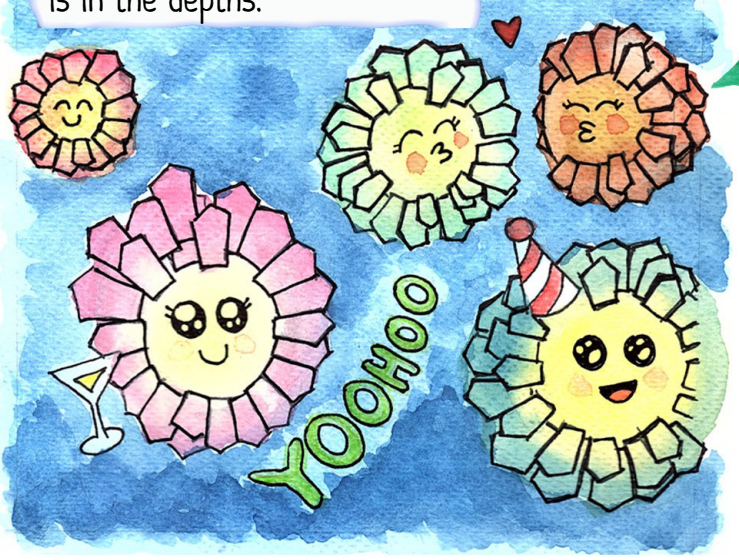

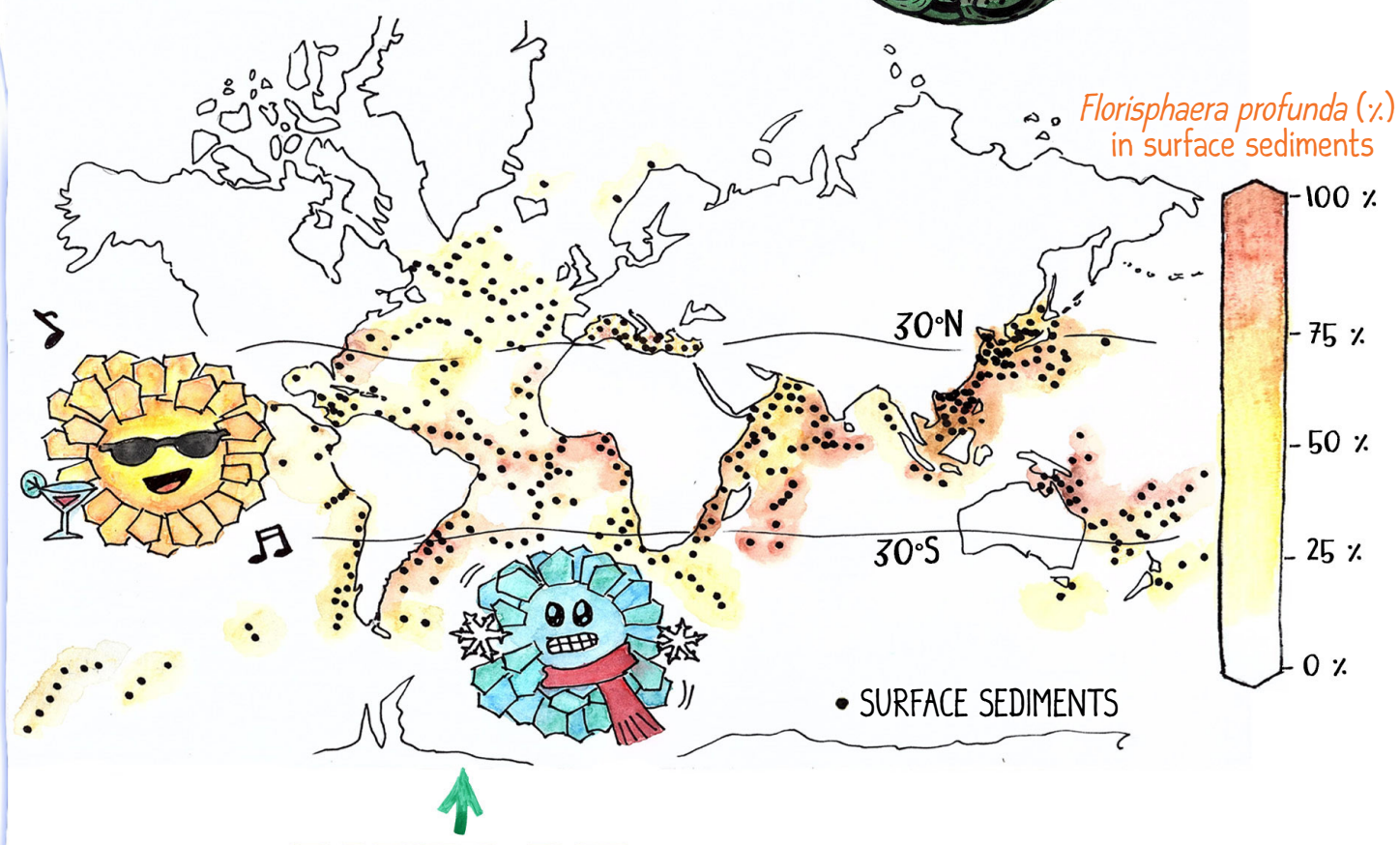

Using the abundance of Florisphaera in surface sediments (=same as modern ocean conditions) and comparing to satellite productivity measurements, we can reconstruct past ocean primary productivity!

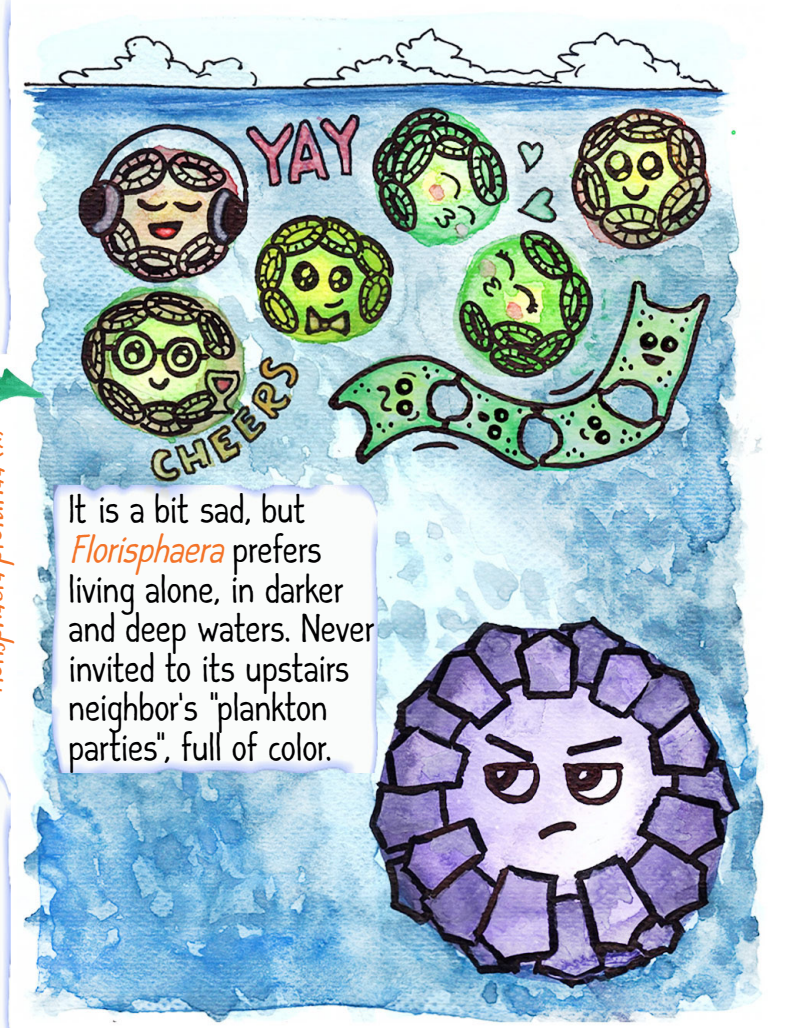


We studied Florisphaera in many sediment cores around the globe, and used that relationship.

We see that...

...thousands of years in the past, when ice-sheets were larger than today and global temperatures colder, winds also blew stronger, mixing surface ocean waters. Photosynthesis was higher, meaning more carbon was transferred into the deep ocean. Florisphaera got a bit upset. With all this higher productivity, it was a bit distressed!
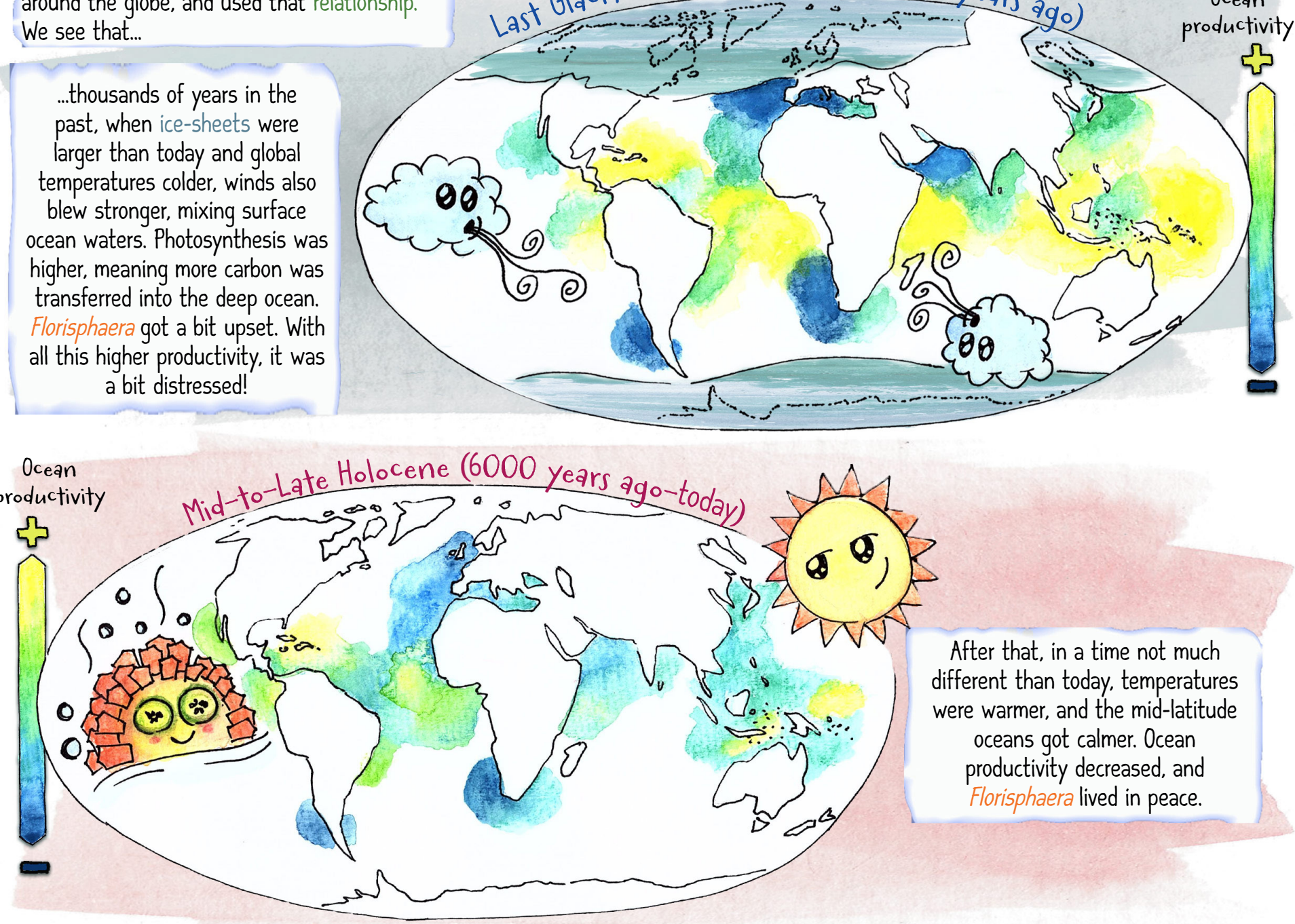

After that, in a time not much different than today, temperatures were warmer, and the mid-latitude oceans got calmer. Ocean productivity decreased, and Florisphaera lived in peace.

Our eyes from space tell us that the low-latitude deserts in the ocean are becoming larger. Rising temperatures of the planet warm up the ocean too. Marine plant life slows down and absorbs less carbon.

WHAT WILL HAPPEN IN THE FUTURE?

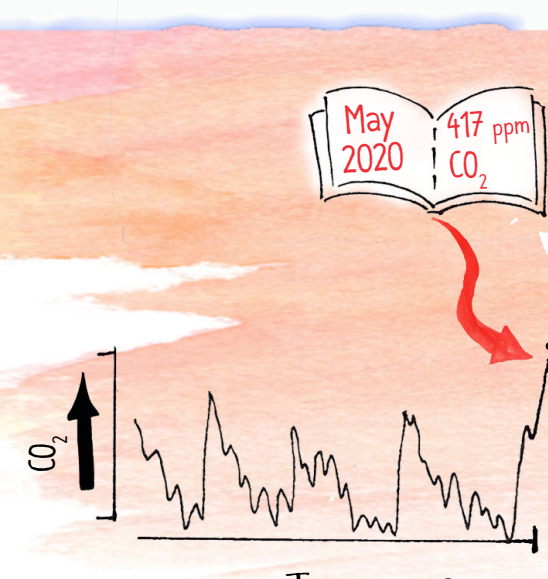

Time

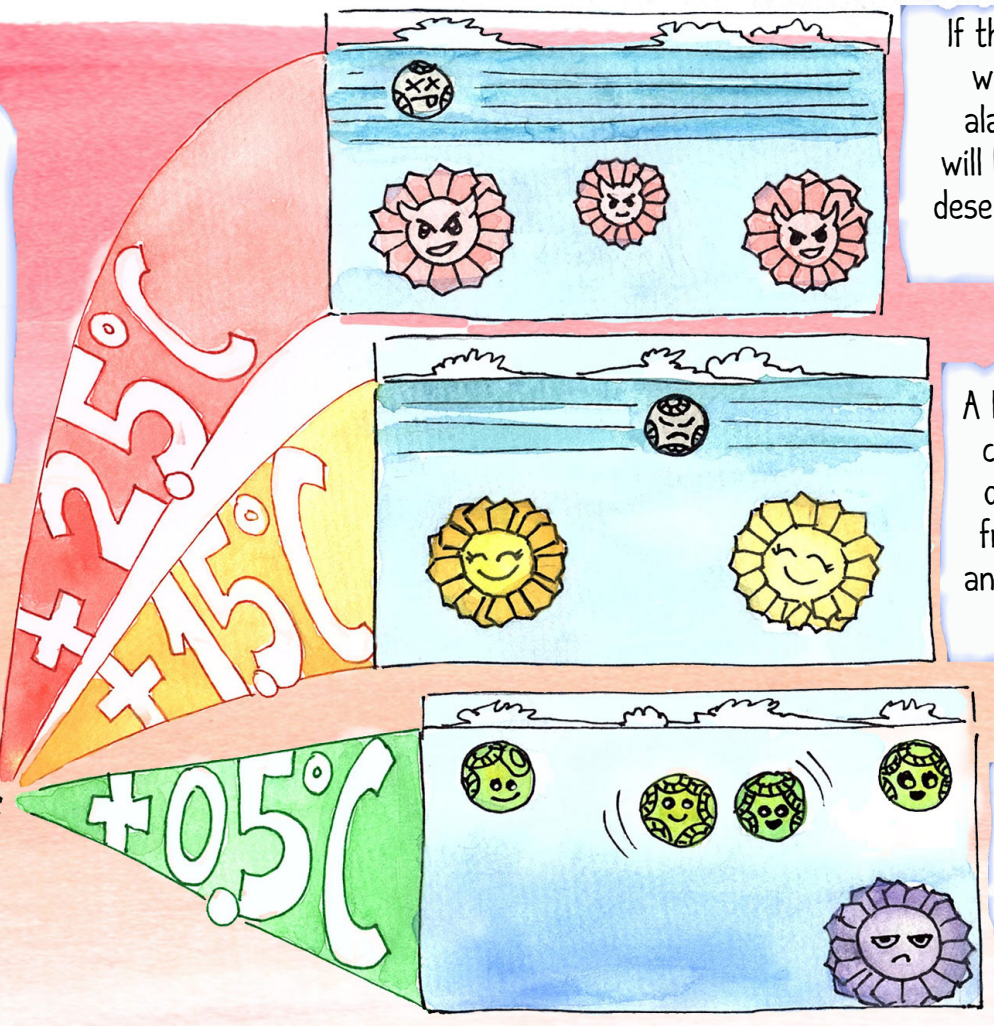

If the planet gets really warm, we should be alarmed! Florisphaera will be happier when the deserts in the oceans will get larger!

A little bit of warm can cause harm! Surface ocean color will turn from green to brown, and productivity will go down!

Only if we take a strong stand can we prevent such change! 


\section{From the depths of the Amundsen Sea: Hidden treasure with hints of future climate!}

\section{Margot Courtillat and all the scientists from IODP Expedition 379}

The news isn't great! You may have already heard: the climate is changing, and sea level is rising. But did you know that the East and West Antarctic Ice Sheets, giant masses of ice covering the continental land, could be one of the main reasons for this?

\section{In 2018, the Intergovernmental Panel on Climate}

Change (IPCC) Special Report on Global Warming

concluded that the instability of the marine ice sheet in Antarctica and the irreversible loss of the Greenland Ice Sheet could be triggered by a rise of about 1.5 to $2^{\circ} \mathrm{C}$ ( 34.7 to $35.6^{\circ} \mathrm{F}$ ) in the global temperature. This could then lead to a rise of the ocean of several meters, over hundreds to thousands of years.

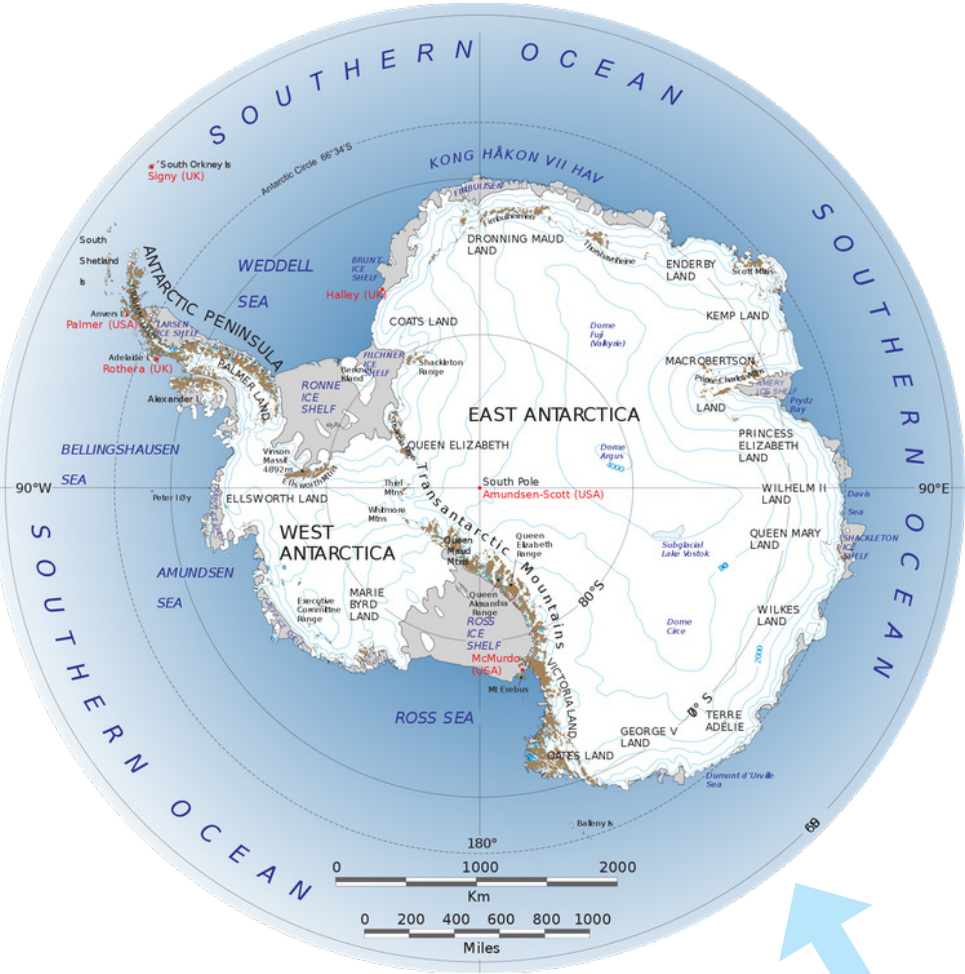

The IPCC also highlighted that the marine ice sheet from the Amundsen Sea Embayment, the indentation in the shoreline which forms an open bay, will likely be one of the major contributors in the substantial increase in sea-level rise over the next century. The Amundsen Sea is located right in front of the West Antarctic Ice Sheet and to the south of the Pacific Ocean. The West Antarctic Ice Sheet is suspected to have previously collapsed 3-4 million years ago, when temperatures were like today. One such collapse raised global sea level by several meters. But to be sure of this we needed to have more information about its behavior over the last few millions of years. This is the main reason why the International Ocean Discovery Program (IODP) decided to organize Expedition 379 to drill the marine sediments from the Amundsen Sea.

\section{Marine sediments}

You are now probably wondering why we need to drill marine sediments to know the history of an ice continent, and that is a good question! When an ice sheet retreats, a lot of icebergs are released. Together with the ice itself, they also transport dirt (also known as sediment) into the sea. This sediment, which eroded from the continent, falls onto the seafloor when the iceberg melts. It falls in chronological order: that is, old sediments end up on the bottom and young ones at the top. 


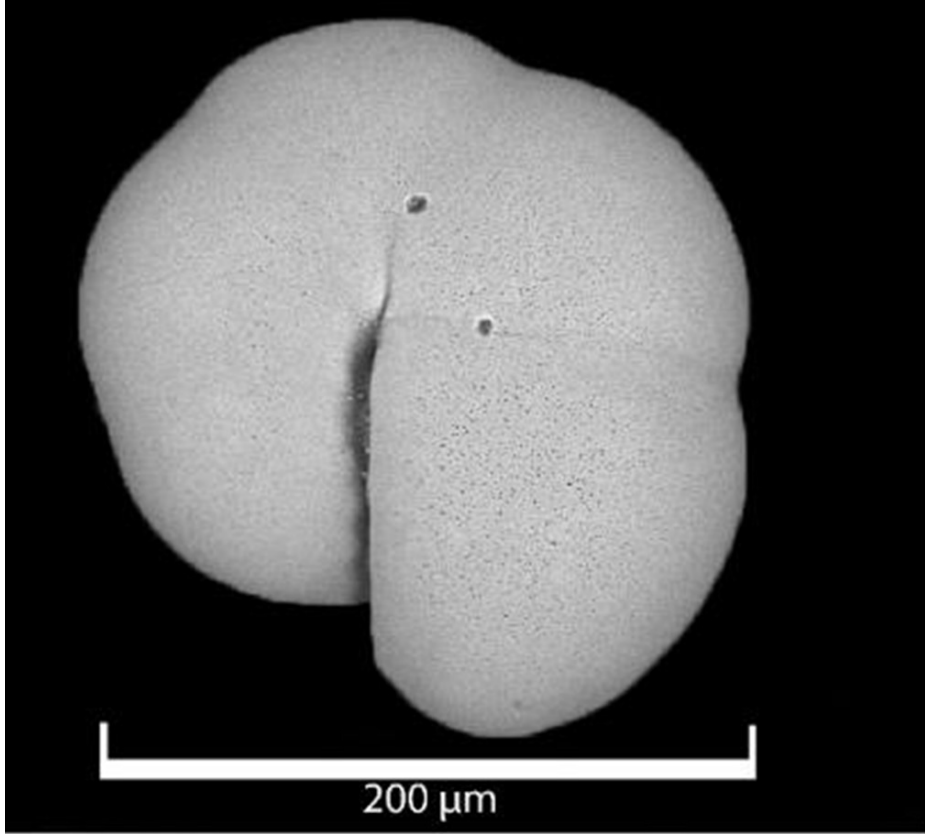

But residues from the continent are not the only type of materials you can find on the seafloor. Indeed, you can also find the shells of dead marine organisms, and that is my specialty! Between complicated words for organisms, like diatoms, coccolithophores, and radiolarians, you can find the foraminifera. Foraminifera are organisms made up of a single cell. They have mineral shells, like many other marine organisms and terrestrial snails, for instance. The shell doesn't decompose over time and therefore remains in the sediment as a fossil.

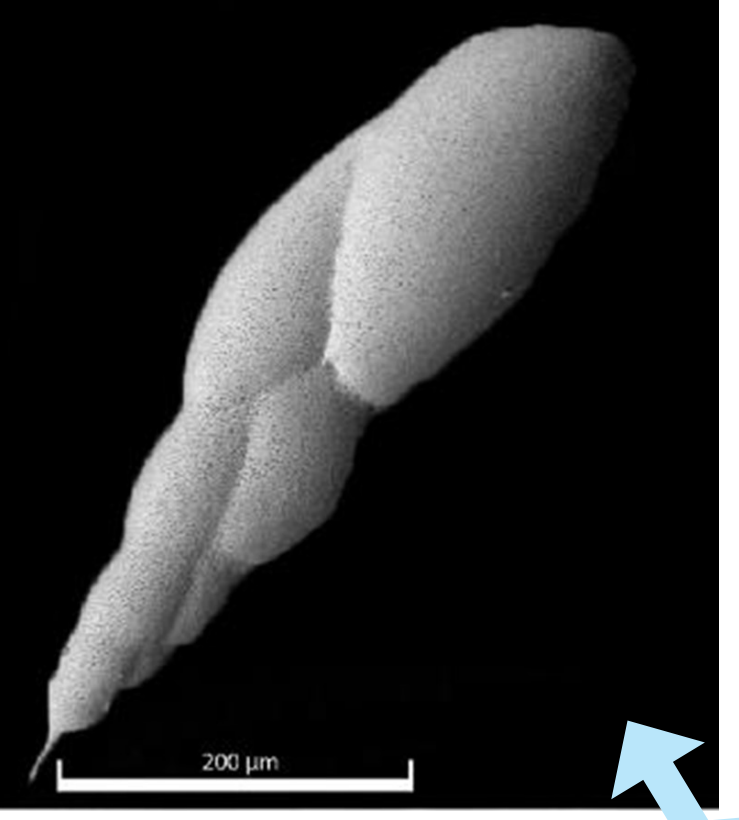

Figure 2: Photo taken with a scanning electron 2. Prom the Amundsen Sea microscope of Expedition 379. These foraminifera have found during Expedition of $3960 \mathrm{~m}(13,000$ been retrieved from a wallenia quinqueloba, and on the $\mathrm{ft})$. On the left is Pullenia quing $200 \mu \mathrm{m}$ corresponds right is Stainforthia sp. The hairs.

to the thickness of two hairs.

Millions of years after the death of the organism, you can find its shell in the sediment, and this tells you which species once lived there. This information gives you clues about the environment in the past and espe-

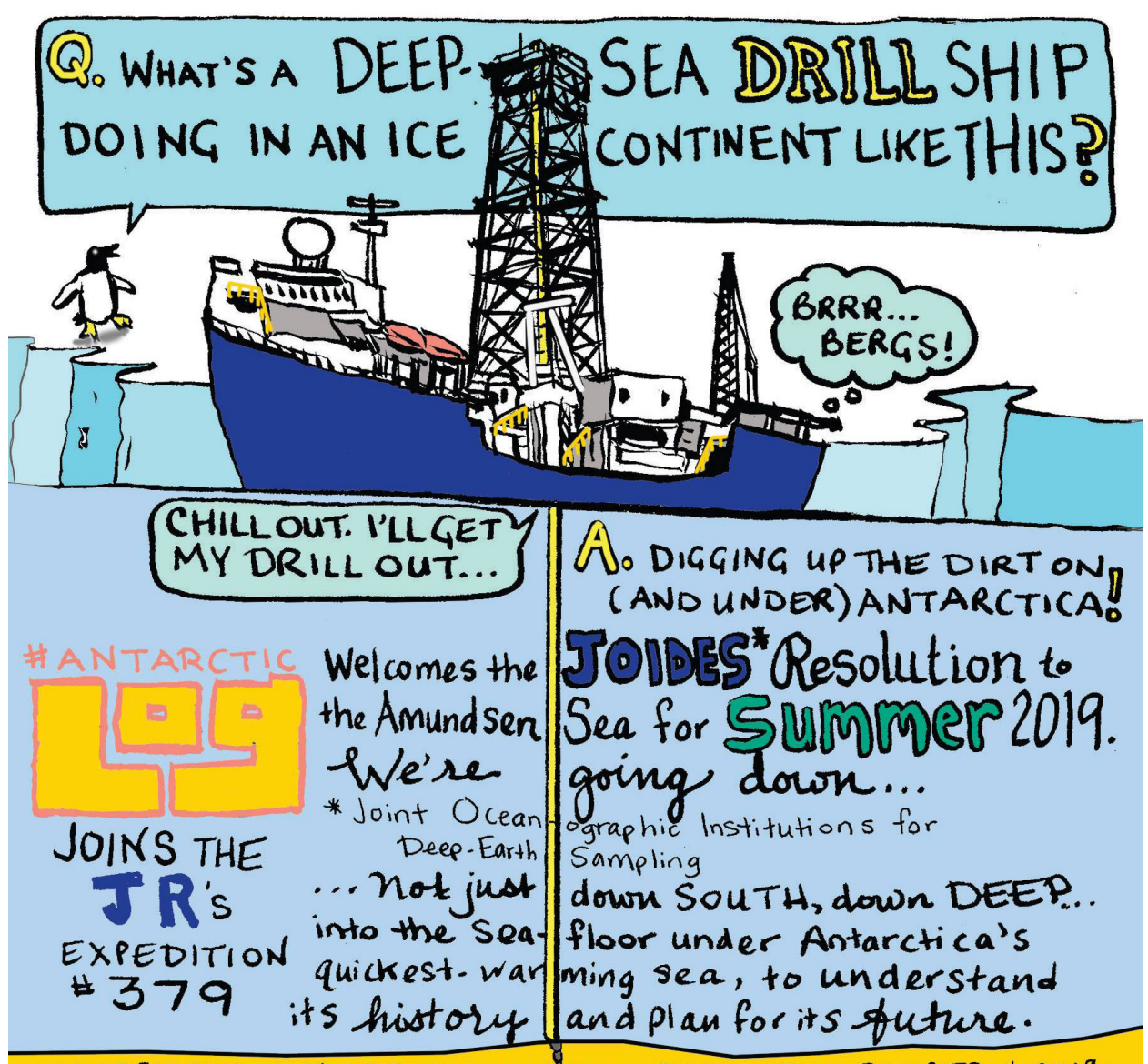

- KAREN ROMANO YOUNG. GETTINGSET TO GO ABOARD O OCTOBER 4,2018. cially information like the former oceanic temperature, concentration of nutrients, and salinity (amount of salt in the water).

\section{Expedition 379}

On 18 January 2019, an international team of 34 scientists gathered in southern Chile and sailed to the Amundsen Sea. The expedition, on board the drilling ship JOIDES Resolution, aimed to recover as much sediment as possible during two months at sea in the Antarctic. Working in such a remote place is not easy, and indeed, we had some trouble with icebergs! 


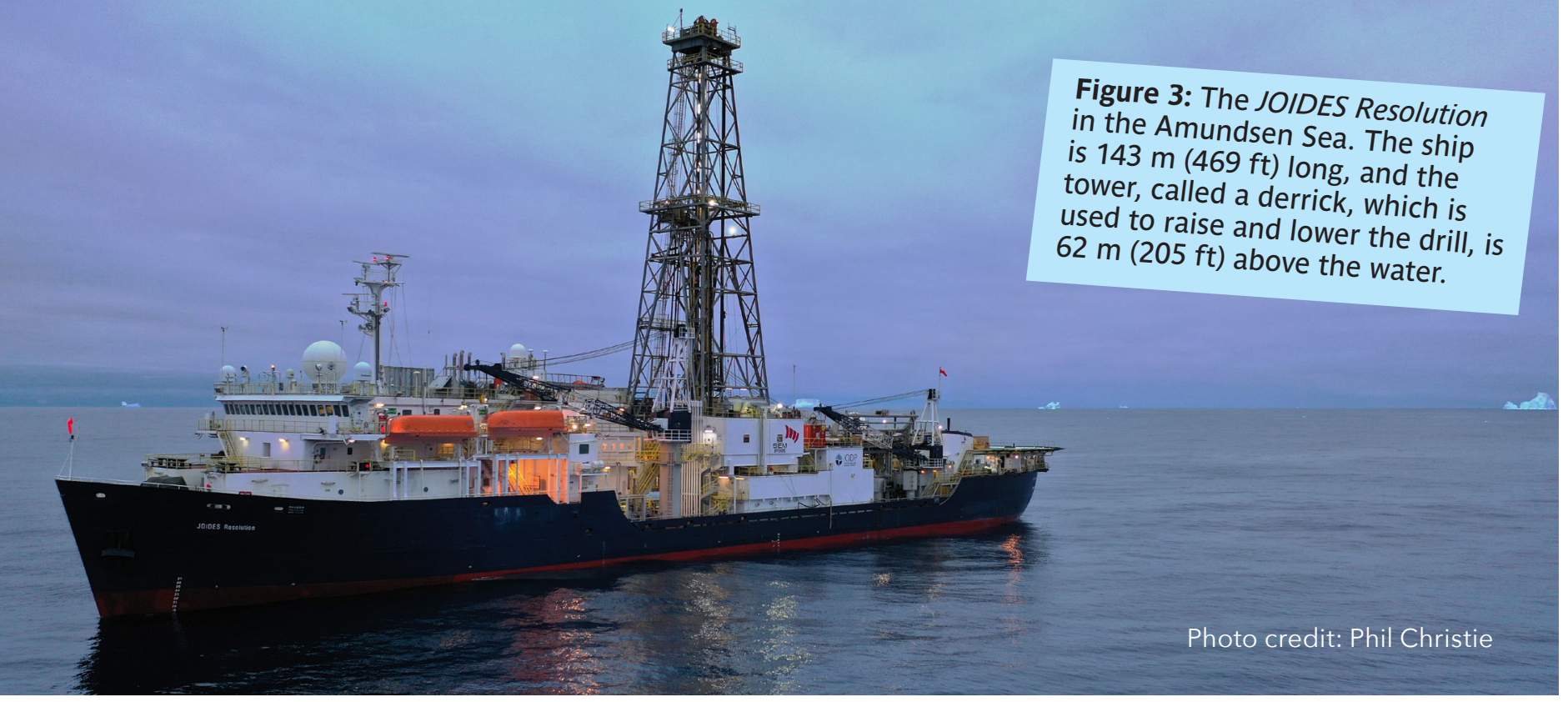

In 2019, the number of icebergs in the Amundsen Sea during the austral (Southern Hemisphere) summer was, compared to previous years, very high. This phenomenon may have been caused by major calving events (sudden release and breaking away of a mass of ice) of the ice shelves over the last two to three years. As you can imagine, we really wanted to avoid re-enacting the Titanic, so we had to avoid the icebergs. We succeeded, thanks to two ice specialists who monitored the ice conditions 24/7. There were two simple rules: if an iceberg floats within two miles ( $3.2 \mathrm{~km}$ ) of the vessel, stop all drilling operations; if it comes within one mile (1.6 km), abandon the drilling hole! The large number of icebergs forced us to pause drilling operations $50 \%$ of the time, and because of a medical evacuation, the expedition was shortened by one week. Despite these interruptions, Expedition 379 was a great success!

\section{Analyses}

We were able to drill at two sites and retrieved 1.08 $\mathrm{km}$ (0.62 miles) of sediment dating from the present to six million years ago, in the late Miocene. This is the longest sediment core from the Antarctic region ever to have been drilled from a marine platform near a rapidly melting, massive ice sheet!

The JOIDES Resolution is a very well-equipped ship. It's like a floating laboratory with a nice view. We

Figure 4: Open cores of marine sediments. The are studying them carefully and will then sample the core.

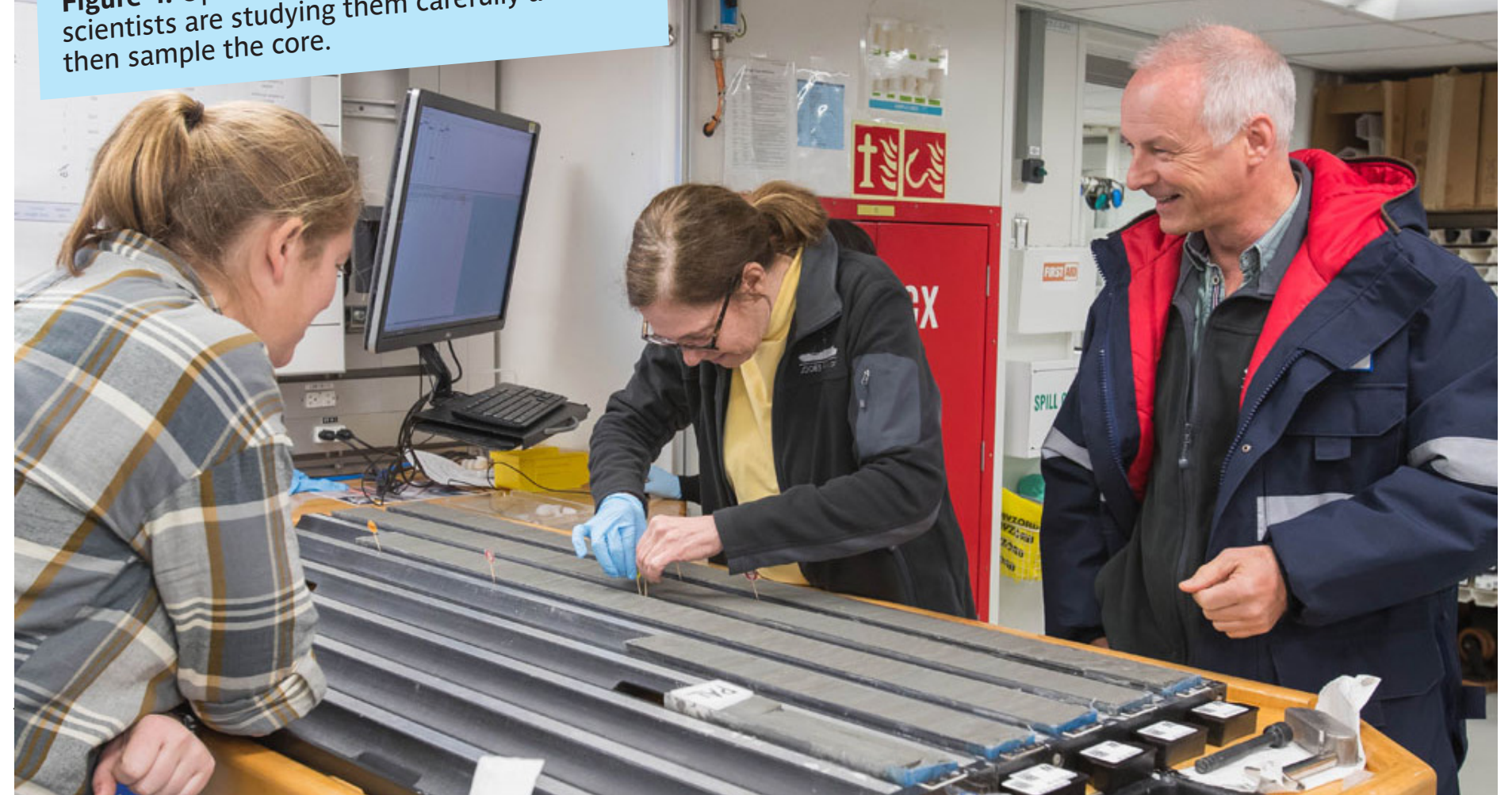


could therefore pre-analyze the collected sediment while we were still onboard and found out that it covered a succession of warm and cold periods. The warm periods are characterized by a high abundance of microfossils and sediments that have been transported by icebergs or sea ice and then released into a marine environment or a lake. In comparison, the cold periods are characterized by a grey, terrigenous mud.

The absence of microfossils and sediment transported by icebergs during cold periods is mainly due to the absence of the intrusion of the warm ocean current (Circumpolar Deep Water). Indeed, this current is responsible for the melting of the ice sheet and, consequently, for the formation of the icebergs. The lack of food for microfossils is another reason to explain their absence.

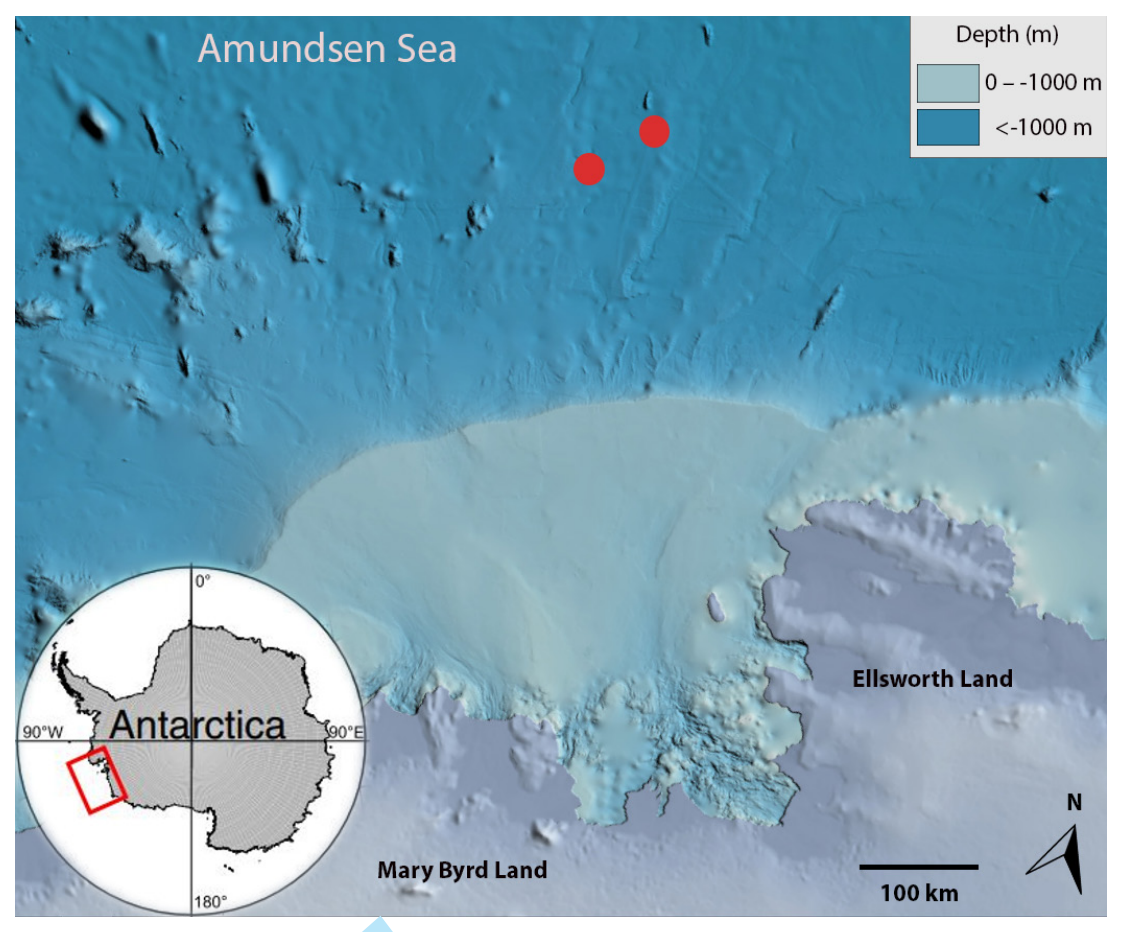

Figure 5: The red circles (U1533 and U1532) show the drilling sites during Expedition 379.

For now, the whole scientific crew is working hard to produce more detailed results, even during a global pandemic.

So, stay tuned for more! (3)

\section{THE DEPTHS OF THE AMUNDSEN SEA:}

A HIDDEN TREASURE WITH HINTS OF FUTURE CLIMATE!

CIMATE CHANGING घ! SEA LEVEL RISING

CLUES about the PAST! - TEMPERATURE:得?

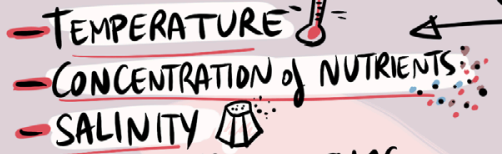
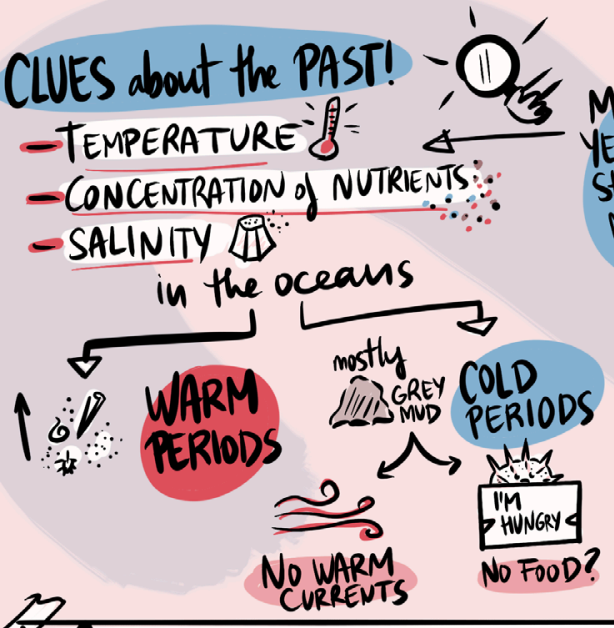

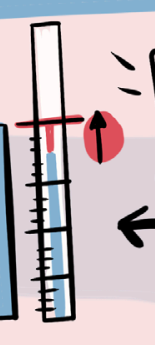
- A $^{\prime+1.5-2^{\circ} \mathrm{C}}$ ATARCTC SHEETS I) COULD BE THE REASON!

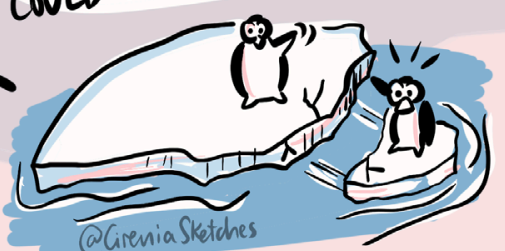
MILLLONS of
YEARS-OLD SHELLS of MARINE
ORGANISMS!

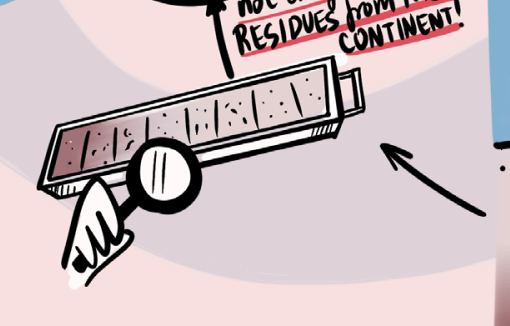

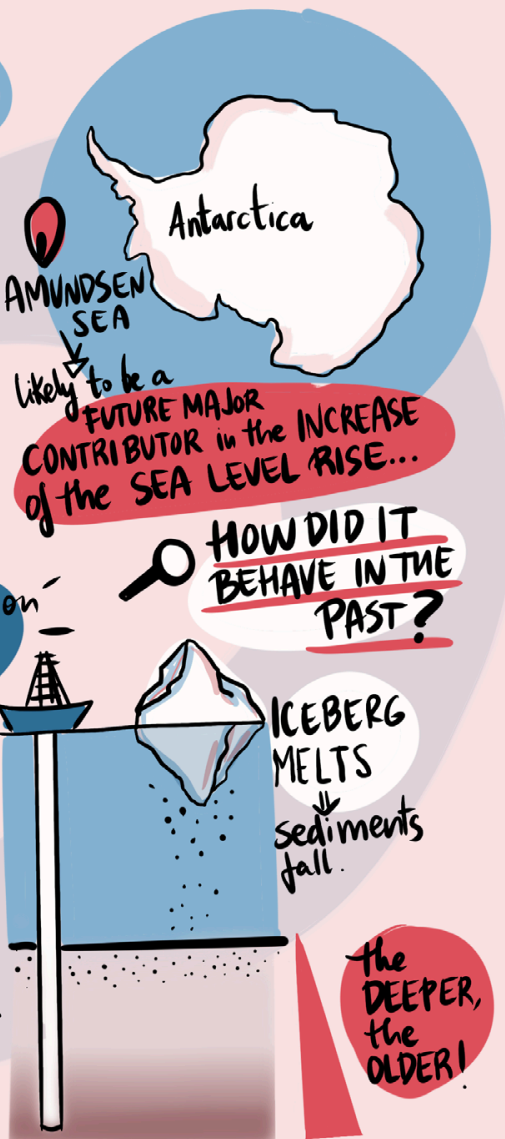

A LOOK ATTHE PAST TO PREDICT THE fUTURE 


\section{Why sea level is not level: An introduction to paleo sea-level science}

\section{Juliet Sefton and Fangyi Tan}

The surface level of the ocean - what we call sea level - is not the same everywhere. Sea level may be rising in one location and falling in another, and by different amounts. Sea levels also change over time.

There are some changes that we can observe on a daily basis, like the rising and falling tides. Other changes are slow and take decades, centuries, millennia, or even millions of years. To understand the processes behind sea-level changes, scientists use both modern instrumental and geological (paleo) observations.

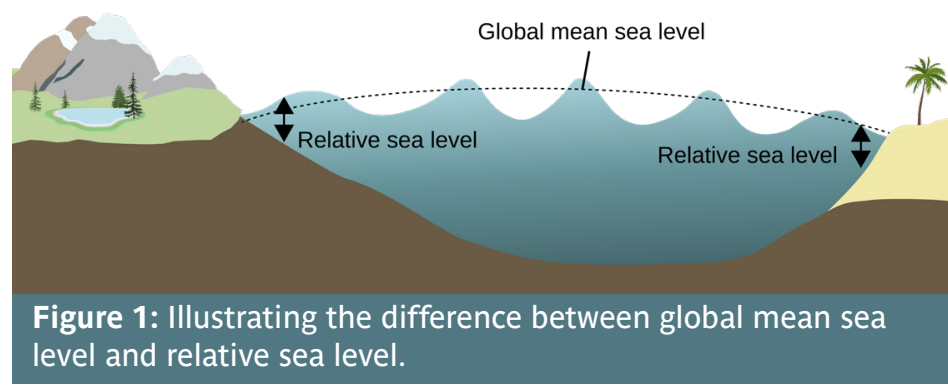

Scientists average the height of the ocean's surface across the globe relative to the center of the Earth we call this global mean sea level. Measurements of sea level in one specific location, made relative to land, are called relative sea level.

Sea-level rise is a threat to human society. Understanding how and why sea levels change is important to accurately predict what may happen in the future.

\section{Processes of global and relative sea-level change}

Short-term processes: minutes, days, years
Medium-term processes: decades, centuries
Long-term processes: thousands to millions of years

Some examples...

1

Tidal cycles and waves change relative sea levels. During storms, storm surges can cause coastal flooding.

2

Tsunamis and sudden landlevel changes generated by earthquakes can cause extreme flooding. Local weather, climate, and ocean currents can change relative sea levels.

4 An increase in ocean temperature and saltiness can cause the ocean to expand, causing global and regional sea levels to rise.

Extraction of groundwater can cause land to subside, causing a rise in relative sea level.

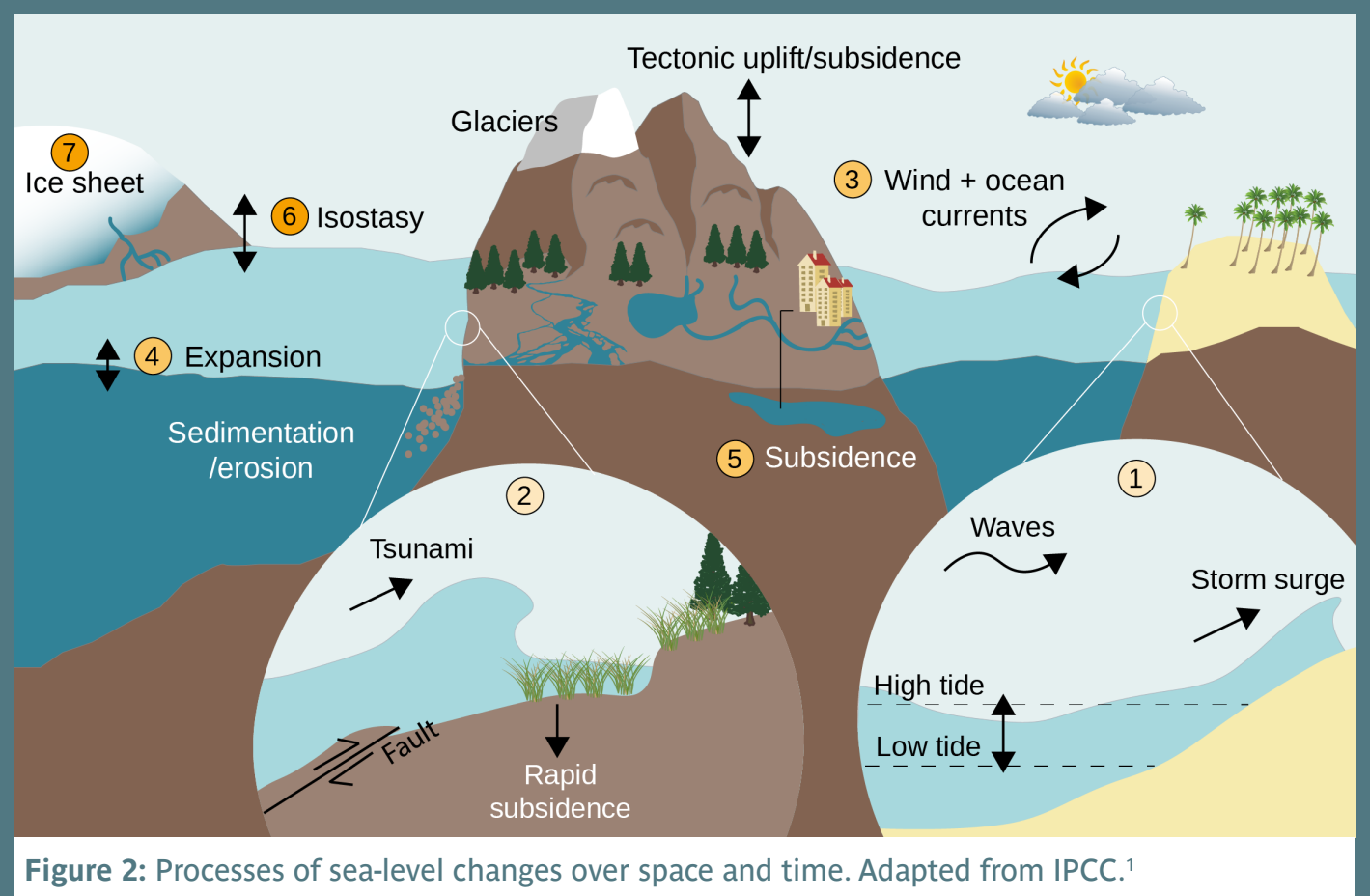

6 Land rises or sinks in response to changes in the weight of water or ice on top of it (called isostasy), causing a change in global and regional sea levels.
Melting of ice sheets (like Antarctica) adds a lot of water to the oceans, raising global sea level. 


\section{Why do we study}

past sea levels?

\section{To learn about long-term processes}

Humans have only been collecting sea-level data for a few hundred years at most. To understand medium- to longerterm processes, we need to look further back in time, before our observational record.

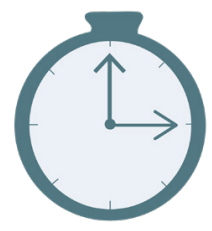

How have sea levels changed over hundreds, thousands, and millions of years? What caused those changes?

Scientific term: understanding temporal variability

\section{To learn about geographical differences}

Our recorded history is also quite geographically skewed - our knowledge mostly comes from coastlines along the North Atlantic Ocean. This might be causing a bias in our understanding of sea-level processes.

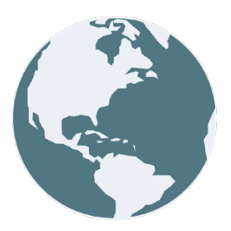

\section{Are sea-level changes different in different places? Why or why not?}

Scientific term: understanding spatial variability

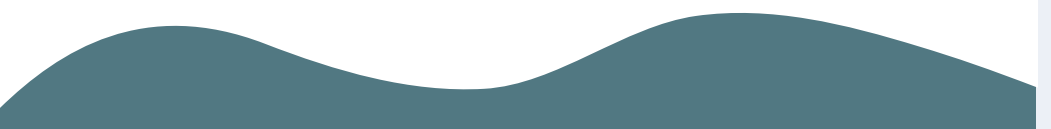

\section{Fun (and not so fun) facts}

- During our last ice age $\sim 21,000$ years ago, sea level was $\sim 130$ $\mathrm{m}(430 \mathrm{ft})$ below present sea level. Land masses were more connected around this time: you could walk from Europe, across Asia, to the Americas!

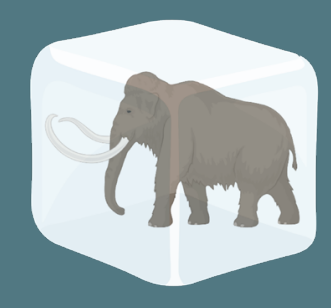

- The Antarctic Ice Sheet, if melted completely, could raise global sea levels by $\sim 65 \mathrm{~m}$ (213 ft).

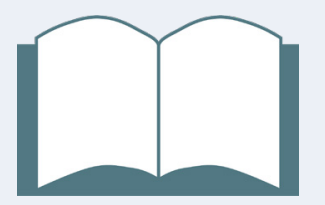

\section{Tales from our predecessors}

Many cultures around the world have rich oral and written histories that refer to memorable sea-level changes in the past.

Fishing up myths: demigods or Earth's furies? In the Pacific, myths speak of demigods fishing up islands from the middle of the ocean. Researchers think this relates to the eruption of underwater volcanoes, or the uplift of the land during an earthquake - which creates "new" islands.

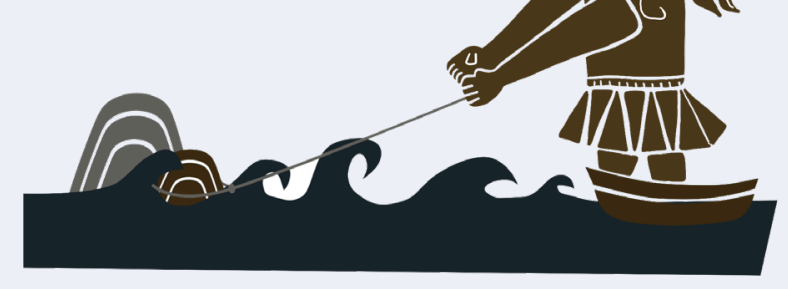

Seashells are meant to be by the sea!

Over 2000 years ago, Pythagoras found marine shells far inland of the modern seashore - evidence that the sea was no longer where it used to be.

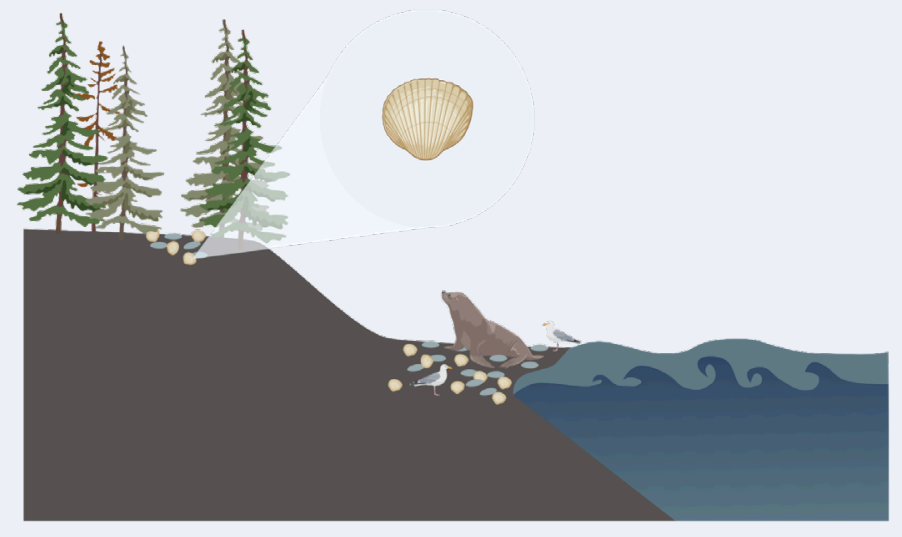

Japanese legend: giant catfish causes earthquakes and tsunamis

"People attempting to capture Namazu, the giant catfish believed to cause earthquakes."

Source: UBC Library, Rare Books and Special Collections, QE537.2 J3 D57 1800z. Page 13

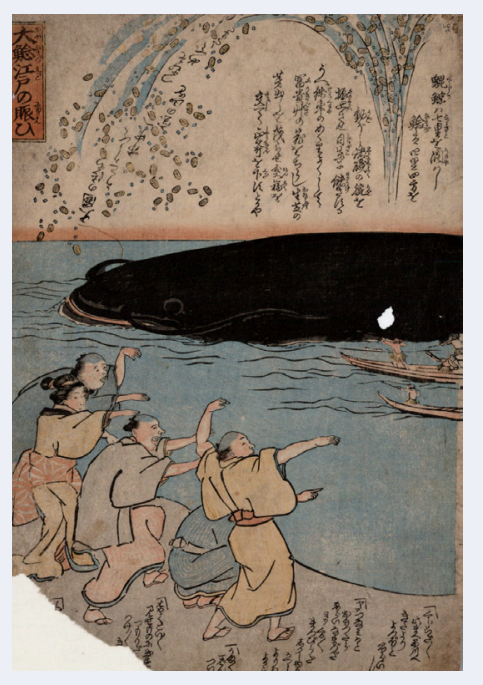




\section{FROM PAST TO PRESENT: How do we measure sea level?}

\section{The instrumental period ( 1800-present)}

Tide gauges were first introduced in the late 17th to early 18th centuries, and are the oldest instrumental records of sea level that we have. Tide gauges measure relative sea level (see Fig. 1).

Since 1993, satellites have made it possible for us to monitor nearly the entire surface of our oceans. Satellite altimetry, unlike tide gauges, measure only changes in the sea-surface height. They do not record changes in relative sea level caused by movement of the land.

\section{The paleo record (before $\sim 1800$ )}

Paleo archives can be dated, which allows us to extend the sea-level record further back in time to before the instrumental period. Examples are archaeological remains, geomorphological features, sediment records, and fixed biological indicators.

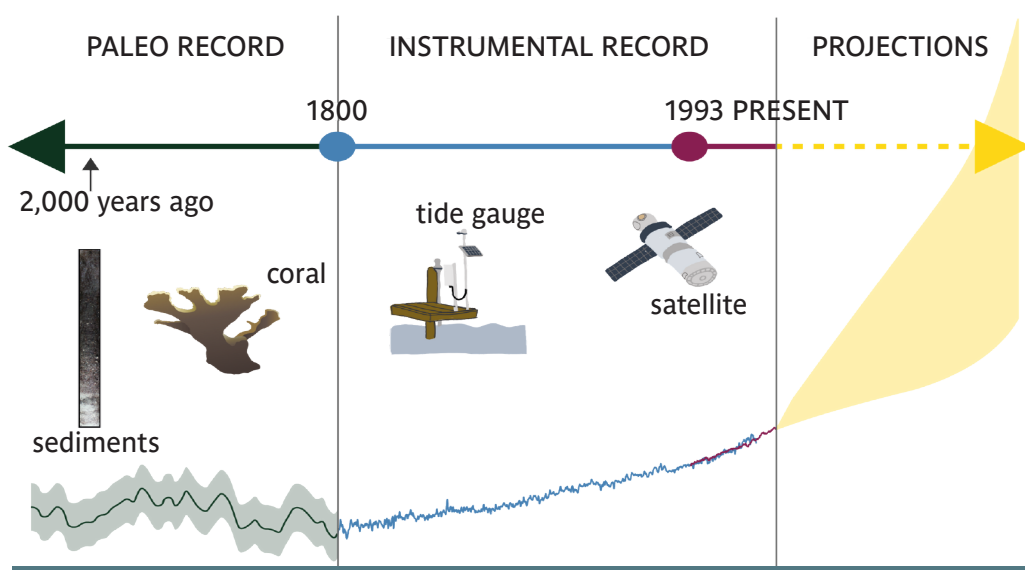

Figure 3: Adapted from IPCC Projection'; Paleorecord adapted from Kopp et al. ${ }^{2}$; Tide-gauge data from $\mathrm{CSIRO}^{3}$; Satellite data from NASA. ${ }^{4}$

\section{Archaeological remains}

Certain archaeological structures are built near sea level, such as piers and fishponds. Finding these abandoned structures where they can no longer serve their intended purposes indicates where sea level was in the past.

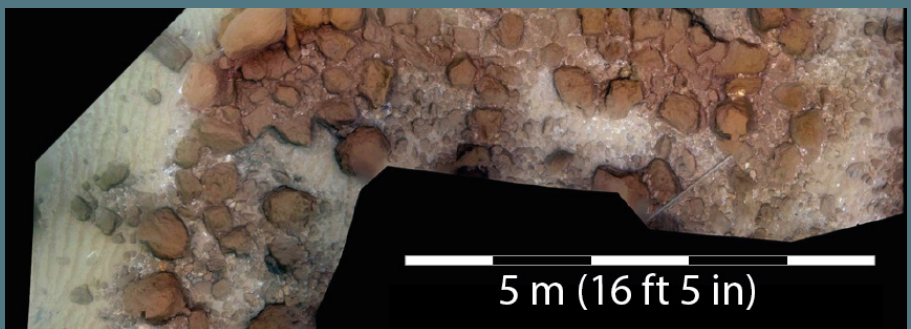

Submerged 7000-year-old sea wall off the Carmel coast, Israel. Adapted from Galili et al. ${ }^{5}$

\section{Geomorphological features}

Erosional or depositional landforms higher or lower than their modern equivalents tell us that relative sea level must have been different in the past, for at least long enough to have carved out these landforms at a different elevation.

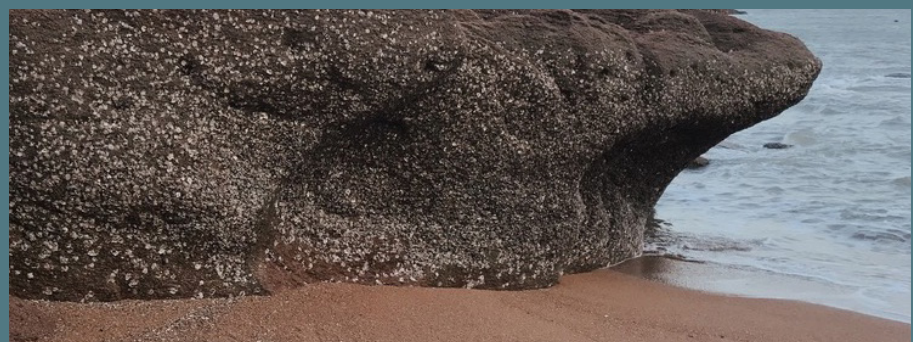

Tidal notches at Xiapu, China.

Source: Fangyi Tan, Earth Observatory of Singapore.

\section{Sediment records}

Changes in the sediments and fossils within a sediment core tell us about changes in depositional environments through time, which can be linked to rising or falling relative sea levels.

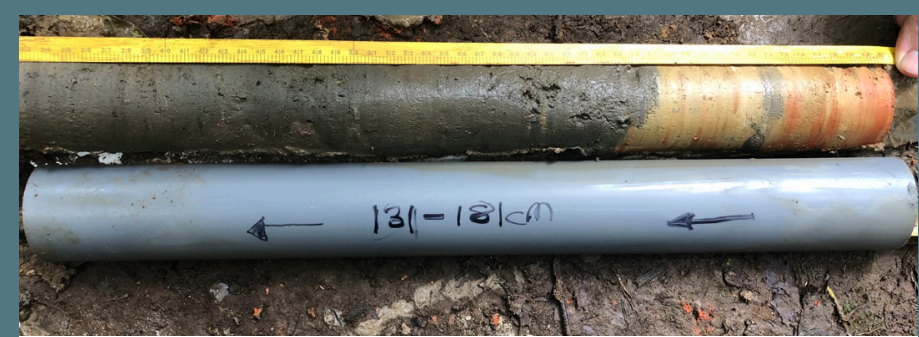

Sediment core from Pulau Ubin, Singapore.

Source: Sarah Cates, Earth Observatory of Singapore.

\section{Fixed biological indicators}

Fixed biological indicators are organisms that are attached to hard surfaces and/or grow at specific depths in the ocean (e.g. oysters, coral microatolls). Because they live in predictable habitats in relation to sea level, they can tell us about relative sea levels in the past.

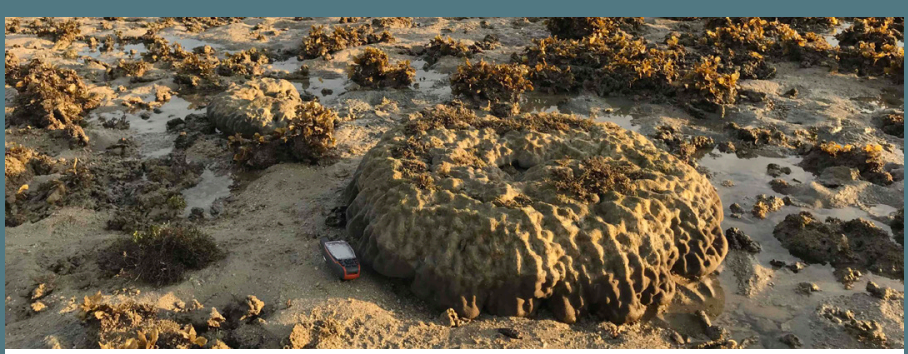

Coral microatoll exposed at low spring tides.

Source: Fangyi Tan, Earth Observatory of Singapore. 


\section{Your turn now, paleo sea-level scientist!}

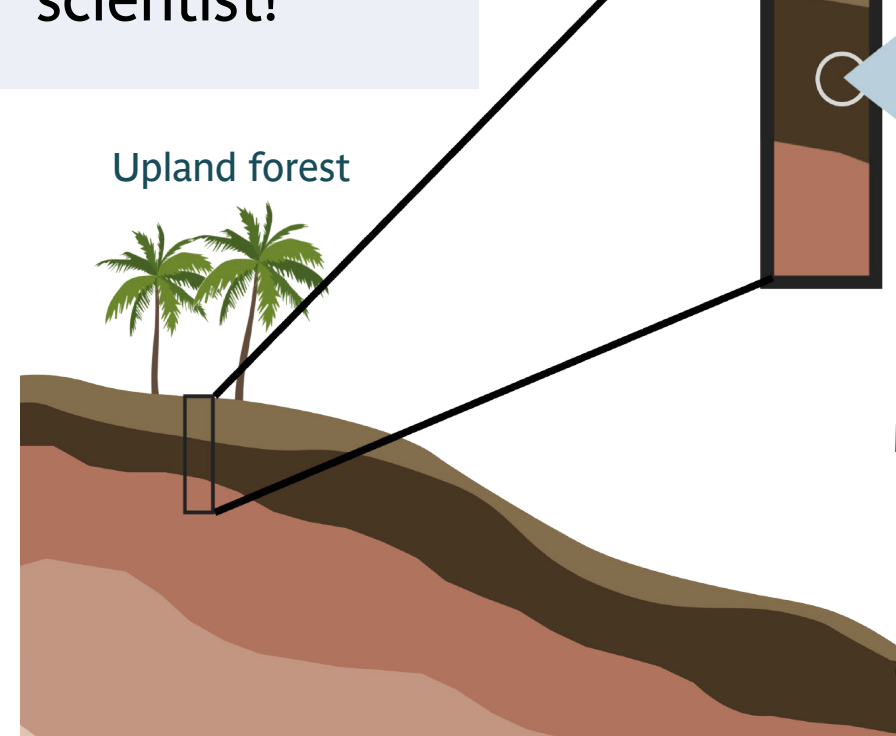

+8 meters ( $26 \mathrm{ft} 3 \mathrm{in}$ ) mean tide level $(\mathrm{mtl})$

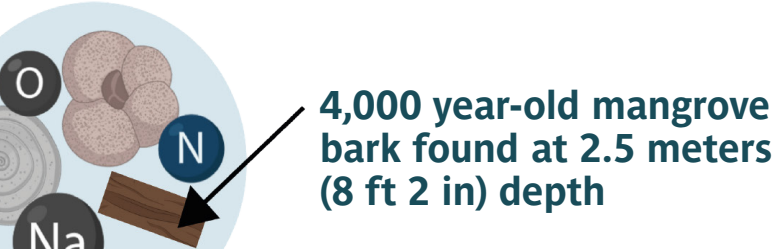

$\mathrm{Na}$

Modern mangrove environment

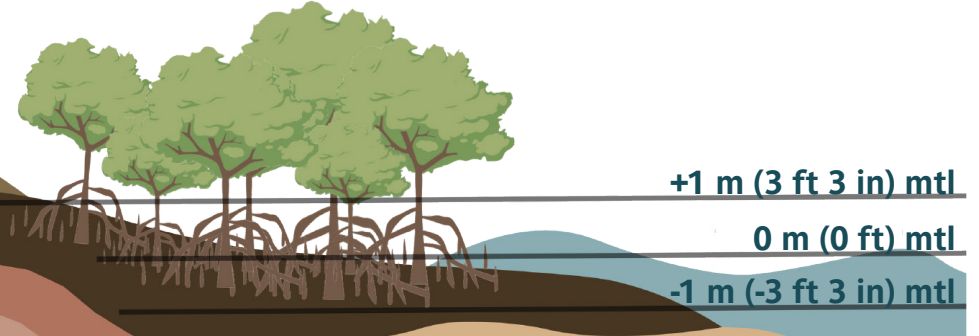

\section{Activity}

Using the information provided in the text, illustration, and the equation below, answer these questions:

Was relative sea level 4000 years ago higher or lower than today?

What was the relative sea level (in feet or meters) 4000 years before present?

Based on the elevation range that mangroves live in today, what is the possible elevation range that sea level could have been (in feet or meters)?

\section{RSL = E - RWL}

RSL: relative sea level

E: elevation of sample

RWL: midpoint of the vertical living range

that a sea-level indicator occupies

\section{Hint: Principle of uniformitarianism}

The present is the key to the past. The processes that we observe today are the same processes that happened in the past.

\section{Context}

We visited an upland forest and drilled a sediment core into the ground. At $2.5 \mathrm{~m}$ (8 $\mathrm{ft} 2 \mathrm{in}$ ) depth within the core, we found fossils that indicate a former mangrove environment (mangrove bark, mangrove pollen). These fossils are 4000 years old.

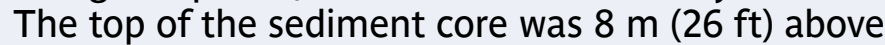
mean sea level.

\section{Necessary assumptions}

\section{$\rightarrow$ MANGROVE HABITATS HAVEN'T CHANGED}

The habitats/elevation zone we find mangroves living in today were the same in the past.

\section{$\rightarrow$ THE TIDAL RANGE HAS REMAINED THE SAME THROUGH TIME}

Where mangroves live is a function of the tidal range; the larger the tidal range, the larger the elevation range in which the mangroves can live.

In assuming that mangroves today occupy the same elevation zone as they did in the past, we are also assuming that the tidal range at the site has not changed. (3) 


\title{
A message from the buried past: \\ Deciphering the location of ancient settlements
}

\author{
Hadar Elyashiv
}

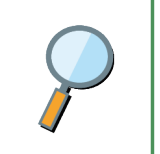

Follow this sign to see the observations, evidence, and interpretation of the data from Haifa Bay.

\section{How can we know what a coastal} environment looked like $\mathbf{4 0 0 0}$ years ago?

In a world with no cars or public transportation, going to the sea to fish or to collect food along the coast, even 1 kilometer or 1 mile can be too far. So why are settlements from 4000 years ago now located between 2-5 $\mathrm{km}$ (1-3 miles) away from the coastline? This question has troubled archaeologists who studied the coastal area now called Haifa Bay in Israel. It is especially puzzling as we know that fishermen would choose to live close to the water, where they can leave their boats rather than carry them.

Did people 4000 years ago have special technology, or was the coastline in a different position than it is today? How can we know what a coastal environment looked like 4000 years ago? Knowing the answer could help us understand how people lived in the past and perhaps tell us about possible future changes to the coastline.

To reconstruct the past environment, a geologist's work resembles the work of a detective reconstructing a crime scene. It begins with observing and collecting evidence such as field observations, sediments, and fossils samples. Once samples are analyzed, the geologist must interpret these natural clues - how did they get there, where did they come from, and how old are they?

\section{How can we find the past in the present?}

A first step towards environmental reconstruction is to follow the principle "the present is the key to the past". This principle suggests that processes we see today also happened in past times. In order to understand how a coastal environment looked like thousands of years ago, we first need to observe how the coastal environment looks and functions today.

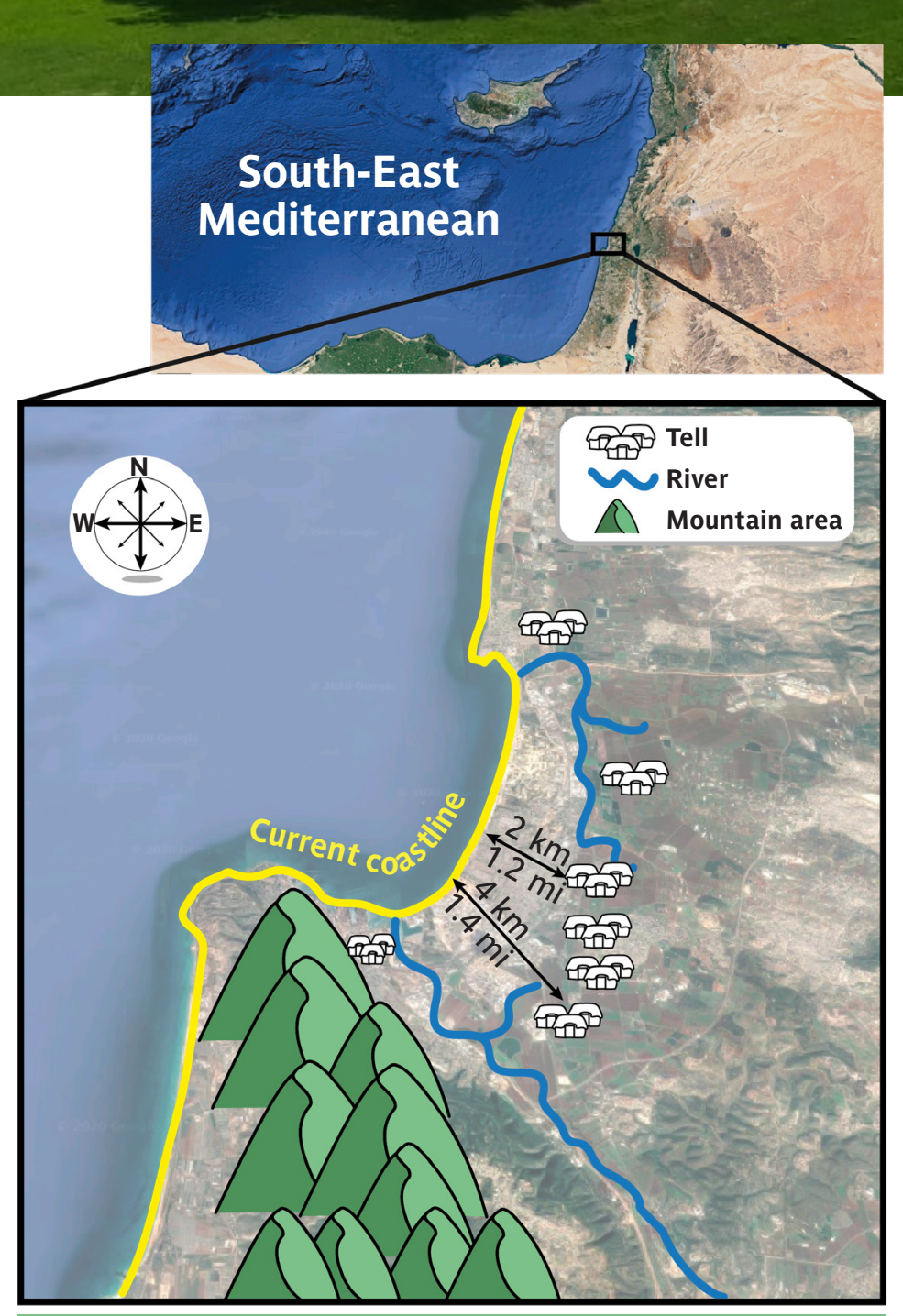

Figure 1: Marine and coastal area of Haifa Bay (Satellite images by Google Maps).

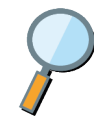

Observing the current coastal environment of Haifa Bay reveals a narrow, sandy coastline stretching almost linearly in the north-south direction. To the south, the coastal area is bordered by a mountainous area. The Mediterranean Sea stretches to the west and the land to the east and north. Two main rivers drain into the bay, thus delivering sediments to the bay. An array of Tells ("Tell" is the local term for an ancient settlement) stretches from south to north in a crescent-like shape. Tells are situated between $2-4 \mathrm{~km}$ (1-2.5 miles) away from the current coastline. 


\section{What can observations from a current}

\section{coastal environment tell us?}

If you visit different coasts around the world, you will notice many differences among coastal environments. Yet in general, there is a strip of sand between the sea and the land (geologists call this land "inland"). The width of that sand strip may differ from place to place, and features such as plants, shells, algae, sand dunes, and wetlands may be found in one place but not another due to different environmental conditions.
These represent the result of many processes in the coastal environment of the recent years. Monitoring and measuring the winds and ocean currents, plus the effect of storms, wave action, and tides, gives us an understanding of the processes that create these deposits along the coast. The location of the coastline is defined by where coastal sediments are found. Therefore, to find the location of the coastline in the past, we need to find such coastal sediments from the past, which are buried within the subsurface of different sediment layers.

To extract that infor-
mation from under-
ground, we drilled
cores along Haifa Bay in the
bay (west of the current
coastline), the beach, and
inland (east of the current
coastline). In cores where we
found coastal sand, we
sampled and measured the
age of the sand. We marked
the coastline 8000,6000 ,
and 4000 years ago on a
map. These results are very
clear - the coastline moved
from west to east during the
past 8000 years. This also
indicates that the sea level
rose from about 15 m (50 ft)
below today's sea level to its
current level.

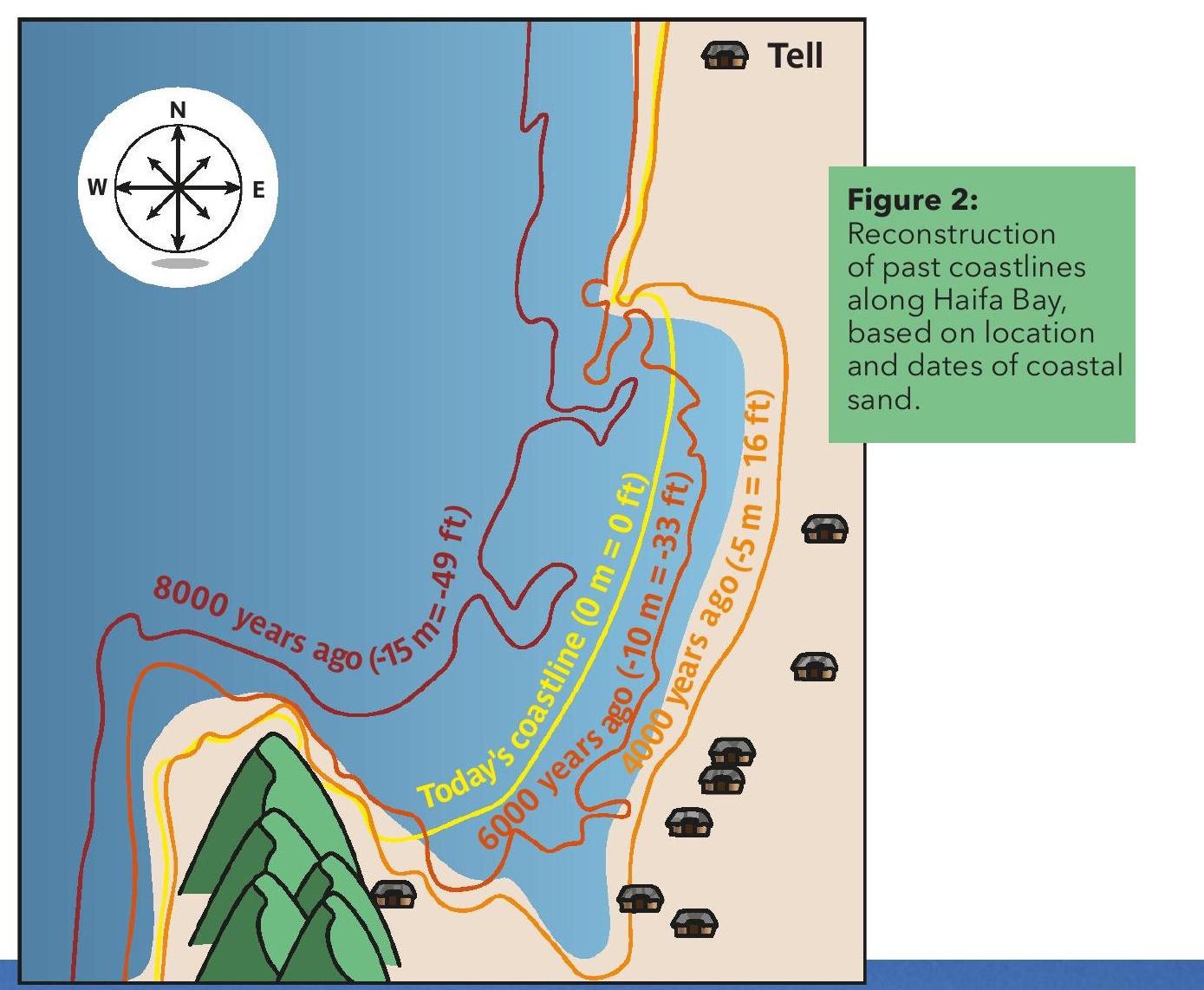

\section{Why does the coastline change with time?}

\begin{abstract}
The coastline changes because of changes in sea level with time. Sea-level changes differ from short timescales, as in hours for the tide, leading to a change of inches to feet (centimeters to meters). Over longer periods - thousands and millions of years - sea level can rise and fall tens to hundreds of feet or meters.
\end{abstract}

Because of the sea-level change, the location and the width of the coastline - the beach itself - is changing as sediments are removed from or added to the coast.

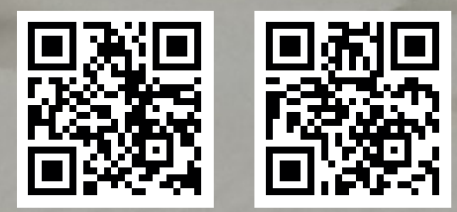




\section{How does the coastal environment change following sea-level rise?}

When we talk about a sea-level change, this refers to the height (or depth) of the water: a change in the vertical direction. However, the changes to the environment, such as the location of the coastline, are in the horizontal direction. When sea level rises, the coastline shifts inland, which affects the environments both onshore and offshore. As seen below, such a transition causes the coastline to migrate (move). This in turn leads to the build-up of water from river outlets, and a wetland is formed inland, behind the sand dunes.

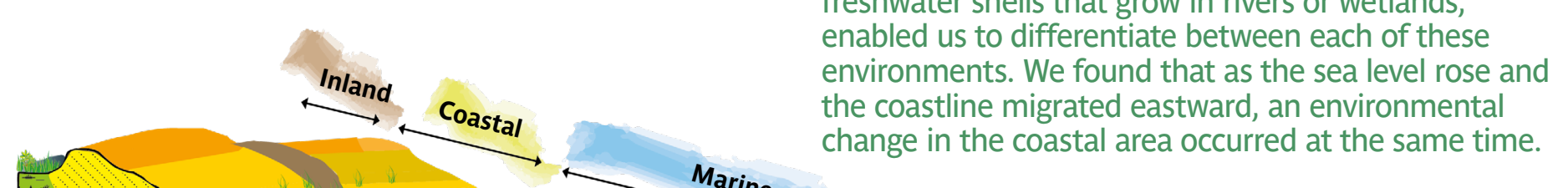
layers of sediments below the water in Haifa

Bay in two cores. The cores showed us that the coastline migrated eastward from around 7000 years ago over almost $3 \mathrm{~km}$ (2 miles) as a result of a global sea-level rise. However, this was not enough to determine the distance between the past coastline and some of the easternmost Tells. To do this, we had to examine the sediments, which showed us that through time, some locations that were marine became coastal and, later, even inland environments: special fossils found within the sediments, such as seashells or freshwater shells that grow in rivers or wetlands, enabled us to differentiate between each of these environments. We found that as the sea level rose and the coastline migrated eastward, an environmental change in the coastal area occurred at the same time.
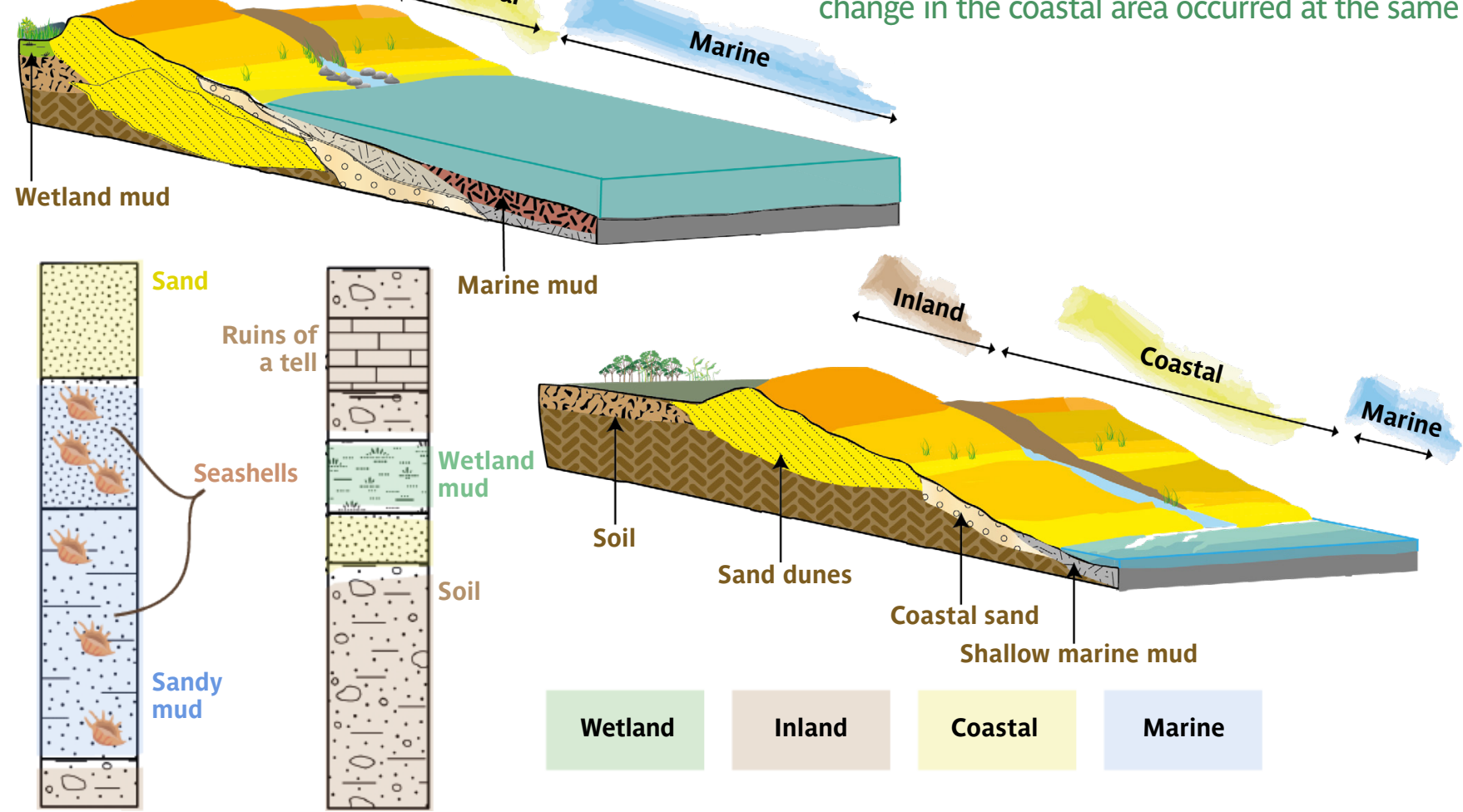

Wetland

Inland

Coastal

Marine

The environmental change in Haifa Bay was caused by a sea-level rise. Sand dunes formed along the coastline, blocking rivers from draining into the sea. The stagnant waters formed wetlands, which created a barrier, which made it more difficult to establish villages close to the sea in these locations.
Understanding the effects of sea-level rise on coastal settlements poses an important question: knowing that the sea level is currently rising, what will happen to our coastal cities in the future?

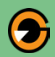




\section{THE STONE READERS \\ JÉRÉMIE MOREAU \\ BORIS VANNIÈRE}
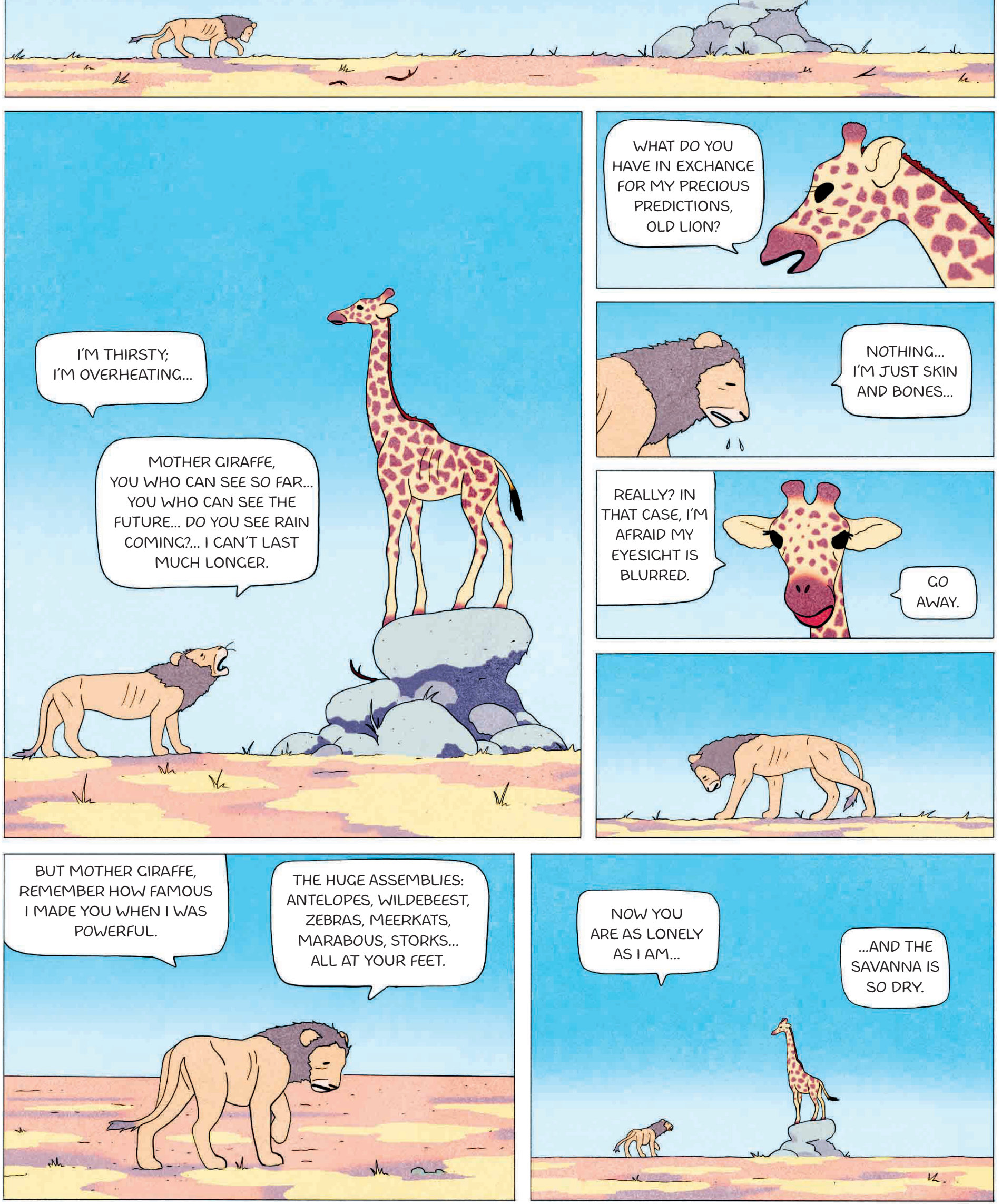

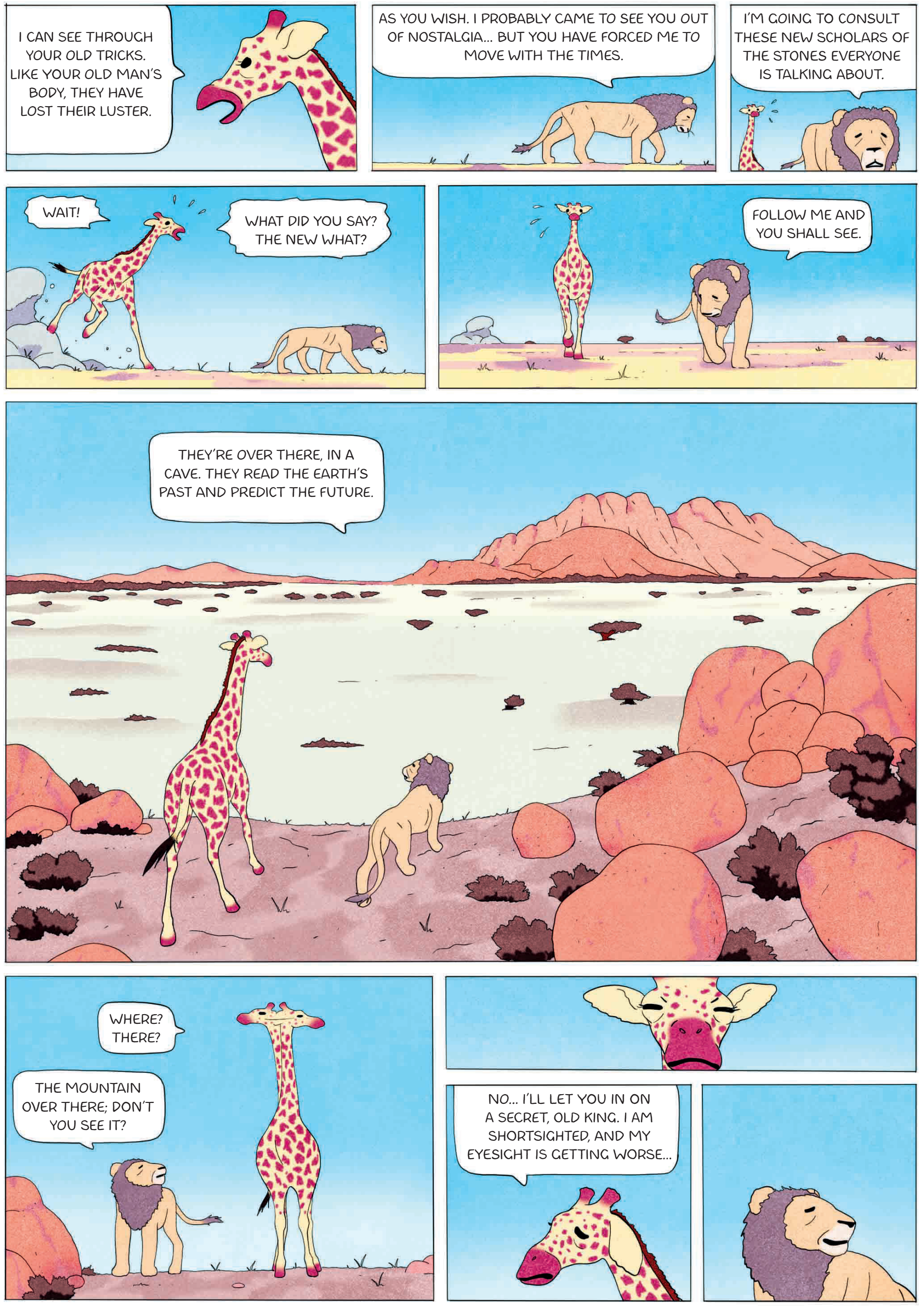

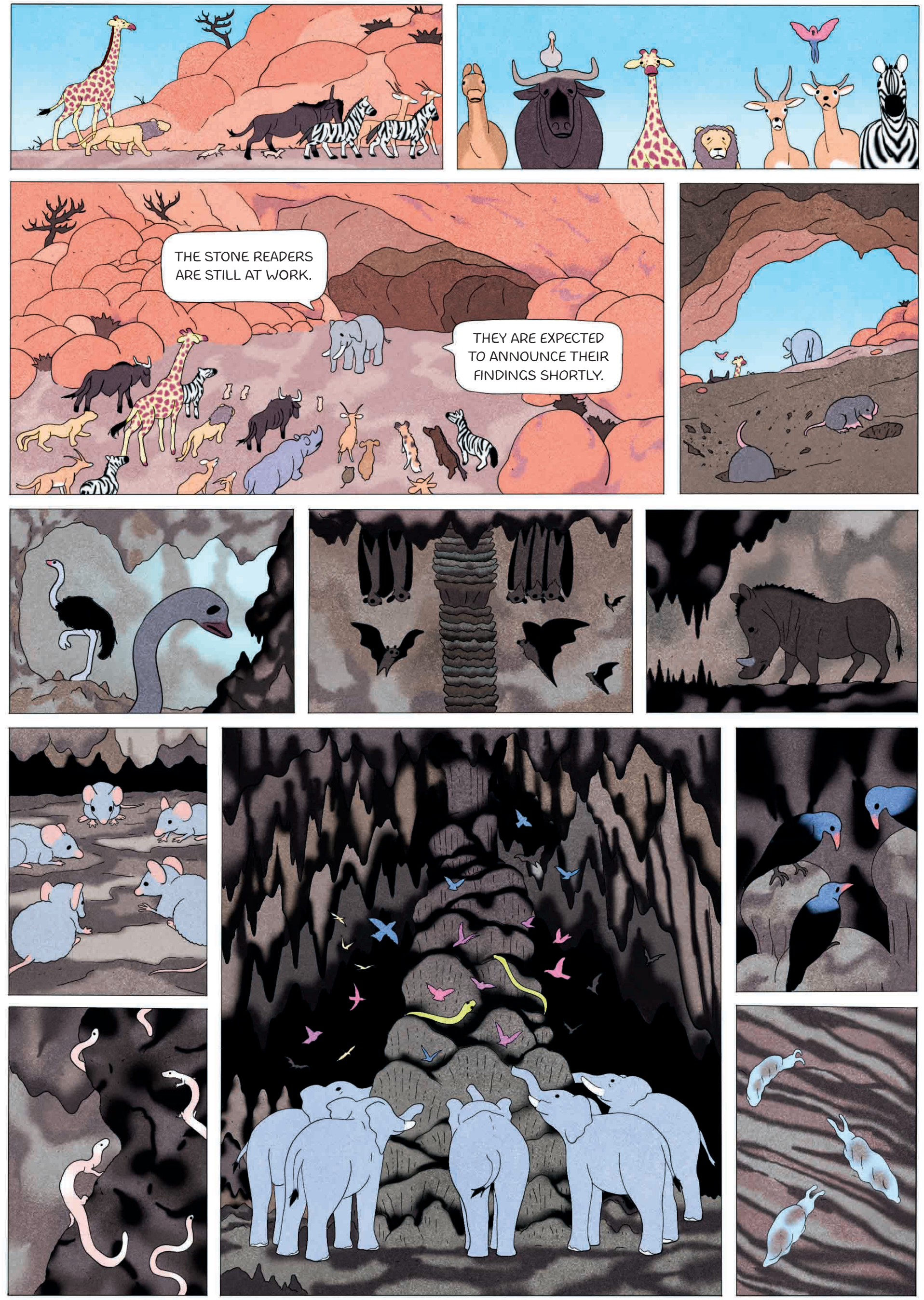

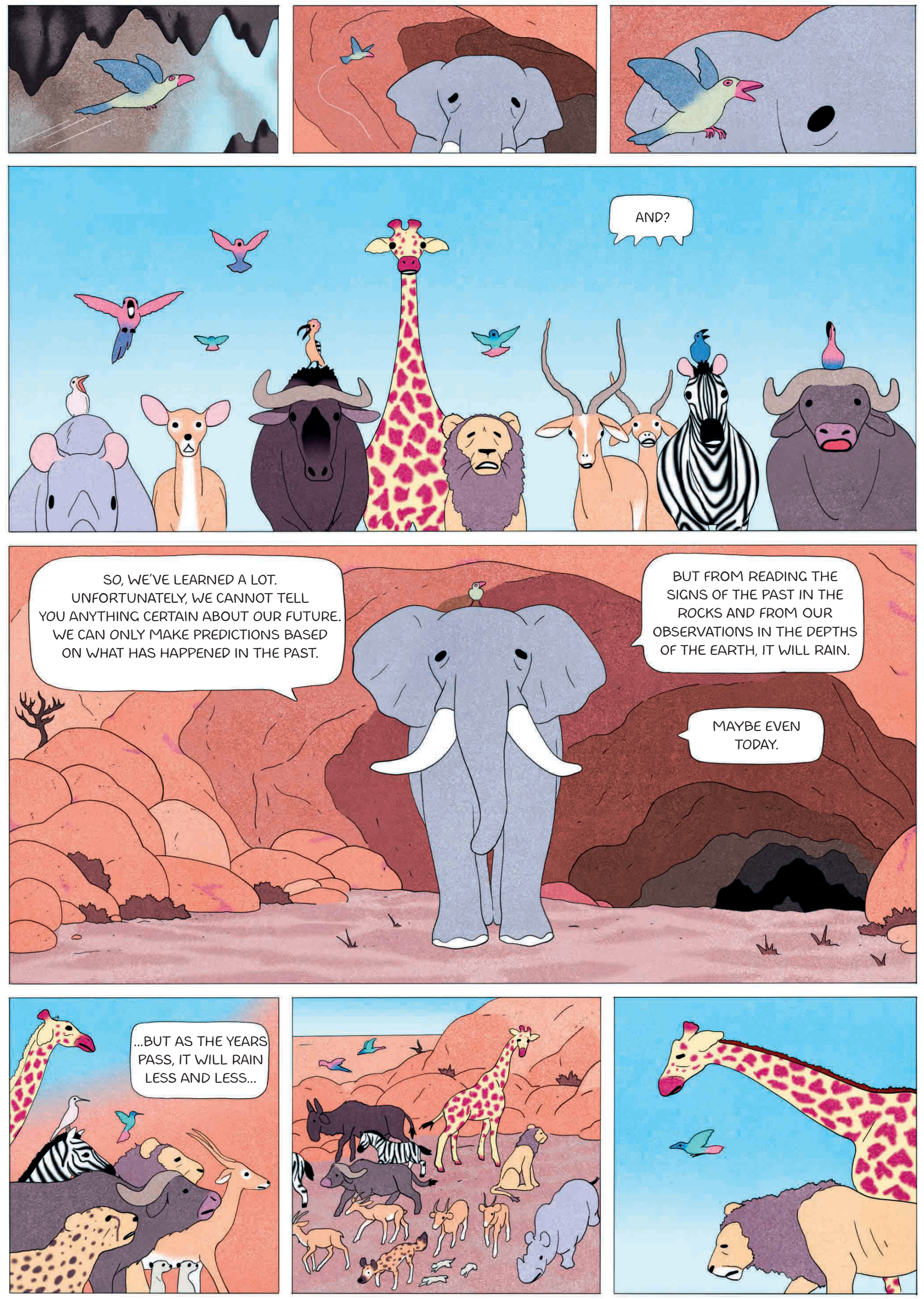

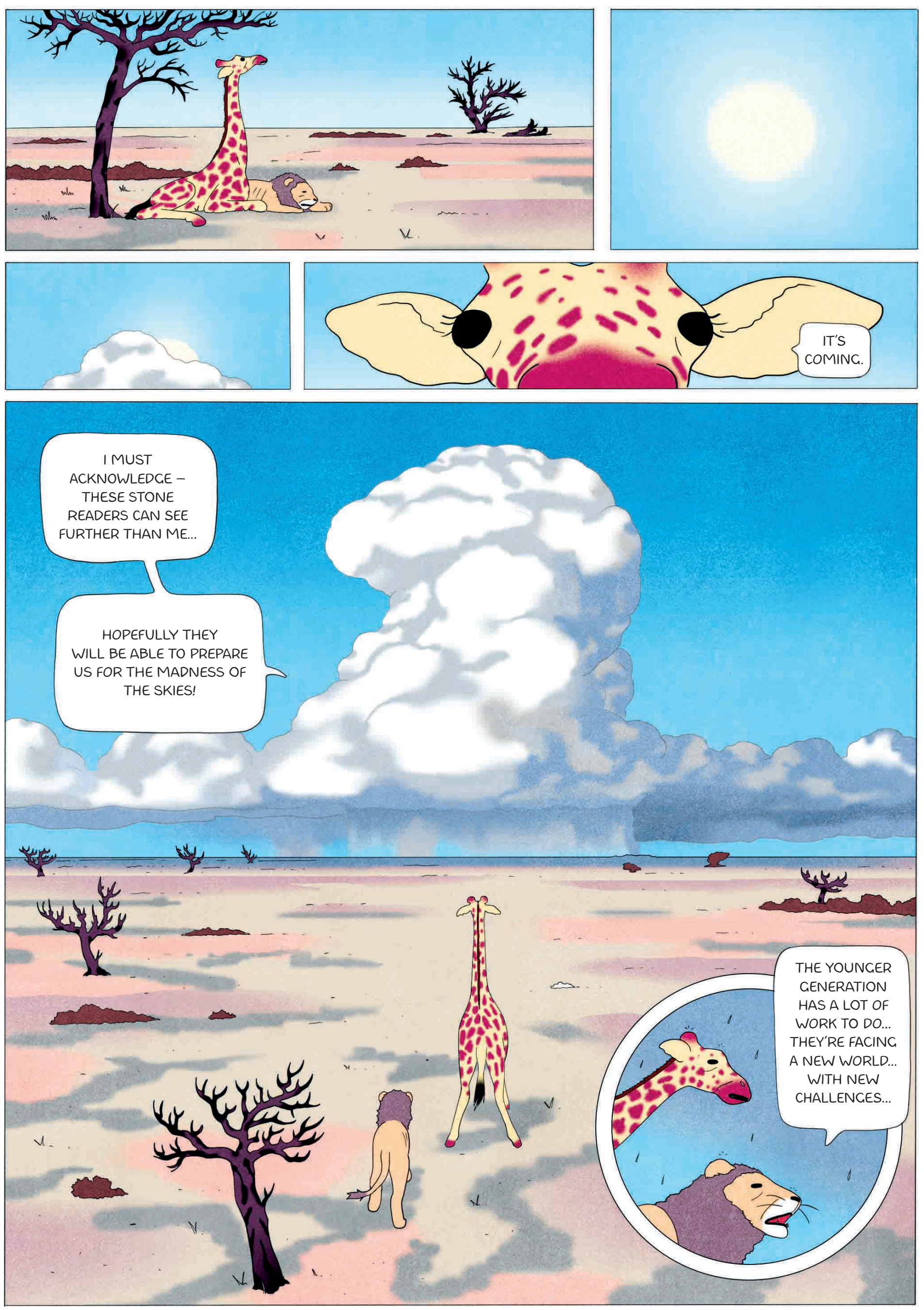


\section{Young scientists speak about global}

\section{change sciences}

\section{PAGES interviewed three members of the PAGES}

Early-Career Network who have been studying different topics in paleoscience. Alicja Bonk is an assistant professor at the University of Gdańsk in Poland; Stella Alexandroff is a research associate at the University of Exeter in the UK; and Tamara Trofimova is a researcher at the NORCE Norwegian Research Centre and the Bjerknes Centre for Climate Research in Norway. They gave us some insights about their research but also their motivation for choosing to study paleoscience and how this can help us prepare for the future.

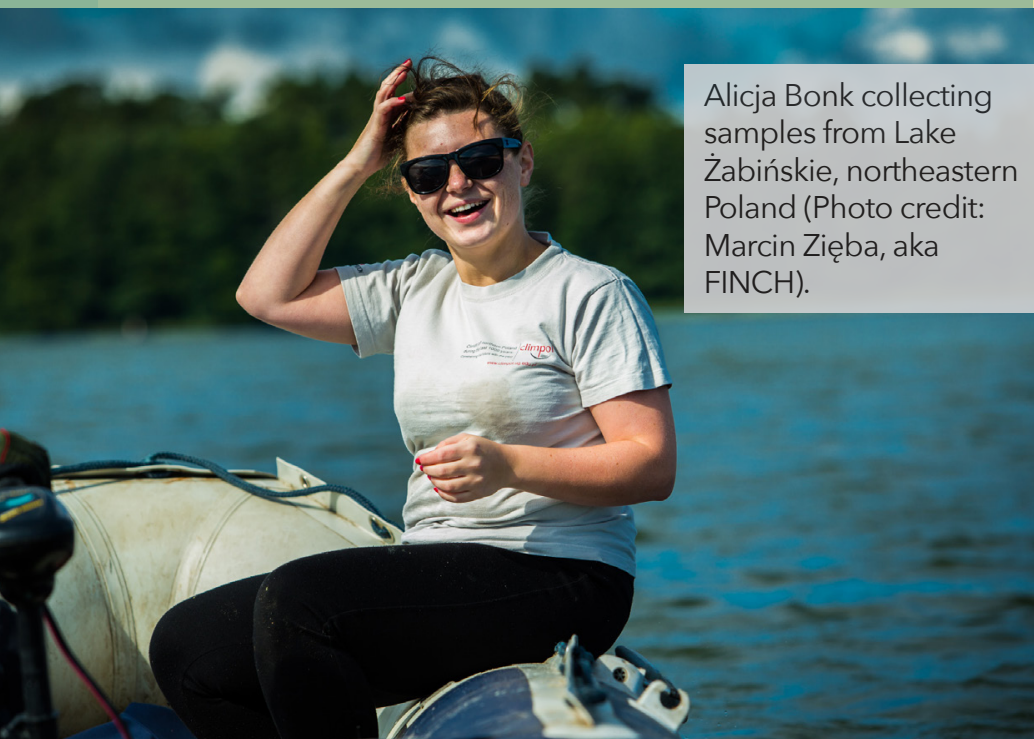

Why should we study the Earth, ecosystems, and/or climate history?

Alicja Bonk: Paraphrasing T.H. Van Andel: "Today is the product of yesterday." There is no better way to express why we should study the Earth and its history. By studying the past we can predict changes that are about to happen, estimate their range, and develop strategies for future generations.

Stella Alexandroff: We can only understand the changes we are causing to the Earth system if we have a baseline - a problem needs context. What does the natural variability look like? How rapid are the current changes? How will the system react? We can answer these questions by looking into the past.

Tamara Trofimova: We know only a fraction of what the world around us is really like, which is, by itself, a good reason to learn more! By studying the history of the Earth and life on it, we can better understand nature, how our actions can affect it, and be prepared for the future.

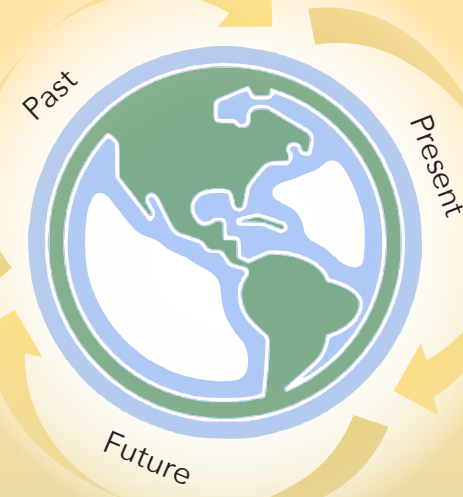

Why did you decide to become a paleoresearcher? How has your education prepared you for paleoresearch?

Alicja: After my graduation I joined a research team which had different scientific interests from mine. It cost me years of filling gaps in my knowledge and I still spend a lot of time learning, because new discoveries await. I didn't expect that paleoresearch would become my career but now I can't imagine doing something else.

Stella: I did not plan to do that from the beginning. I followed my interests, and the many small choices I made along the way led me to the field I am in now. I studied ecology, which, although we heard a lot about shifting baselines, did not really include paleoresearch. It was through my diploma thesis on fossil coral reefs that I eventually understood the importance of the paleo aspect, and that is how I got into studying past marine environments. I often feel unprepared for it, but with solid research skills and enthusiasm you can do just about anything.

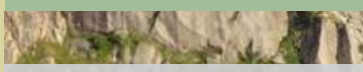

Shell samples (ocean quahog, Arctica islandica) drying on the shore, Lofoten islands, northern Norway (Photo credit: Tamara Trofimova).

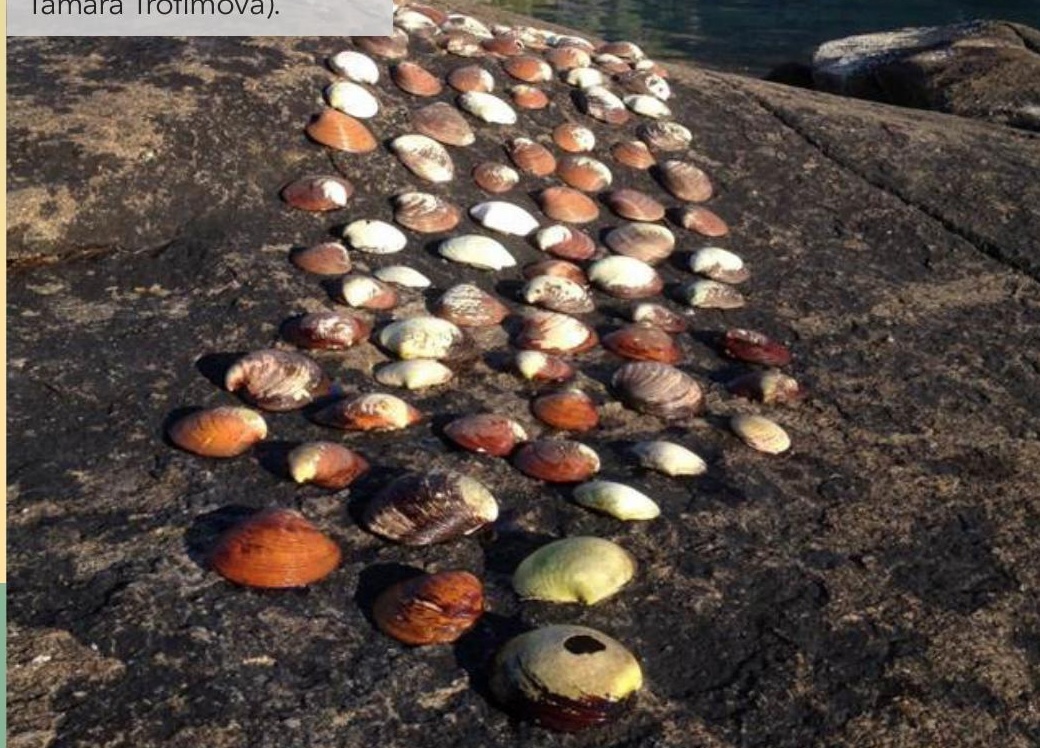


Tamara: It is fascinating that we can study what the world was like thousands of years ago and learn how it has been changing through time! Much like detective work, we use small clues to reconstruct the big picture and the course of events. I became interested in paleoresearch when I learned how some organisms and their fossil remains can provide such clues and help us better understand past, present, and even future climate. I studied ecology and marine biology and later focused on paleoceanography. My education helps me to interpret paleorecords provided by the organisms I use in my research.

\section{What is your research specialty? More generally, how is it useful?}

Alicja: To talk about the dynamics of change, including abruptness and duration, a robust and accurate chronology (arranging events in time order) is needed. My primary research specialty is constructing chronologies based on lake sediments, which are incredibly important archives tracking environmental and climate changes.

Stella: My research field is called sclerochronology - I study past marine climate variability using the annual banding and geochemical signals in clam shells. Natural archives of past marine climate are needed because instrumental records are very scarce and only cover the past few decades. The great thing about our techniques in particular is that the records we produce are very highly resolved (daily to annually), they are absolutely dated, and can go back several centuries or millennia. Thus, this is an incredibly powerful and precise tool that can further our knowledge and understanding of the history of marine environmental changes.

Tamara: I study past marine climate and use clam shells and coralline red algae in my research. While growing, these organisms record ambient conditions in their carbonate skeletal structures (mollusks' shells and thalli of algae), just like weather stations. By analyzing a physical and chemical composition of these structures, we can "read" their records and "extract" environmental information on, for example, past ocean temperatures and salinity. These structures also have annual bands similar to tree rings, which we use as a calendar marking the beginning and the

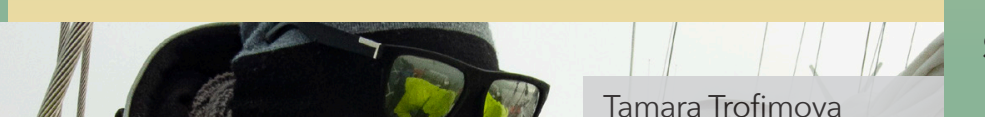
examines a sample of coralline algae during a research cruise off the coast of Svalbard (Photo credit: Raymond Olsen).

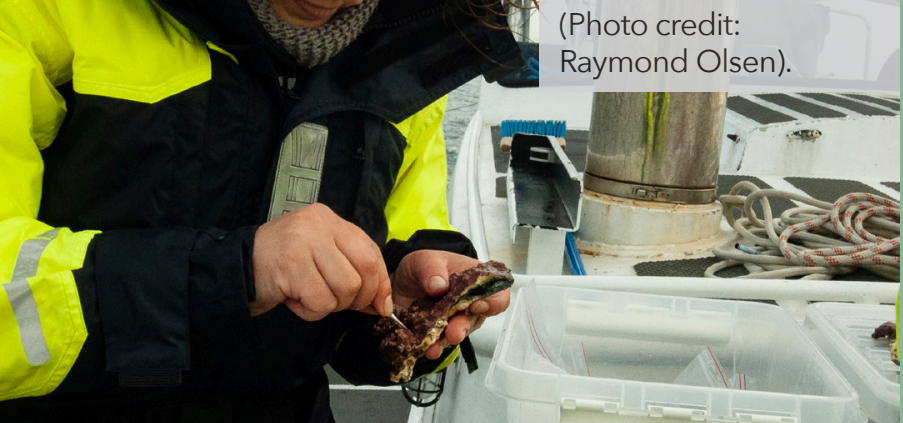

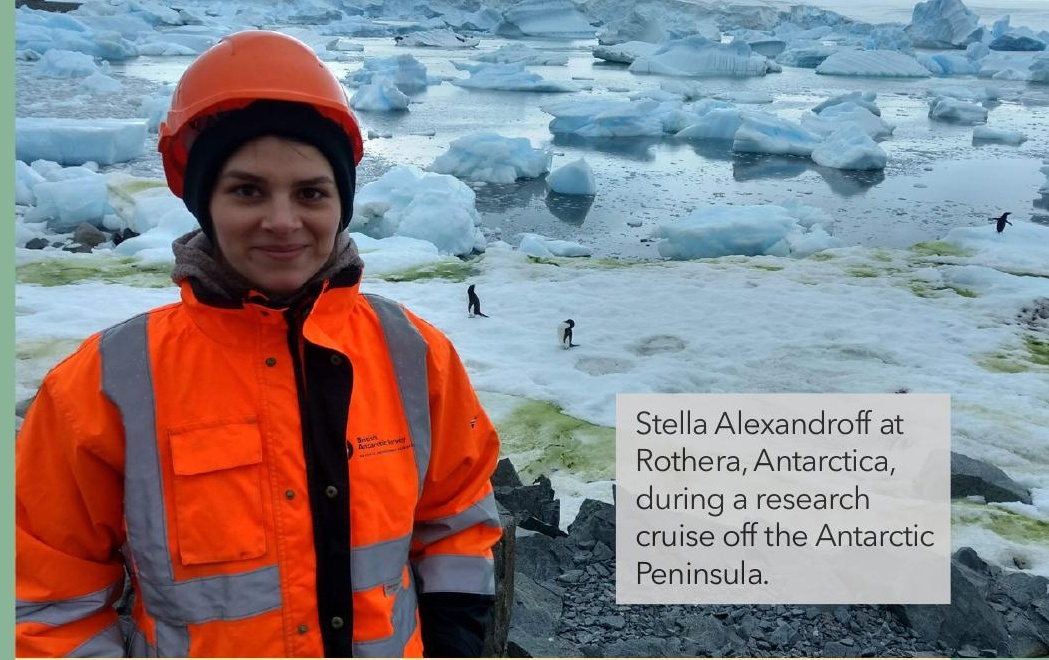

end of a year in the "skeletal records". Through these records, we can learn how ocean and climate were changing through time and what are the mechanisms controlling these changes.

\section{How do you think your work can change the world?}

Alicja: I don't think my work alone is powerful enough but I believe that joint effort of (paleo)researchers and society can influence the future of our planet. There are examples of climate-environment-human interactions in the past which can be useful in tackling today's problems. Education and innovative approaches will change the world.

Stella: I believe in community effort, and I see my work as one piece of the puzzle. A network of records across geographic regions and geological timescales is needed to improve our understanding of the environment. It takes a village - or rather a global community - of researchers from various backgrounds.

Tamara: My research helps to fill the gaps in our knowledge of past climate, nature, and the processes within it. My work might not change the world but can change the way we see it.

From a personal point of view, what would you like to say to the younger generation about past, present, and future global changes?

Alicja: The Earth is a very dynamic and complex system and so are global changes. To reconstruct the past, understand the present and predict the future, networking, collaboration and engaging the younger generation is necessary. It is crucial to ask tough questions and look for the answers beyond a single discipline.

Stella: It can be difficult not to feel world-weary with everything going on. The key is to seek out examples of positive progress and nuggets of hope - they are sometimes hard to find among a wealth of messages of doom, but they do exist. The climate movement is one of them.

Tamara: There is much to learn from the past if we want to know what the future might be. Although our knowledge is limited, we know that the world around us is changing at an unprecedented rate. If we want to avoid dramatic consequences, we need to change the way we act towards nature. 
doi.org/10.22498/pages.horiz.1.30

\section{SECRETS HIDDEN IN CAVE STORIES}

Silvia Frisia, Nicole Pierce and Pauline Treble

\section{The past is the key to the future}

Peoples of the South Pacific tell stories of male rain, Te Ihorangi, and female light mist, Inewhai. They usually alternate with the seasons, but there have been years with only little rain, when crops withered and people starved. And there were years when furious winds, rain, floods, and storm surges brought destruction. Crops rotted, people could not go fishing, and they starved. Today, food is sourced from far away, but tropical cyclones can still hinder cargo boats and planes, leaving Pacific Islanders without essential goods for months.

The South Pacific stretches from Australia to South America and includes thousands of island nations spread across a vast region that is highly exposed to natural disasters. Life in this island network is threatened by the changing nature of tropical cyclones as they become stronger with global warming. Just like we forecast daily weather, we need to predict future extreme events, such as tropical cyclones and drought. But our knowledge of climate in

Figure 1: Location of the Cook Islands and what to do

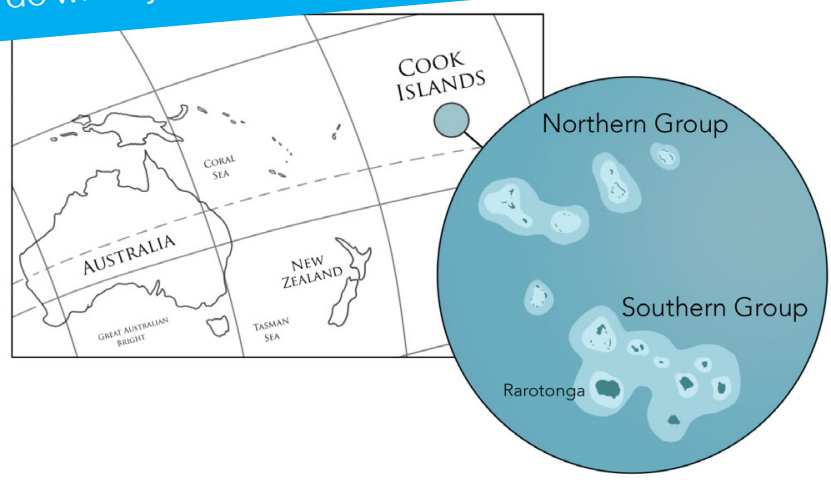

Figure 2: From living corals to limestone.

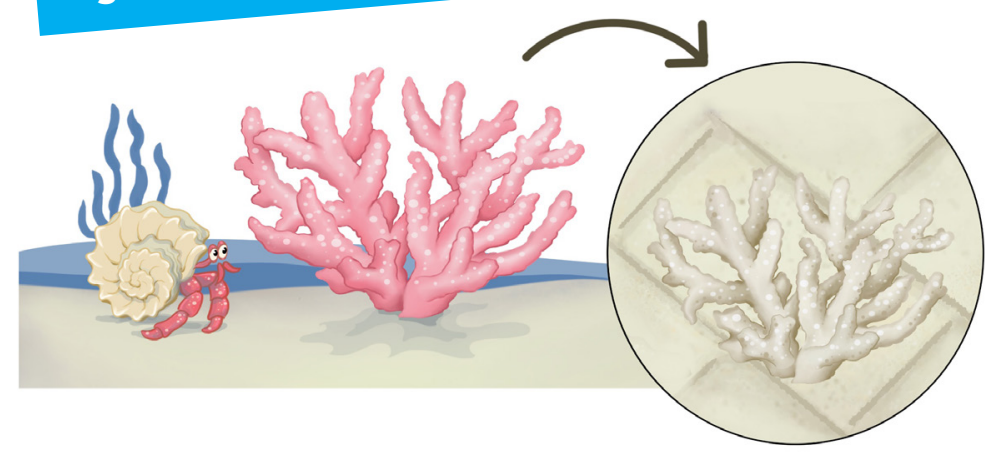

the South Pacific is limited by a short record of weather data. We can't travel back in time to collect more data, so we look at long archives found in natural materials that give clues about past rainfall and droughts. We study the clues that are held deep underground, inside cave stalagmites.

\section{The Cook Islands:}

\section{From coral reefs to stalagmites}

We go to the Cook Islands (Fig. 1) because there are many caves there carved into ancient coral reefs, which have turned into limestone rock over thousands of years (Fig. 2).

Limestone is formed from the mineral calcite,

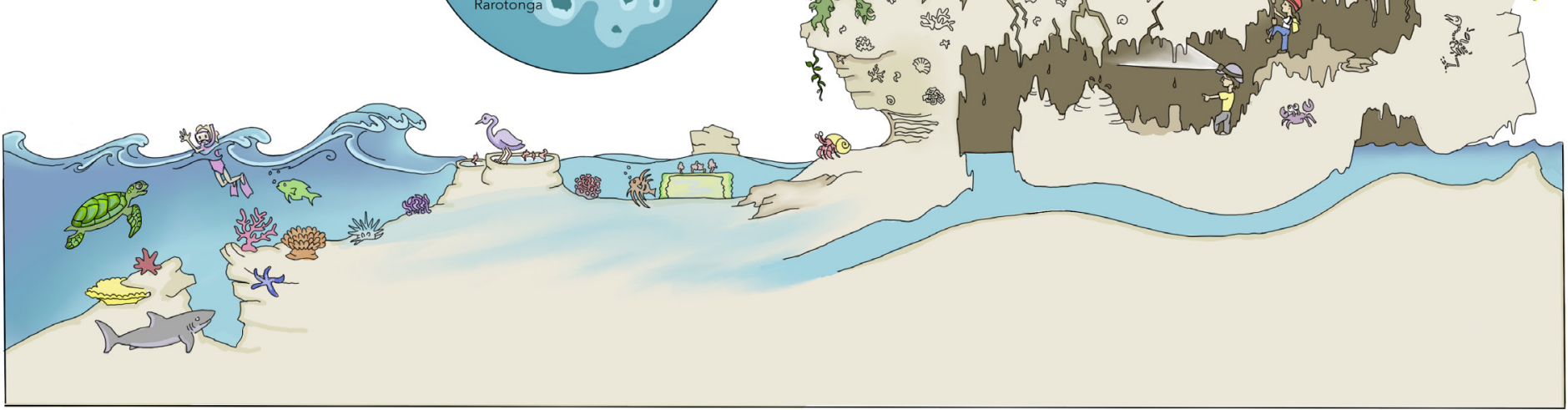


flimestone and sources of chemical components that enter into the cave in the dry and wet seasons, 列
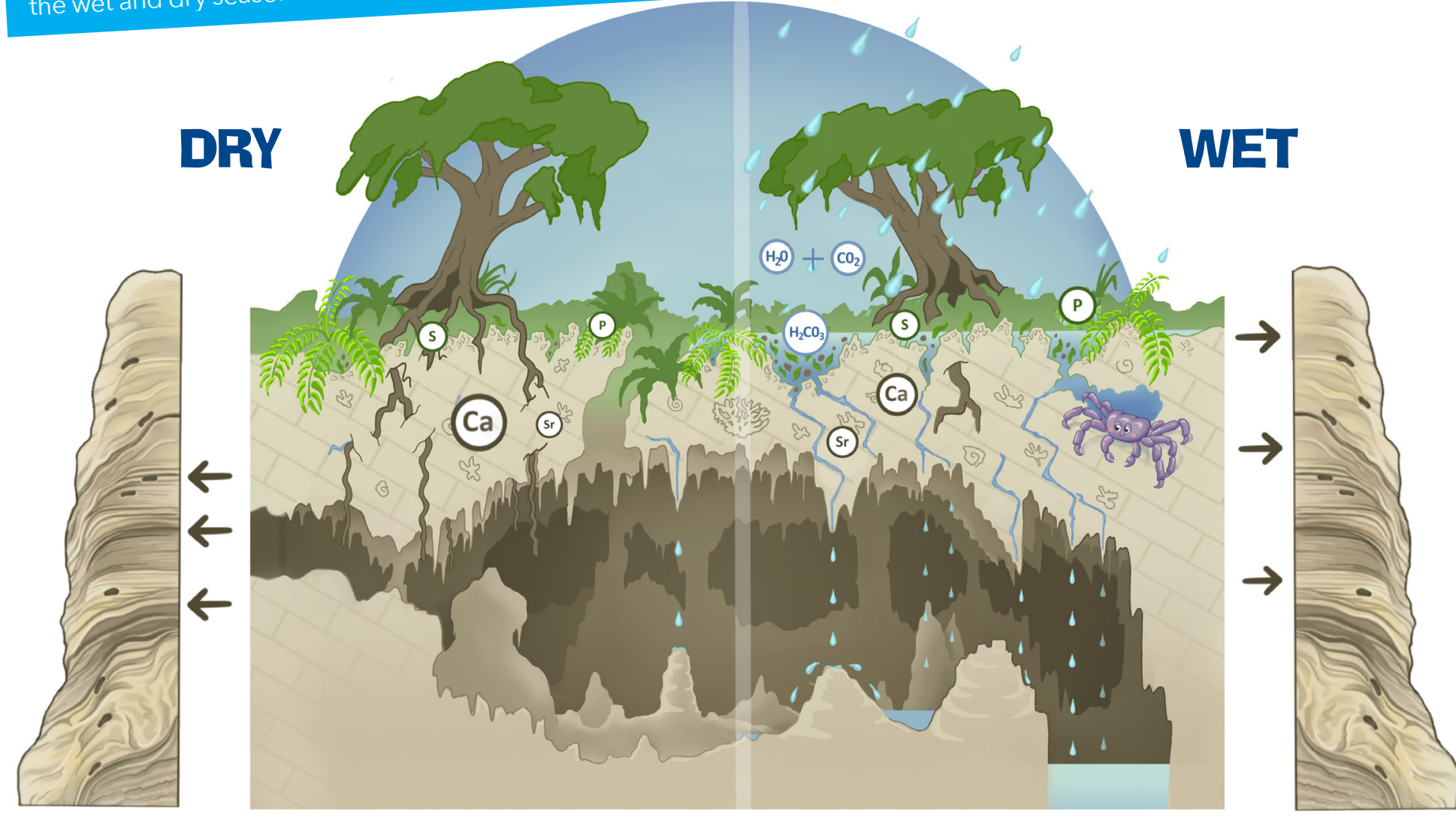

which contains calcium (Ca), carbonate $\left(\mathrm{CO}_{3}\right)$, and tiny quantities of other components, such as strontium (Sr).

Calcite is slowly dissolved by the rain. Above the cave there are trees and ferns. Their roots breathe and give off carbon dioxide $\left(\mathrm{CO}_{2}\right)$. This $\mathrm{CO}_{2}$ combines with the rainwater to form carbonic acid $\left(\mathrm{H}_{2} \mathrm{O}+\mathrm{CO}_{2}=\mathrm{H}_{2} \mathrm{CO}_{3}\right)$, which is more efficient than rainwater alone in dissolving the limestone (Fig. 3).

\section{How do caves record changes in rainfall?}

Rainwater that flows into the cave passes through pores and fractures of the host rock. This water is very concentrated in dissolved chemical components originating from the rock, such as $\mathrm{Ca}$ and Sr. When this water enters the cave by dripping from a stalactite, it splashes onto the floor forming a stalagmite. Some of the dissolved $\mathrm{CO}_{2}$ is able to escape into the cave air - a process called degassing - and new calcite crystals are deposited on top of this stalagmite. When climate is dry, these crystals contain Ca and very small amounts of $\mathrm{Sr}$ and form a stalagmite layer that has no pores and is translucent (somewhat dark). But when it rains too much and destructive cyclones hit the islands, the rainwater flows much faster into the cave. Organic compounds that are transported from the soil carry with them chemical elements from the soil, such as sulfur (S) and phosphorous (P). These organic compounds, $\mathrm{S}$ and $P$, are not parts of the mineral calcite. Imagine building a house and mixing glass spheres and clay bricks. It is impossible: there will be empty spaces between the spheres and the bricks. This is what happens to each stalagmite layer that grows in the wet season. There is a mixture of building blocks ( $\mathrm{Ca}$ and $\mathrm{CO}_{3}$ ) and spheres (the organic compounds plus $\mathrm{S}$ and $\mathrm{P}$ ). Thus, the "wet season" layers will have hundreds of tiny pores and because of these pores, they will look milky-white (see Fig. 3 for the whole story). 


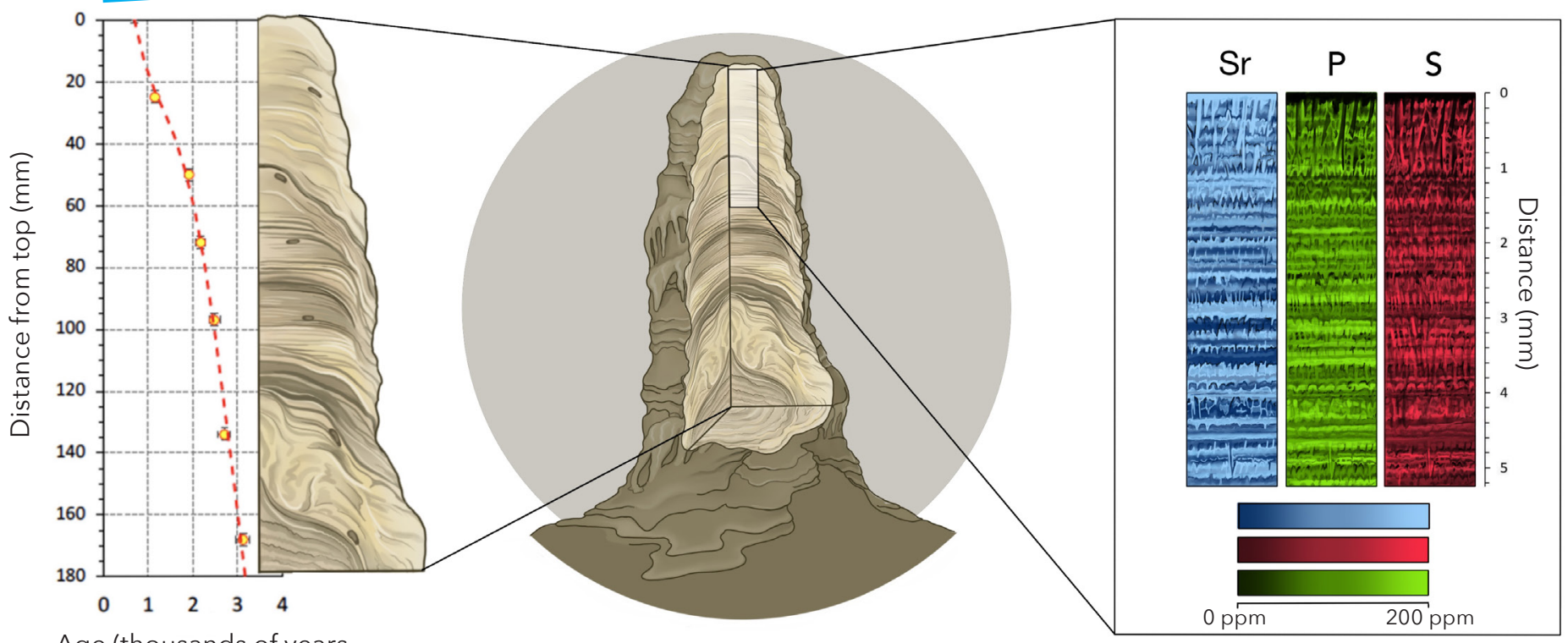

Age (thousands of years before present)

\section{How do we know when the climate changed?}

Layers in the stalagmite start to resemble tree rings, or pages in a history book that you cannot simply read with your eyes. Years that are wet will be recorded by layers of milky-white and porous calcite containing organic compounds, $S$ and $P$ (Fig. 4). Compact layers with Sr mark dry years. Now we have the clues we need to read our book of climate change. Well, not quite yet! We first need to put an age to this record of climate change. To do this, we use radiometric dating. Tiny amounts of the uranium isotope ${ }^{234} \mathrm{U}$ that are trapped inside the stalagmite crystals decay into the thorium isotope ${ }^{230} \mathrm{Th}$ by a precise rate over time. We also count the annual layers between two radiometric ages. Now we have our climate calendar.

\section{How do we gather climate information?}

In the cave we collect dripping water and measure certain chemicals in the water and the temperature and relative humidity of the cave. This is how we know that when it rains too much, there will be more material from the soil on the top of a stalagmite: $P$ from plants and $S$ that is transported from the sea by storms.

In the lab, the stalagmite layers are revealed when we cut the stalagmite open (Fig. 4). There are many techniques that help us find clues about past climate. Many researchers measure the isotopes of the oxygen $(\mathrm{O})$ atom within the calcite. Isotopes of an atom have a different number of neutrons in the nucleus. Scientists measure the proportion of the light $O$ isotope, which has 8 neutrons $\left(\mathrm{O}^{16}\right)$, to the heavy $\mathrm{O}$ isotope $\left(\mathrm{O}^{18}\right)$, which has 10 neutrons. In the South Pacific stalagmites, more rain results in more $\mathrm{O}^{16}$ within the calcite and droughts in more $\mathrm{O}^{18}$. But it is difficult to measure $O$ isotopes in the very thin layers of our stalagmites. Thus, we use another method that detects how chemical compounds vary year after year. With a special X-ray machine, known as a synchrotron, we obtain a map of the amount of chemicals picked up from the rock and from the surface for each stalagmite layer, even when this is so thin that one can only see it with a microscope. A synchrotron is many times bigger than your doctor's $X$-ray machine! It excites $\mathrm{Sr}, \mathrm{P}$, and $\mathrm{S}$ in the stalagmite, causing the electrons in these atoms to jump from the inner orbit into an outer orbit. Before falling back to the inner orbit, they emit a type of radiation called fluorescence. The synchrotron transforms the fluorescence into a colorful map, revealing "clues" to climate change. We see that there are many milky layers with more $P$ and $S$ (Fig. 4). These record many powerful cyclones. Plus, when we see more Sr in several adjacent compact calcite layers, we know this represents long droughts. These droughts influenced the history of the Pacific long before we started taking instrumental measurements. 


\section{Stalagmites and other stories}

Looking at the patterns of the layers and their chemical fingerprints, we found that very dry or very wet periods lasted much longer than 10 years, which is a long time when food and other necessities are in short supply. We put precise ages to these wet and dry periods seen on the synchrotron maps, then compared our stalagmite data with information obtained through other methods and by other researchers. For example, we discovered that about 1000 years ago there was a drought that lasted many decades (in yellow on the big computer screen in Fig. 5)! Archaeologists tell us that Polynesians built sophisticated canoes and sailed across the Pacific Ocean in search of land where they could grow their most nutritious plant: taro. They located this land in the Cook archipelago. The Polynesians were fortunate, because after they landed in the Cook Islands the long drought ended and it was followed by about 100 years of wet summers about
900 years ago. Our stalagmites tell us that Te Ihorangi rains helped the farmers to provide nutritious food for their children and the entire population (wet period in blue on the big screen). And, in fact, archaeologists discovered that about 900 years ago the Polynesian settlers burned the forests on the Cook Islands to plant more and more taro. The climate was good for taro crops, so life was also good.

Our climate book has more pages than the instrumental record, which helps us to better model what the climate in this region may be like in the future. It also improves our understanding of how humans have coped in the past and might cope in the future with climate change in the Pacific. Better climate models and better knowledge about how climate shaped societies and their resilience to climate change will help the Pacific nations devise a sustainable future and protect communities, their culture, and their land.

Figure 5: Our scientist

uncovering stalagmite

secrets. The big screen

shows our stalagmite's section, dated 1000 to 900 years ago (or years 1000 and 1100 Common Era), and the interpretation of high and low Sr. The yellow bar marks many dry years and the blue bar many wet years. And coffee is a great help!

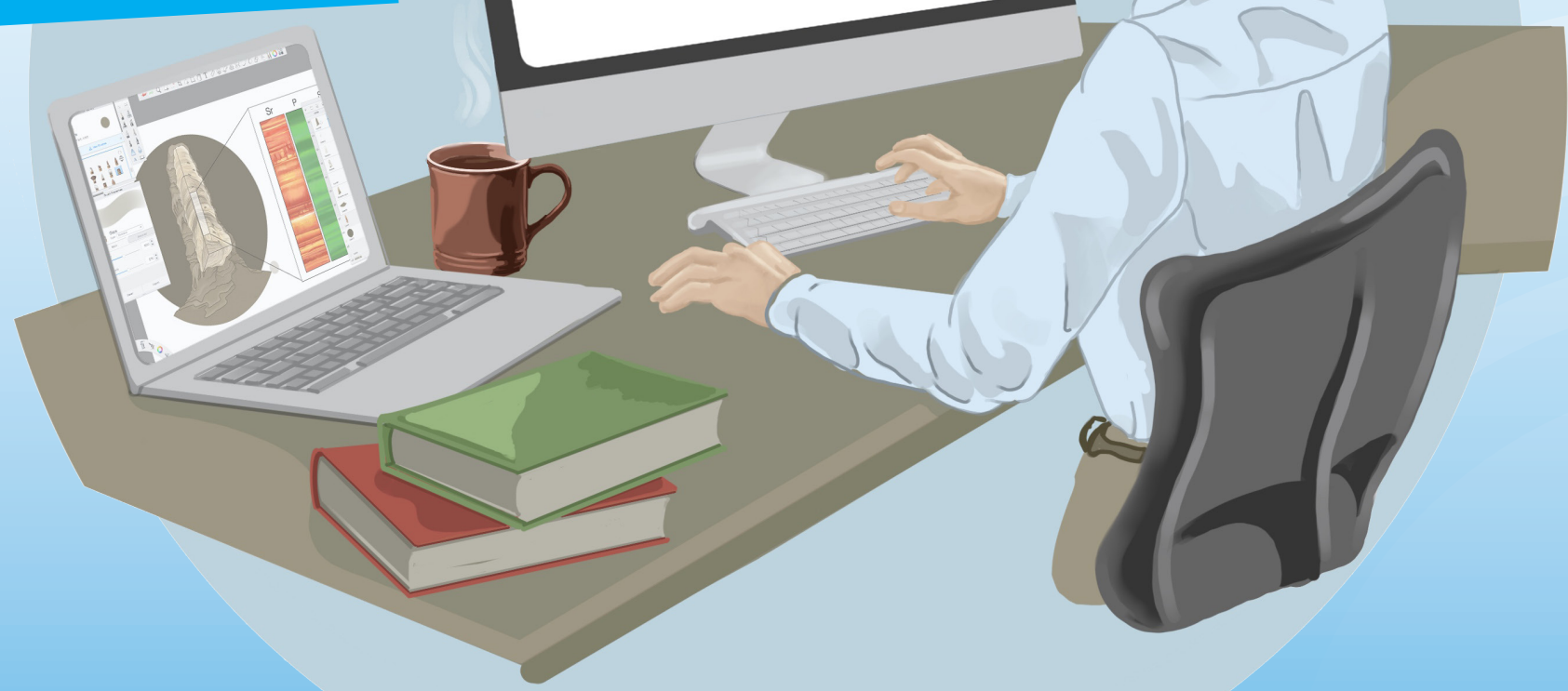




\section{Linking lead pollution in ice cores to ancient history}

\section{Nathan Chellman and Joe McConnell}

\section{Human impacts on Earth}

Both modern and ancient human societies have left a significant imprint on the environment over the past few thousand years. From the ancient Romans, who constructed buildings 2000 years ago that still stand today such as the Colosseum and Pantheon, to the present day where cities, roads, and towns are spread out all over the globe, we have had an undeniable impact on our planet. But did you know that humans have had such a far-reaching impact on the environment that scientists can track the progress of human society - starting from ancient civilizations such as the Romans through the Middle Ages and to the present day - by measuring pollution in snow and ice from places as far away as Greenland?

Lead - a toxic heavy metal harmful to human health - is one of the pollutants emitted by human activities. Until 50 years ago, when the harmful effects of lead were recognized and emissions were significantly lowered by government regulations, the amount of lead pollution was closely related to the economic and industrial development of societies. As civilizations mined and extracted more metals or burned fossil fuels, lead emissions increased. When there were wars or pandemics that caused industrial activity to stall, however, lead emissions decreased dramatically. By measuring the amount of lead frozen in Greenland ice cores, scientists can create year-by-year records of lead pollution to learn about the industrial progress of societies in Europe and North America. In this article, we will explore how lead pollution has changed during the past 2000 years, and what can we learn from lead measured in remote ice cores from Greenland.
Figure 1: This map shows how far away Greenland (blue) in sources in North America and from main lead en ice cores used in this Europe. The black crosses indicate the ice compire was a major lead project. Did you know that Keep reading to find out why.

\section{Evidence in the ice}

The chemicals, such as lead, that are found in the ice in Greenland, Antarctica, and high-mountain glaciers provide information about Earth's climate and atmosphere, allowing scientists to understand how the environment has changed over thousands of years. Human industrial activities - such as coal burning in factories or powerplants, gasoline burning from cars, or mining to make metals - emit pollutants into the atmosphere. Lead is one of these pollutants, and it can be emitted as particles that are 100 times smaller than the diameter of a human hair - so small that they can stay in the air for weeks and travel great distances through the atmosphere. Each year, winds carry these lead particles, emitted by factories, mines, or car exhausts, thousands of kilometers across Europe and North America to Greenland where they eventually fall onto the ice sheet and are buried by a layer of snow (Fig. 1).

As layers of snow continue to fall year after year, the snow from the previous years is buried and eventually transformed into ice, locking the tiny lead particles within the ice sheet and preserving a record of pollution that can extend thousands of years into the past. To get ice samples that are thousands of years old, scientists use a special ice-core drill to bore through the ice, meter by meter, and extract ice samples captured inside the drill (Fig. 2). An ice core is comprised of hundreds or thousands of individual samples of ice that represent a vertical profile through the glacier when they are stacked on top of each other. Because glacial ice is so clean - meaning naturally there are very low concentrations of chemicals in the ice - ice cores have been particularly useful for scientists to study pollution since even very small amounts of certain chemicals can be detected in ice.
Figure 2: Cutting end of the ice-core drill. The three blades core, which you can see just inside the hollow section of the drill. 


\section{How is lead measured?}

Measuring lead in an ice core requires specialized techniques as well as sensitive scientific analysis equipment and machines, which scientists call "instruments". Since there are small amounts of lead almost everywhere in the environment, the ice cores must be decontaminated by removing the outer layers that have been exposed to the air (Fig. 3). Then, the ice is melted and this water is sent to instruments that can make measurements of lead concentrations as low as 70 parts per quadrillion! One part per quadrillion is so small it is hard to visualize. You can try thinking of one part per billion first - this is like looking for one milliliter of water in an entire swimming pool, and one part per quadrillion is a million times smaller than that! The instruments that scientists use to detect lead are measuring tiny amounts of pollution in the ice.

\section{Lead pollution from the Romans to present day}

Figure 4 shows lead data compiled from 12 different ice cores from Greenland. The records go back to 800 years Before the Common Era (BCE), or about 2800 years before present day. The data show that between 2800 years ago and 1970 (just 50 years ago as we write this), lead pollution increased by over 300 -fold! Even as far back as 2000 years ago during the ancient Roman Empire, we are able to detect lead pollution in the Greenland ice cores. What could have caused lead pollution so long ago? In order to make coins, the Romans melted lead/silver ores from mines to extract silver. As they heated up the ore to extract the silver, lead escaped as a waste product and entered the atmosphere to be eventually transported to Greenland. This process of heating up ores to extract metals is called smelting, and is also what caused lead pollution to increase during the Middle Ages.

Starting around 200 years ago at the start of the Industrial Revolution, humans discovered that they could burn fossil fuels - coal and oil - to generate enormous amounts of energy. Similar to smelting, when coal is burned without any technology to control emissions, lead is emitted as a waste product since fossil fuels naturally contain lead. In addition, lead previously was added to gasoline to help car engines run better. The combination of coal, oil, and gasoline burning over the past 200 years led to massive increases in lead pollution measured in Greenland that peaked in about 1970. Once people realized that lead was a toxic metal that could harm humans and that lead pollution was a serious problem, governments enacted legislation to clean up the environment by reducing lead emissions. As a result of such laws, between 1970 and today lead pollution has decreased 80\% a major improvement. However, there is still room to improve because lead concentrations in the Arctic today are still at least 60 times higher than they were before humans began to affect the environment.

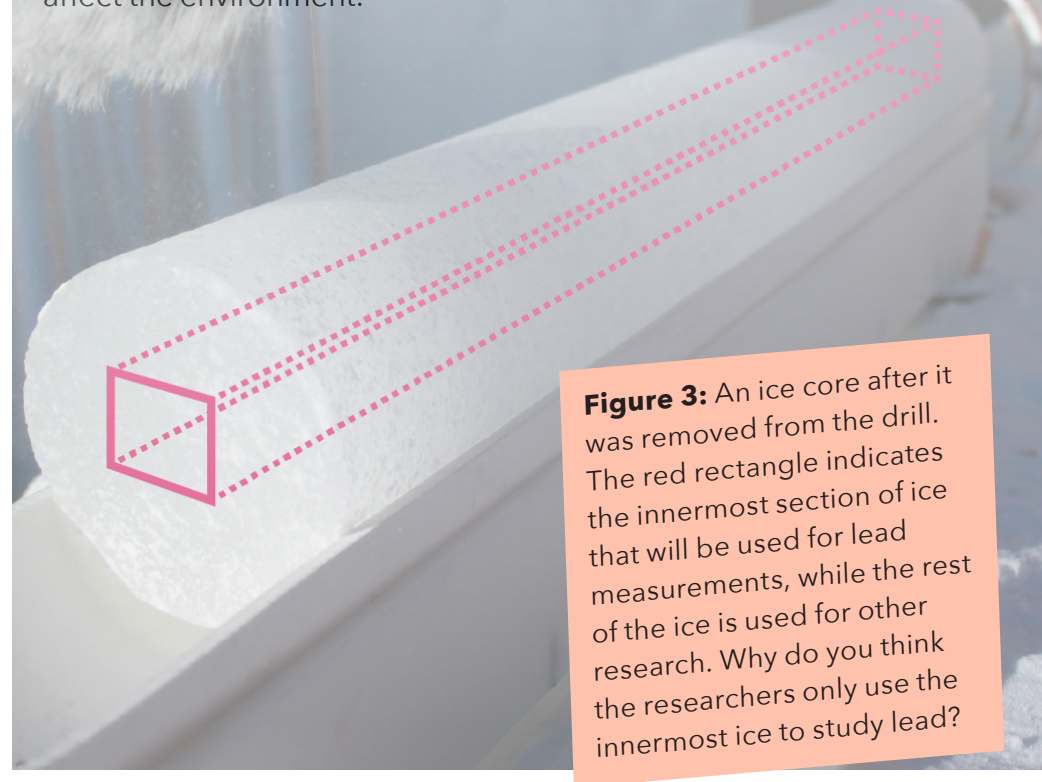

\section{The Anthropocene?}

Scientists use what is called the "geologic time scale" to refer to different periods in Earth's history. For example, dinosaurs roamed the earth millions of years ago during the Triassic, Jurassic, and Cretaceous periods. The most recent ice age that ended about 12,000 years ago - when much of North America and Europe were covered in thick ice sheets - was called the Pleistocene. Some researchers have argued that humans have modified Earth in such a profound way that we now live in a new geologic era: the Anthropocene. Based on this study and what you see around you, do you think that humans have altered the planet significantly enough to justify naming a new geologic time period? (3)

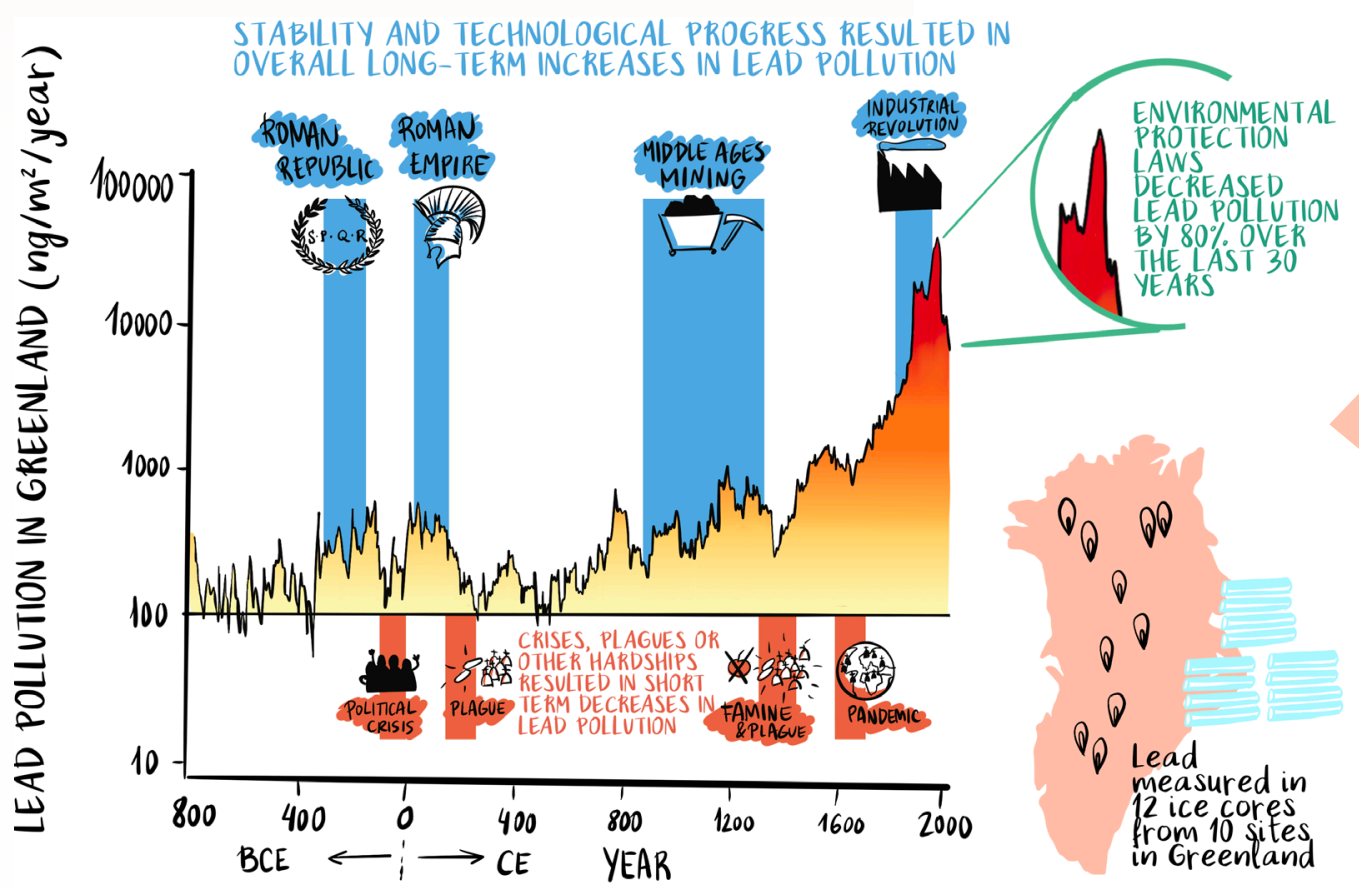

Figure 4: Average lead pollution measured in 12 Greenland ice cores. Note that the vertical axis is a that the vertic (not linear!) scale. Why do you think the researchers used many ice researchers us just one for cores inste Why do you think lead pollution decreased during plagues or famines but increased when there was political stability, more mining, or technological improvements? 


\section{Laura Hunt, Angela Nankabirwa and Tessa Driessen}

\section{Lake Nyungu in Uganda provides important water resources to local communities, but faces increasing pressure from human activities. To learn more about how to take care of Lake Nyungu and how to best help the communities living nearby, we asked ourselves a couple of questions: how has the lake and the surrounding environment changed in the past due to human activities? Can we predict how the lake will respond to current pressures?}

\section{HUIMAN IMPACTS ON LAKE NYUNGU}

Unfortunately, Lake Nyungu is under increasing pressure from human activities, such as the clearance of natural vegetation near the lake to create space for growing crops. These crops are essential for feeding local communities. This has led to the land surrounding the lake becoming more easily eroded, so during periods of heavy rainfall large amounts of soil are washed into the lake. This threatens the ability of the lake to provide drinking water and support fishing, which is an important protein source for nearby communities.

By understanding how Lake Nyungu responded to human activities in the past, we can predict how the lake will react to current and future pressures. This will help local communities to manage the lake and surrounding area in such a way that will continue to protect the lake and the resources it provides in the future.

Monitoring of the crater lakes (water $\mathrm{pH}$, salinity, and oxygen content) and the climate they experience (temperature and rainfall) began 30 years ago. To find

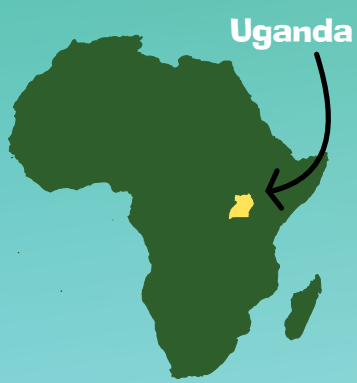

out about how the lakes have responded to environmental change even further into the past, we have to use a natural record of the lake and its surrounding environment.

\section{TROPICAL LAKES}

Forty percent of the world's lakes are located within tropical latitudes (between $23.5^{\circ}$ north and south of the Equator). However, tropi-

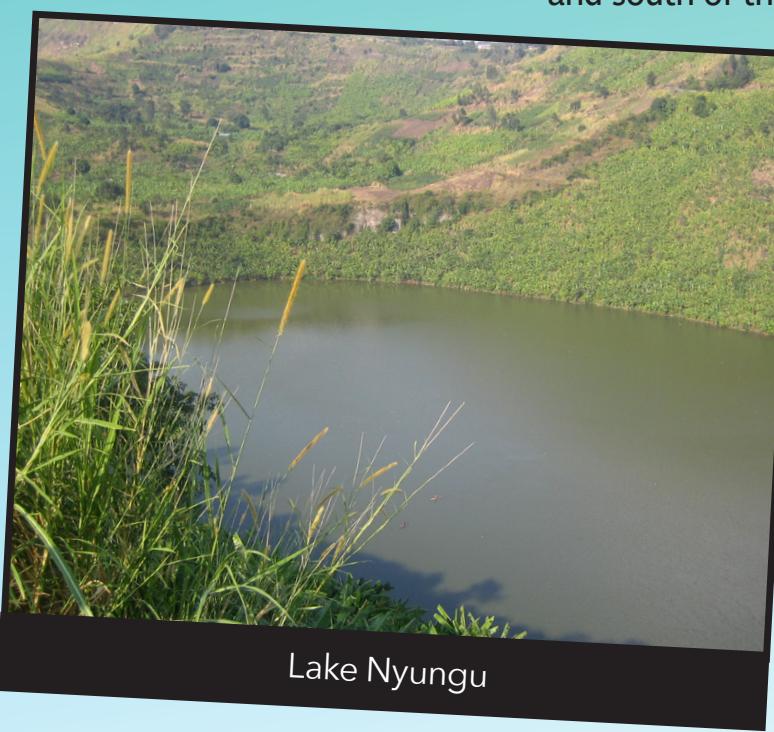
cal lakes have not been studied as much as lakes in other parts of the world. Seasons, which affect the mixing patterns of lakes, are less pronounced in the tropics compared to temperate regions. This means that tropical lakes function differently to lakes in higher latitudes, so may respond differently to environmental change. We hope our research will help improve our understanding of how other tropical lakes in Africa are impacted by humans.

\section{Traveling back in time}

Sediment (mud) cores are our natural record of the lake's past conditions and the surrounding environment. They can date back hundreds or even thousands of years!

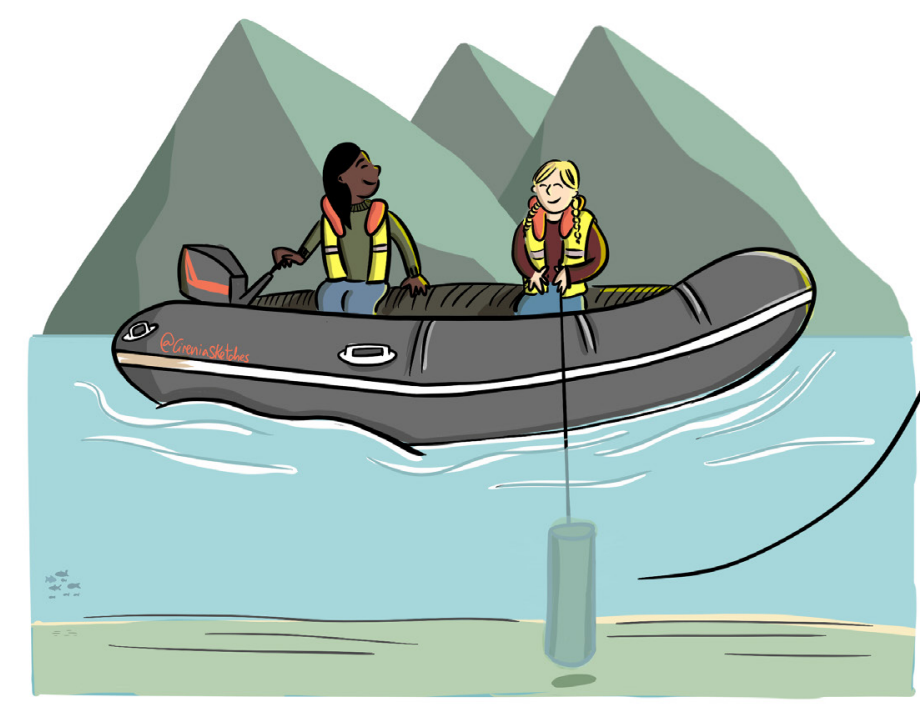

Layers of sediment build up on the bottom of the lake over time, recording what the environment was like when they formed.

SEDIMENT CORE

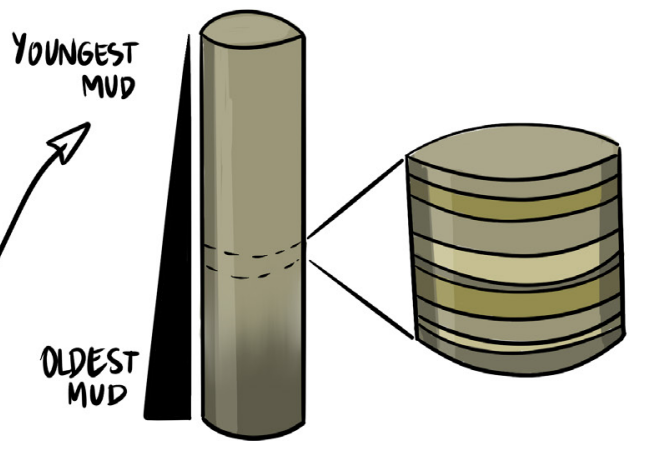

We work out how old the sediments are by measuring how radioactive the mud is at several depths down the core. 


\section{RECONSTRUCTING THE PAST}

Clues about the lake's past are preserved in the lake sediment (mud). These clues are called environmental proxies. By analyzing these clues in the lab, we can build up a picture of the lake's environment hundreds and even thousands of years ago, like detectives at a crime scene working out what happened from a few clues left behind.

Diatoms, tiny single-celled algae, are one kind of environmental proxy. They are about a hundredth of a millimeter (about 0.0004 inches) in diameter - this is approximately the width of a human hair! They photosynthesize and live in all water bodies on Earth. Their cell walls are made from silica (glass), a structure that can be preserved for millions of years. The types of species found in the sediment can give us clues about the lake and wider environment when the diatoms were alive; for example, some diatom species thrive in cold water, whereas other diatom species prefer warmer conditions.
This is a diatom species called Rhopalodia gibba. It lives in lakes and other water bodies that are alkaline (where the lake water $\mathrm{pH}$ is greater than 7). When this species is found in high abundances, we can tell that the environment has been disturbed by humans. This is because farming can cause more nutrients to be washed into the lake, which causes more algae to grow than usual, and changes the chemical composition of the lake (such as pH, salinity, and oxygen content).

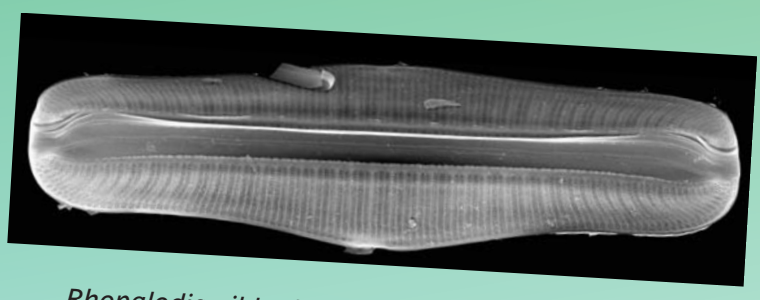

Rhopalodia gibba (photo from Wang et al. 2010)

\section{Irake Nyungu diatom record}

We took a sediment core from Lake Nyungu and looked at how the species of diatoms present in the core have changed over the last 150 years.

The diatom species $N$. lancettula loves clean, fresh lakes, whereas G. pumilum and N. palea thrive in dirty lake water that contains a lot of organic matter and sediment. The major shift in diatoms species in the sediment core from $N$. lancettula at the bottom of the core to a combination of $G$. pumilum and N. palea at the top of the core suggests that the water quality of Lake Nyungu has declined over the past 150 years.

The diatom record, combined with a number of other environmental proxies from the sediment core, suggests that the change in water quality is because more sediment is being washed into the lake from the surrounding area. This is a result of vegetation being cleared from the area around the lake to make room for growing crops. The removal of vegetation means the surrounding area is less stable, so soil is more easily washed into the lake.

\section{LOOKING AFTER LAKE NYUNGU FOR THE FUTURE}

Our results show that removal of vegetation in the catchment has led to a decline in water quality at Lake Nyungu over the last 150 years. By restoring the catchment to what it was like before humans had a significant impact, water quality at Lake Nyungu will improve.

Helping local communities implement sustainable land management practices and replanting natural vegetation on the land surrounding the lake will improve the water quality and make sure that the local communities have access to clean water and fish from Lake Nyungu. This helps to achieve the United Nations' Sustainable Development Goals 2 (zero hunger) and 6 (clean water and sanitation) in the area.

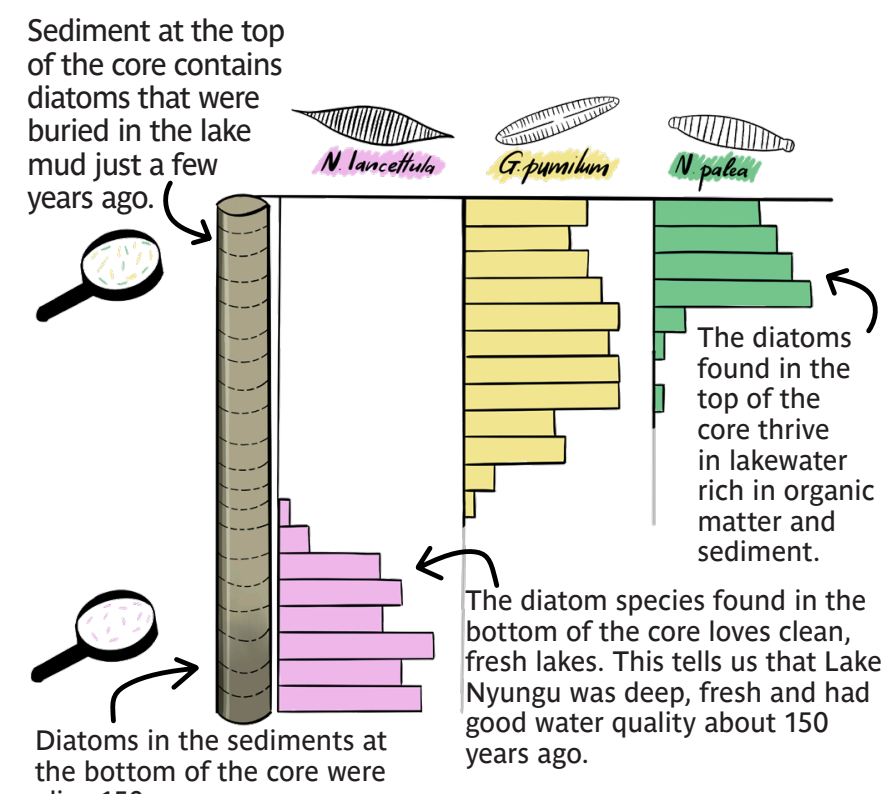

the bottom of the core were alive 150 years ago. 


\section{Pollen reveals the plant world of the past}

\section{Andrea Miebach}

Achoo! Everyone knows it: it's getting warm outside, plants are flowering, and allergy sufferers are having a hard time. Pollen! It's annoying, but studying pollen grains unveils their beauty and utility. By having a look through the microscope, we can discover how diverse and pretty they are. Most importantly, pollen helps us understand past vegetation and the factors that control it, like climate change. How? Let's explore where we find pollen, what pollen grains look like, and what we can learn from them. There is so much to discover about these microscopic structures...

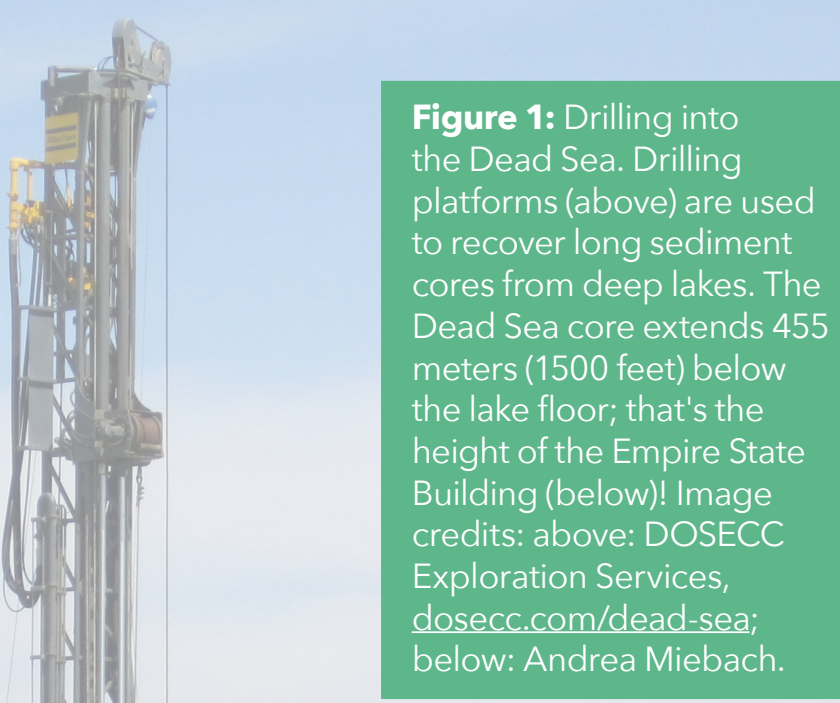

\section{Drilling into the history}

A team of researchers and technicians is working on a platform that is floating on the Dead Sea. Below them are 300 meters (1000 feet) of salty water and tons of sediment (Fig. 1). The sediment is the mud at the bottom of the lake. Lake? Yes, the Dead Sea is actually not a sea but a deep and very salty lake in the Middle East. The international team is drilling into the lake floor to recover a sediment core. The deeper they drill, the older the sediment is. This is a tough task because the sediment is not only made of soft clay and organic material but also of salt that's hard as rock (Fig. 4). In addition, the sediment covers particles that are hardly detectable with the naked eye: pollen. That's one reason that they drill into the lake floor: they want to find pollen that was continuously trapped and preserved in the lake because it tells what the surrounding landscape looked like thousands of years ago.

How does pollen reach the lake? Pollen is almost everywhere. Plants produce millions of pollen grains in order to reproduce. Since plants can't move, they have found ways for pollen to be transported from one flower to another. Wind is a powerful assistant, as it can blow the small grains into the air. However, only a few pollen grains find the appropriate plant for reproduction - most pollen grains are scattered across the landscape. The majority of these grains eventually get destroyed. However, luckily for us, some grains are trapped in a suitable setting, such as the bottom of a lake, where they are preserved for hundreds, thousands, or even millions of years.
The Dead Sea drilling team is successful and recovers a 455 meter-long (1500 feet) sediment core - one of the longest lake cores in the world. Now the analyses can begin.

\section{Let's take a look through the microscope}

Their mission is clear: the researchers want to find pollen grains in the Dead Sea sediments. However, if you were to look at the mud cores - even through a

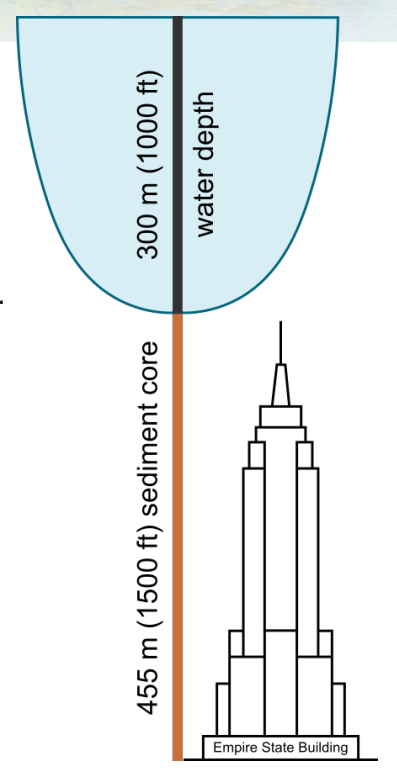
microscope - you would hardly see any pollen. First, you would have to get rid of the remaining sediment, which is done with the help of chemicals and very fine sieves. The final pollen samples would comprise hundreds of pollen grains and only a few other sediment components. Pollen grains have a robust wall that protects them from the chemical treatment and allows them to survive for millions of years. The grains differ in size, shape, and surface structure (Fig. 2). Furthermore, the grains from different pollen types have characteristic pores and furrows. This is where the pollen tube grows out of the grain, allowing the plant to reproduce. Most importantly, these features are specific for certain plants, which allows us to identify the parent plant that produced the pollen. 
Figure 2: This is a small selection of pollen types with their parent plants representing the main kinds of vegetation of the Dead Sea area. See how small (scale = only one-tenth of the width of a human hair), diverse, and beautiful the world of pollen is? Fun fact: these pollen grains from the Dead Sea are 77,000 years old but look just like modern ones. Image credit: Andrea Miebach.

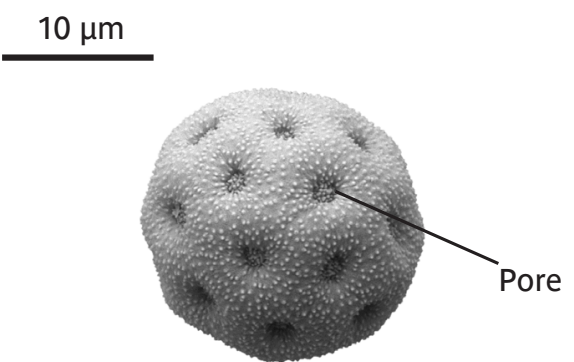

Amaranth family a typical desert plant family

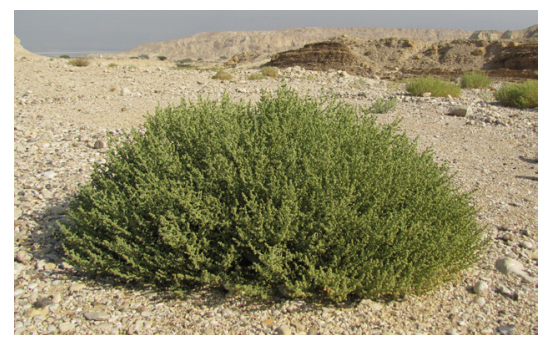

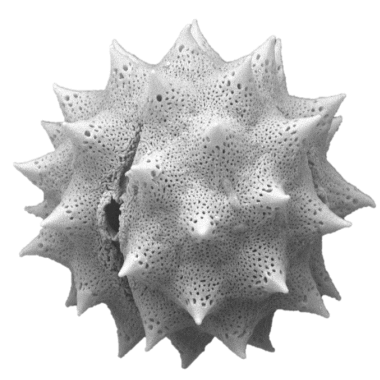

Composite a typical steppe herb

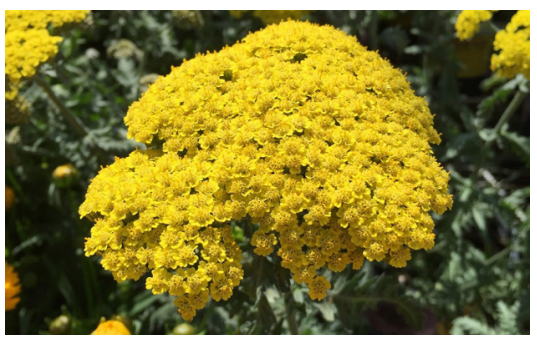

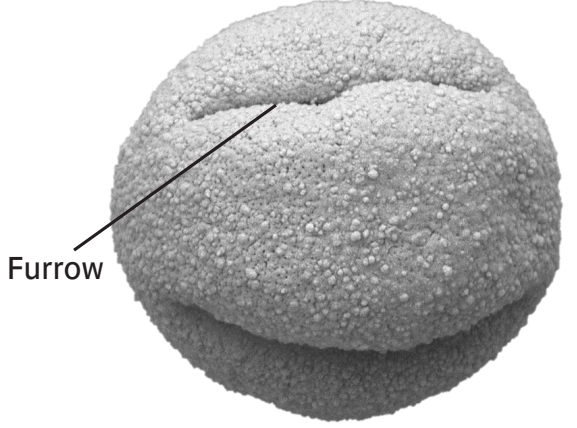

Oak a typical forest tree

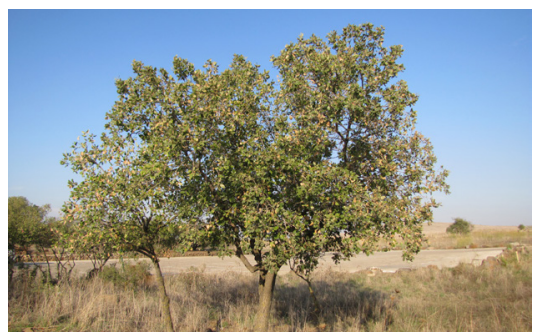

Figure 3: With the help of pollen, we can infer the ancient vegetation surrounding the Dead Sea (top). Moreover, we can reconstruct climate, for instance annual rainfall (bottom). The stronger the blue color, the more likely it is that the amount of rain was somewhere in this range. Figure adapted from Litt et al. ${ }^{1}$
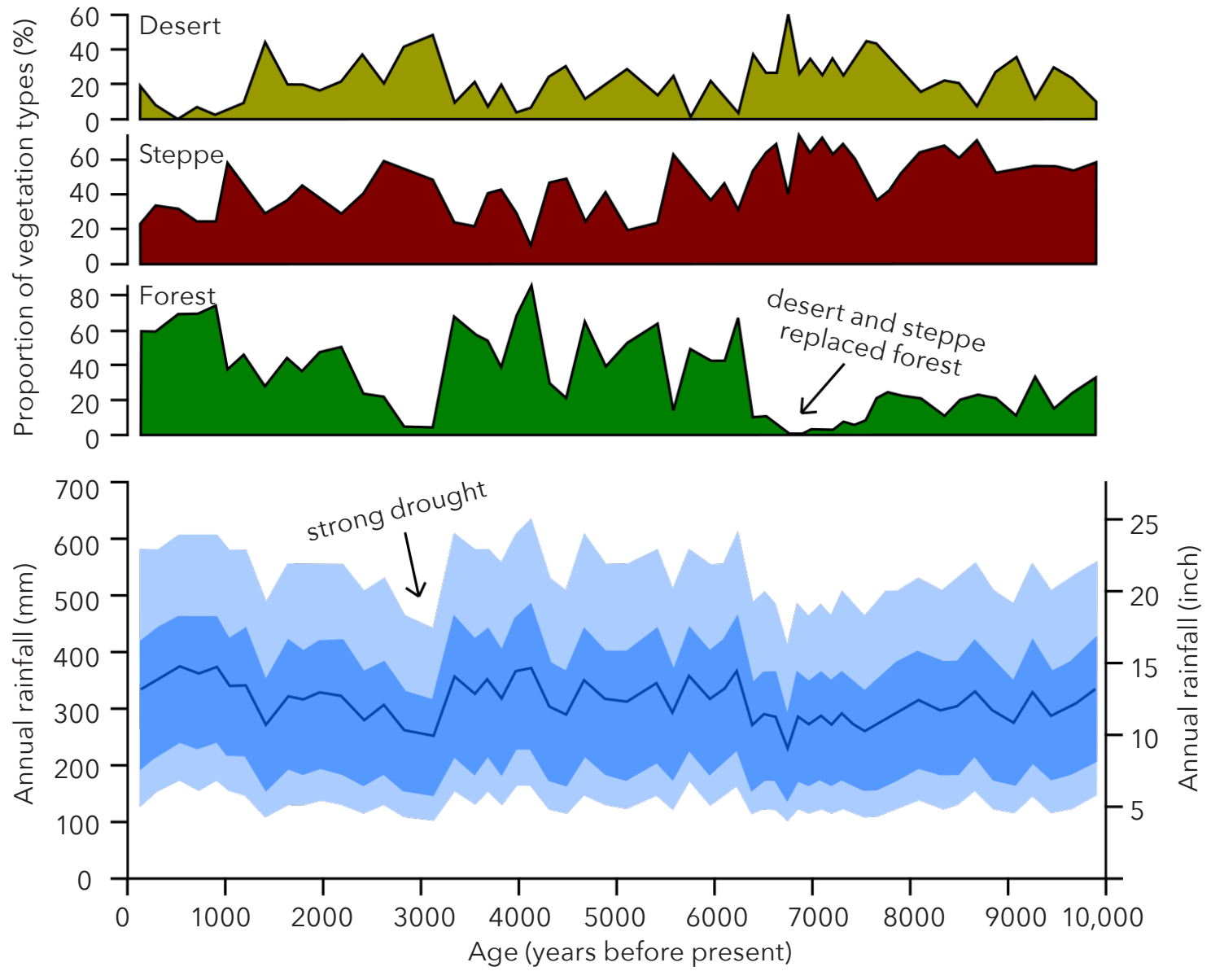
Learning from the past to better understand current climate change

The team of scientists is excited. After spending weeks in the lab and countless hours at the microscope, they have finished the pollen identification and counting. Now it's time to reconstruct the vegetation and the climate of the past. But how? The principle is easy: the analyzed pollen grains were produced by plants surrounding the lake; thus, they allow us to figure out what kind of vegetation was formerly found in this region. Since every plant is adapted to a certain climate, the ancient climate can be reconstructed as well.

Let's have a look at the Dead Sea. Today, the lake is surrounded by forested mountains, and the tree pollen is blown into the lake. However, there were also times in history when almost no tree pollen reached the Dead Sea. Desert and steppe were widespread during these phases, replacing the forest (Fig. 3 top). Think of a landscape with little vegetation, comprised of shrubs, herbs, and grasses. These periods must have been drier than today because grasses and herbs need less water than trees to survive. Even past rainfall can be calculated if complex statistics are used (Fig. 3 bottom). Analyzing the entire sediment sequence, the scientists can infer the vegetation and climate history of the region and relate this to human history. For example, the strong drought about 3000 years ago that is indicated in the Dead Sea record in Figure 3 most likely played an important role in the end of Bronze Age civilizations of Middle Eastern societies.

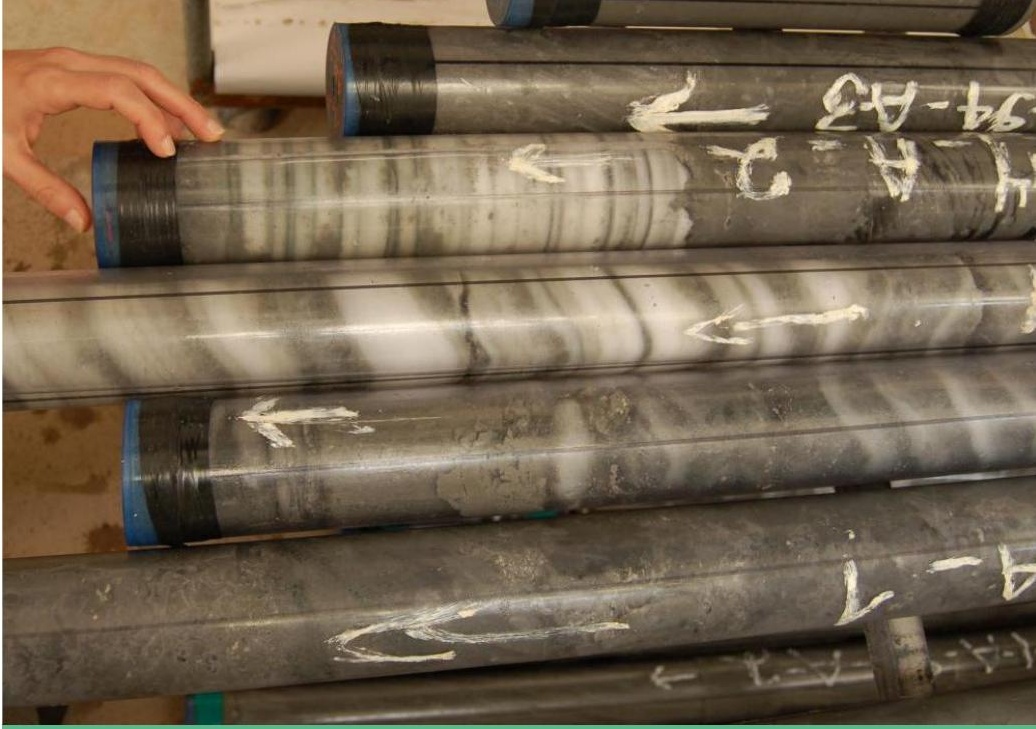

Figure 4: The variety of sediments reflect the varied environments of the past. Sediments are comprised of different components including pollen grains. Image credit: ICDP Office 2020, GFZ German Research Centre for Geosciences, icdp-online.org/projects/world/asia/dead-seaisrael/details

This knowledge helps us to evaluate recent and future changes in climate. Instrumental weather records from weather stations are limited to the last few centuries. With the help of pollen and other climate indicators of long sediment cores, we can detect climate changes over a much longer period. We can learn how fast climate was changing under natural conditions and how shifts in climate influenced ecosystems. These insights help us predict how our planet will react to the ongoing climate change.

\section{POLLEN REVEALS THE PLANT WORLD OF THE PAST}

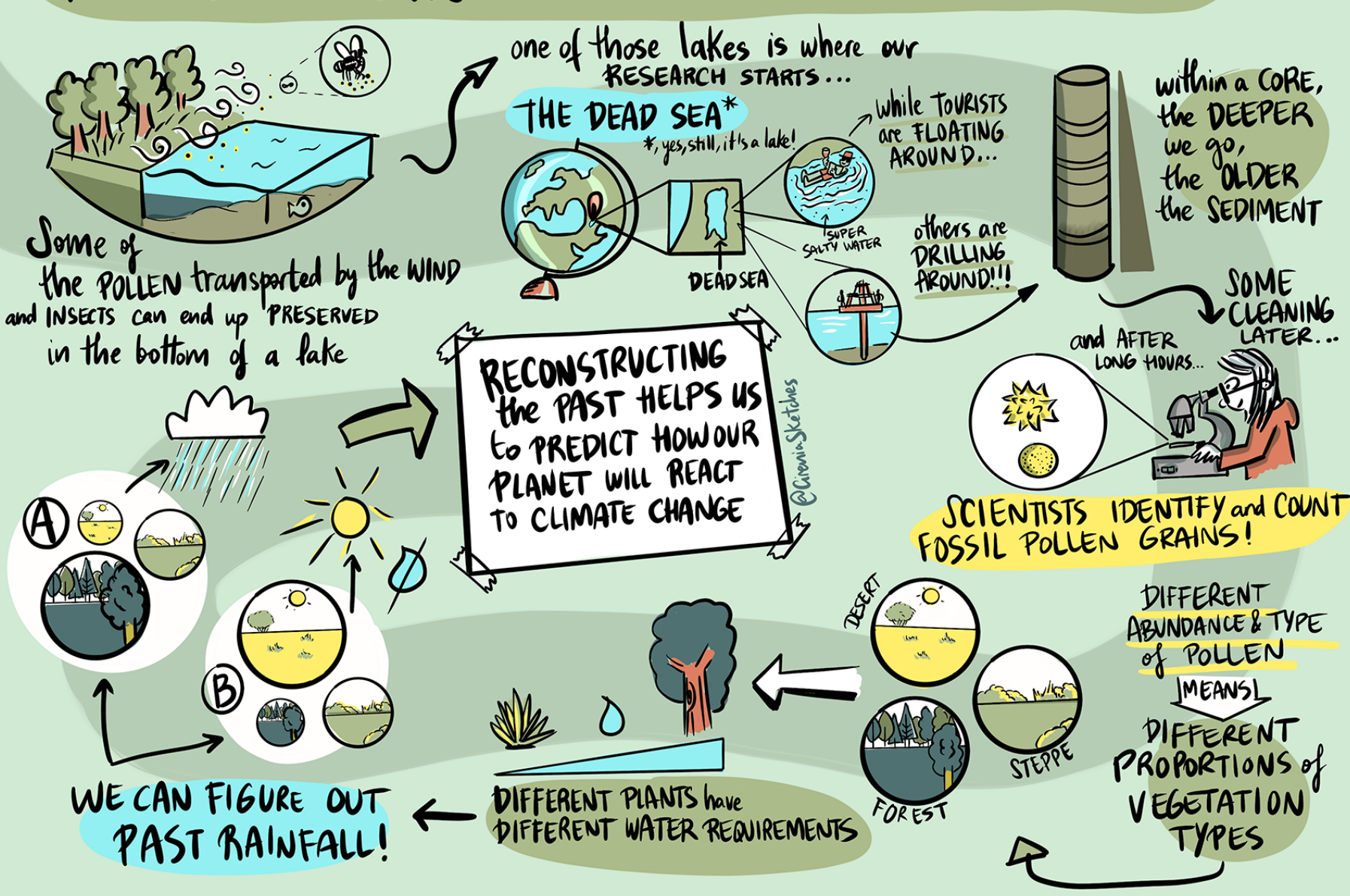




\section{HOW TO: Record fires that burned thousands of years ago}

Emma Rehn

Fire has shaped environments around the world over thousands of years, sometimes controlled by people or by changing climates - but how do we know what fires were like in the past? Scientists use a range of methods to learn more about past fires, including how often fires happened and what types of plants were burning. This graphic briefly shows how these methods have been used to look at fires in northern Australia, and why looking at thousands of years of fires can help us understand and make decisions about fires today.

\section{Fires today}

Fire plays a key role in environments around the world, but climate change is causing large, destructive fires to happen more often in many places. In southeast Australia in 2019-2020, intense bushfires destroyed more than 3000 houses and burned across an area bigger than the size of England (DPS March 2020). But written records of fires in Australia only go back around 100 years - we need to know if times of fires like this have happened before, what fires were like when things like long droughts happened in the past, and how cultural burning by people might keep fires smaller and less intense.

This is where lake mud can help. Fires burn plants into things like charcoal and ash. This charcoal can fall or be washed by rain into lakes and settle at the bottom, building up in layers of mud. Scientists can use this mud to make records of fires far into the past.

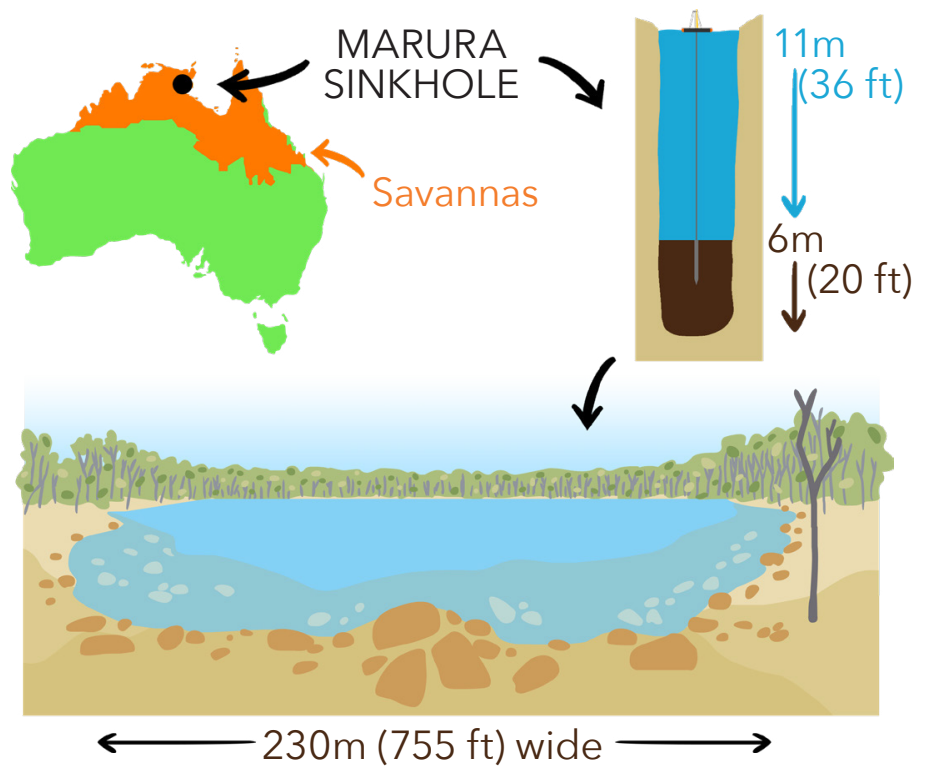

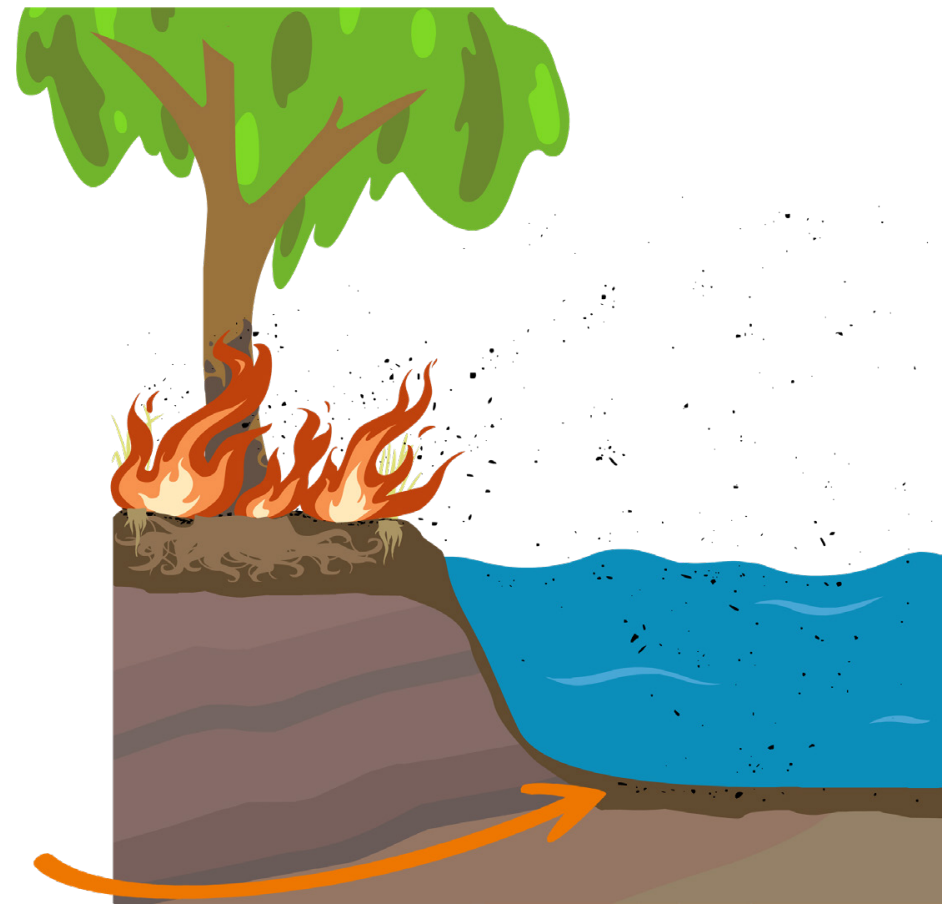

We can see how this works at Marura sinkhole in northern Australia. Marura ("Mah-ROO-rah") is 11 meters (36 ft) deep, with 6 meters ( $20 \mathrm{ft}$ ) of mud at the bottom that has built up over 10,000 years. The savanna (a mix of grasses and trees) around Marura sometimes burns every year. The Indigenous people of the land, the Yolngu, still live in the area but many were moved away or killed when Europeans colonized Australia.

Recording the history of ancient bushfires at Marura will show how cultural burning by Indigenous people affected fire, and how fires have changed recently.

We collected samples (sediment cores) from Marura and applied different methods to see what fire was like there over the last 4,600 years.

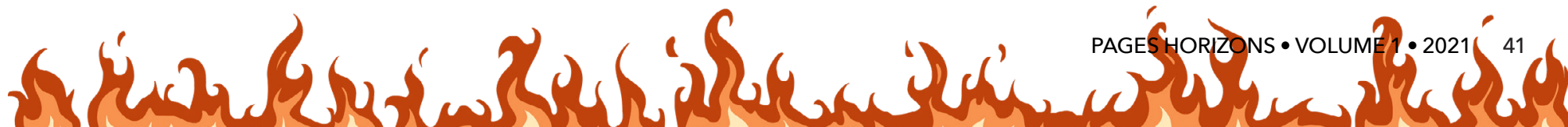




\section{How much fire was there?}

Key areas for reconstructing past fires include fire abundance (how much), fire incidence (when), and fire frequency (how often). The two broad approaches to this are OPTICAL and CHEMICAL:

\section{OPTICAL: CHARCOAL}
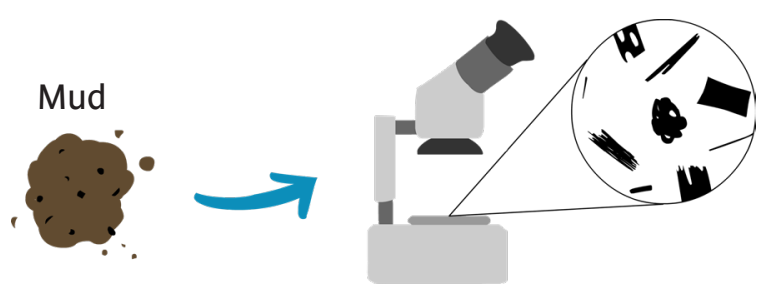

Charcoal particles on slides or in a petri dish in water can be put under a microscope for counting by an analyst. Larger charcoal often represents fires close by, while smaller particles are created in both nearby and distant fires. Samples can also be processed, using a combination of chemicals, heat, and pressure, to separate out carbon burned by fires (black carbon).

\section{CHEMICAL: BLACK CARBON}
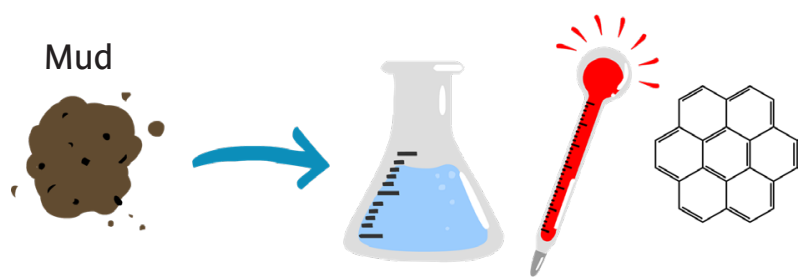

Chemical methods isolate the most resistant black carbon (made under higher fire intensities and temperatures) but optical counting includes charcoal made under all temperatures, so these techniques can be combined to look at fire intensity. This is important because cultural burning usually creates cool, low-intensity fires.

\section{What was burning?}

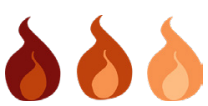

It is important to know when fires happened but also what plants were burning. Plants and fire influence each other, with some fuel types encouraging fire and some fire regimes leading to more grasses versus trees. There are optical and chemical methods to look at what was burning:

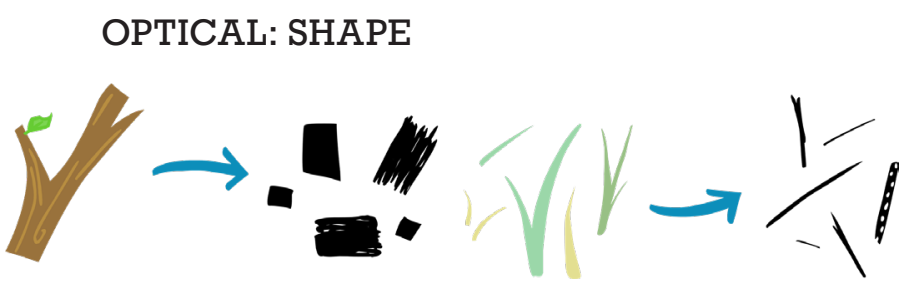

The shape of a charcoal particle can reflect what type of plants burned to create it. Grasses and sedges when burned create long, skinny charcoal particles while wood charcoal is blocky, so recording charcoal shapes shows how much grasses versus trees were burning. Some plants can also be identified chemically using isotopes of carbon (an isotope is an atom with different numbers of neutrons). In northern Australia, most trees are $C_{3}$ types with a lower $\delta^{13} \mathrm{C}$ ("delta-C-13") number and grasses are $\mathrm{C}_{4}$ types with a higher number.
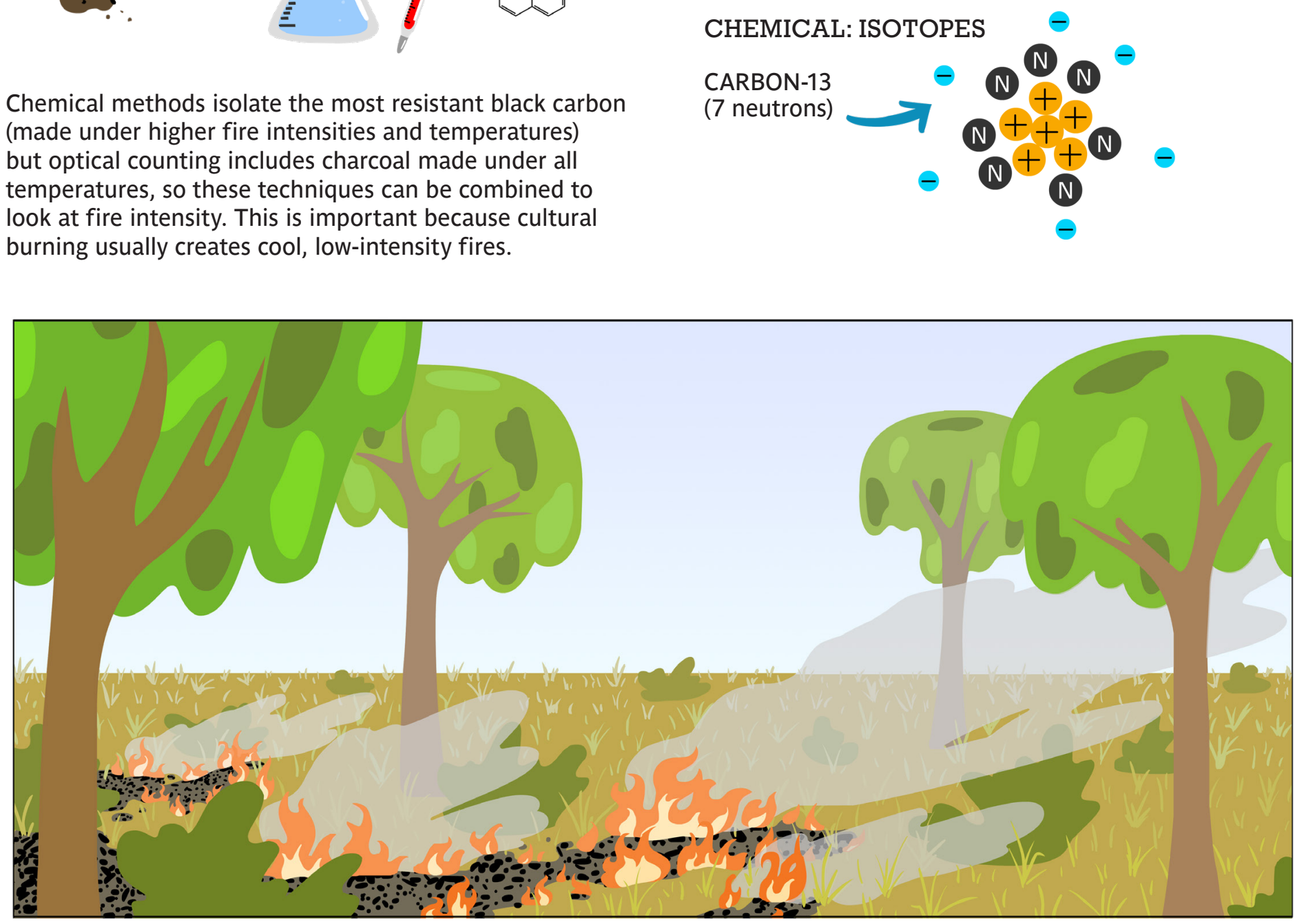


\section{Putting it together at Marura}

The Marura record shows that a lot of plant material was burning over 4000 years ago and has declined since then. Fires around Marura have been a mix of different intensities, with high-intensity fires happening regularly from about 4600-2600 years ago and less often after that, probably because of Indigenous cultural burning creating more low-intensity fires. Recent burning has been high intensity.

\section{Vegetation}

The mix of grass and trees around Marura hasn't changed too much, and only a few hot fires early in the record show any effect on plants (those fires burned mostly trees and shrubs). The record of fire at Marura shows that much more was burning 4000 years ago than today. High intensity fires happened about every 400 years until around 2600 years ago, when we know that Indigenous people were living on the nearby coast, and cultural burning kept fire intensities lower. Higher fire intensity in the recent past shows that fires may be increasing in amount and intensity in a way that hasn't happened at Marura in the last 900 years.

The Marura fire record shows how to look at bushfires thousands of years in the past, and will hopefully help land managers make decisions about fire in the future. As scientists improve these methods, create new techniques, and study more sites around the world, we get a better picture of what fire was like in the past to better plan for the future. (5)
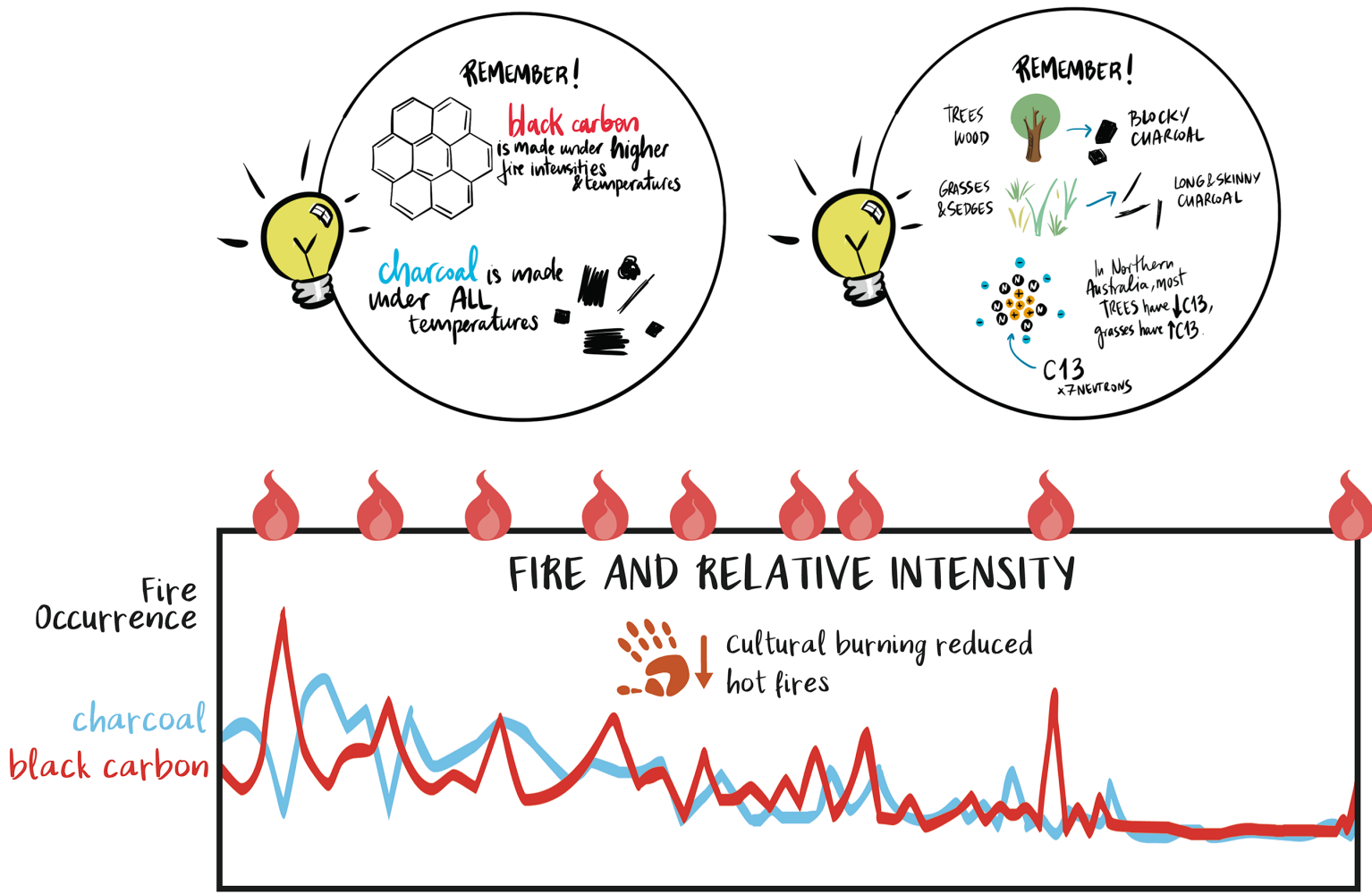

Intense

Fire Events

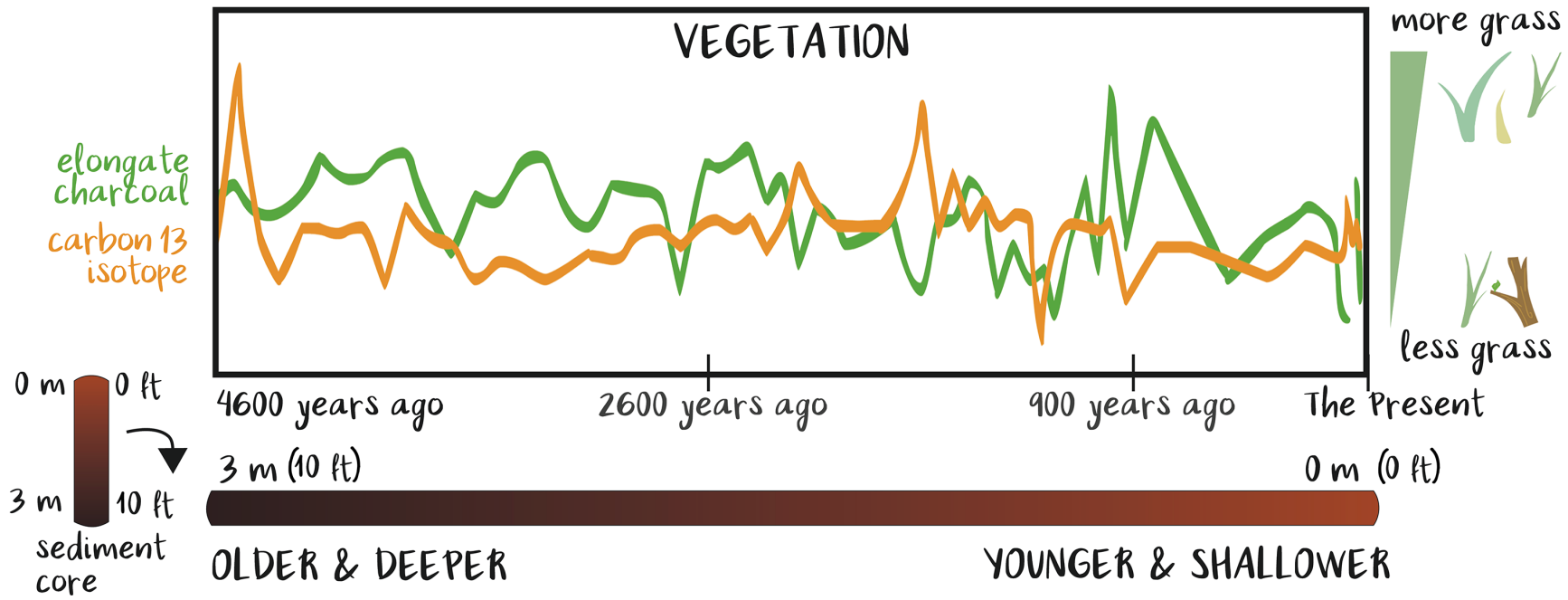




\title{
Humans and environments in the most arid place in the world: The Atacama Desert
}

\section{María Eugenia de Porras, Eugenia M. Gayó, Mauricio Uribe and Antonio Maldonado}

The Atacama Desert lies between the Pacific coast and the Andes in northern Chile. It is the largest desert in South America and the driest on Earth. Here, annual precipitation is almost zero. The little water that is available depends on the summer rainfall that falls on the Andean mountains. It reaches the desert by runoff and is found within some canyons or by the emergence of groundwater.

The presence of life in this extreme environment may seem unimaginable today; however, fossil and archaeological records reveal that plants, animals, and even humans lived in this region during various periods over the last 18,000 years.

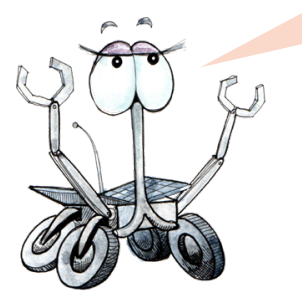

\begin{abstract}
Wow! Really? The Atacama Desert is like the surface of Mars! Now I get why I was sent here to be trained for my mission! But has the desert ever hosted life? Hmmm, I'm wondering ... has it been less dry in the past?
\end{abstract}
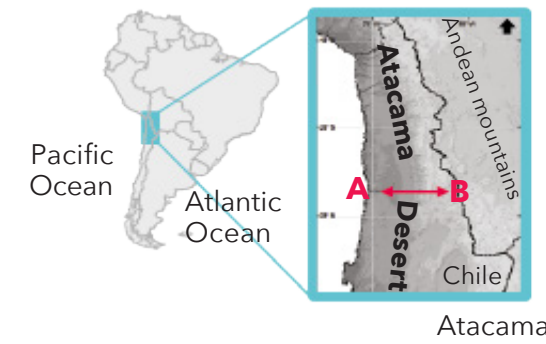

Hey Zoë! Scientists working with paleoenvironmental archives have indeed found evidence that there were wetter periods several times in the Atacama Desert over the last 18,000 years.

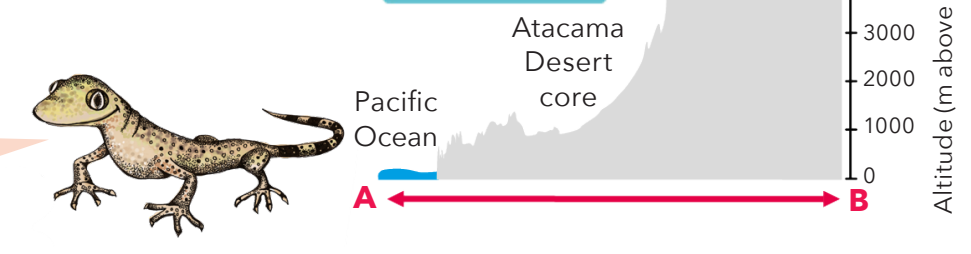

Different paleoenvironmental records indicate that extensive wetlands, springs, shallow lakes, and several perennial rivers existed between 18,000 and 14,000 years ago in the core of the Atacama Desert. These landscape transformations are explained by higher precipitation over the Andes in the past (named the Central Andean Pluvial Event 1), that watered the core of the desert. This led to a flourishing of life, including several perennial native trees (Prosopis tamarugo ${ }^{\mathrm{A}}$, Escallonia angustifolia ${ }^{\mathrm{B}}$, Schinus molle ${ }^{\mathrm{C}}$ ) growing along rivers (riparian areas) and close to wetland oases. ${ }^{1}$

Such a vegetated landscape also allowed many types of animals to live in this region, including rodents, birds, and South American camelids (guanacos ${ }^{D}$ ), as well as some larger, now extinct, South American animals (megafauna) such as small horses ${ }^{\mathrm{E}}$ and ground sloths. ${ }^{\mathrm{F}, 2}$ This wetter phase ended abruptly about 14,000 years ago,

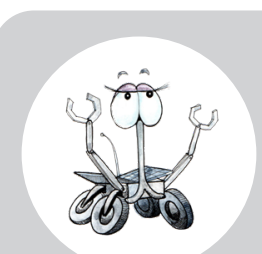

\section{Name: Zoë}

Type: Solar- powered autonomous robot

Mission: Detect microorganisms and map the distribution of life in the Atacama Desert; perform tasks that could be used in future exploration of Mars.

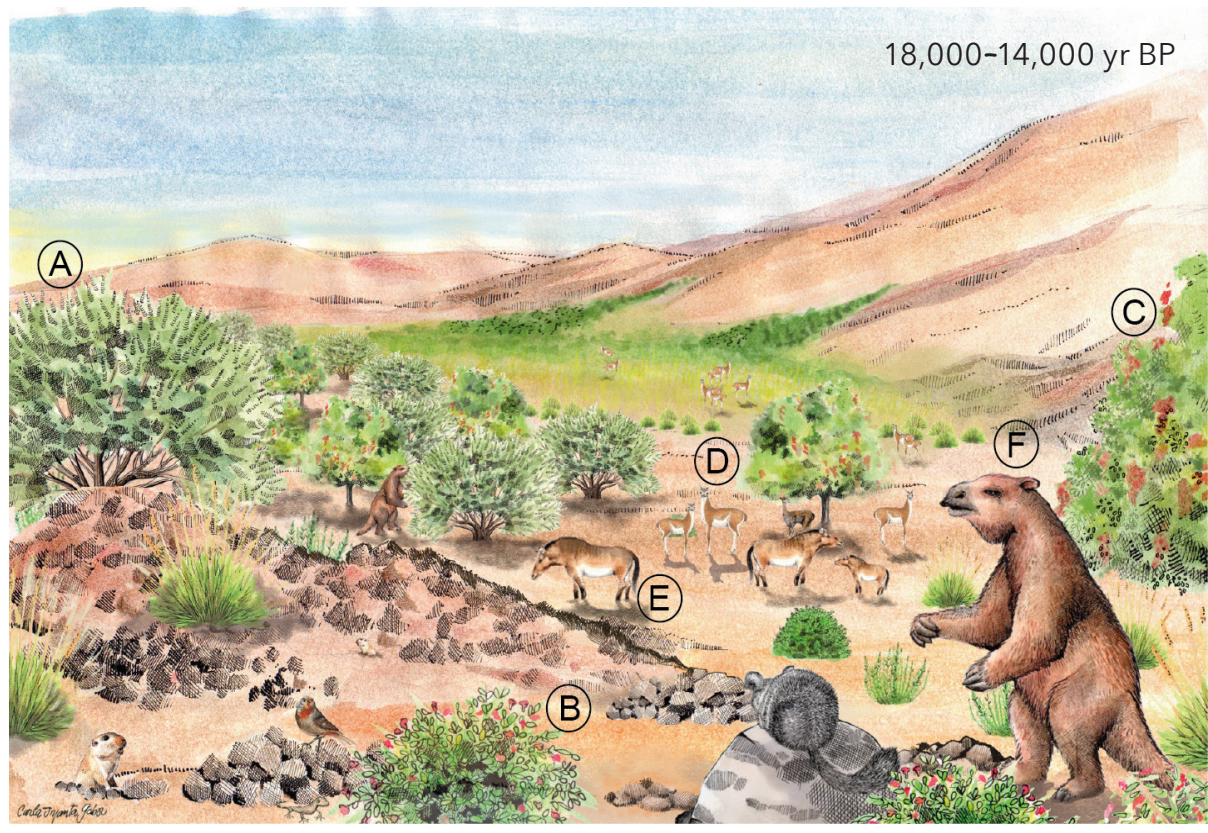

leading to climatic and ecological conditions similar to today, which persisted over the following 1000 years. ${ }^{1}$

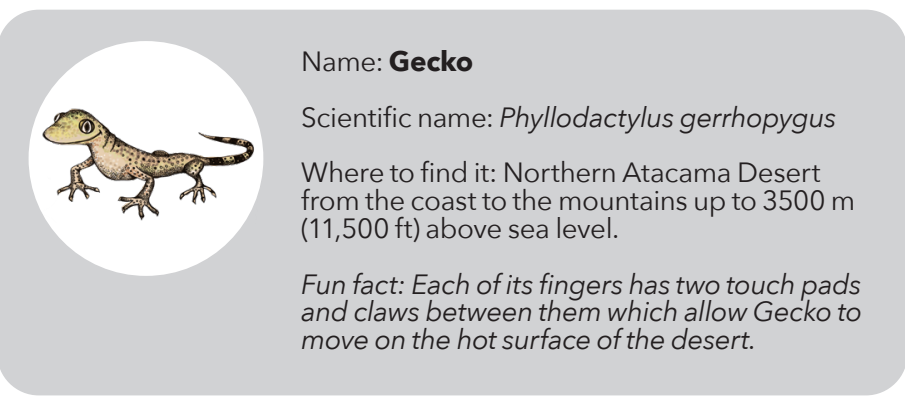




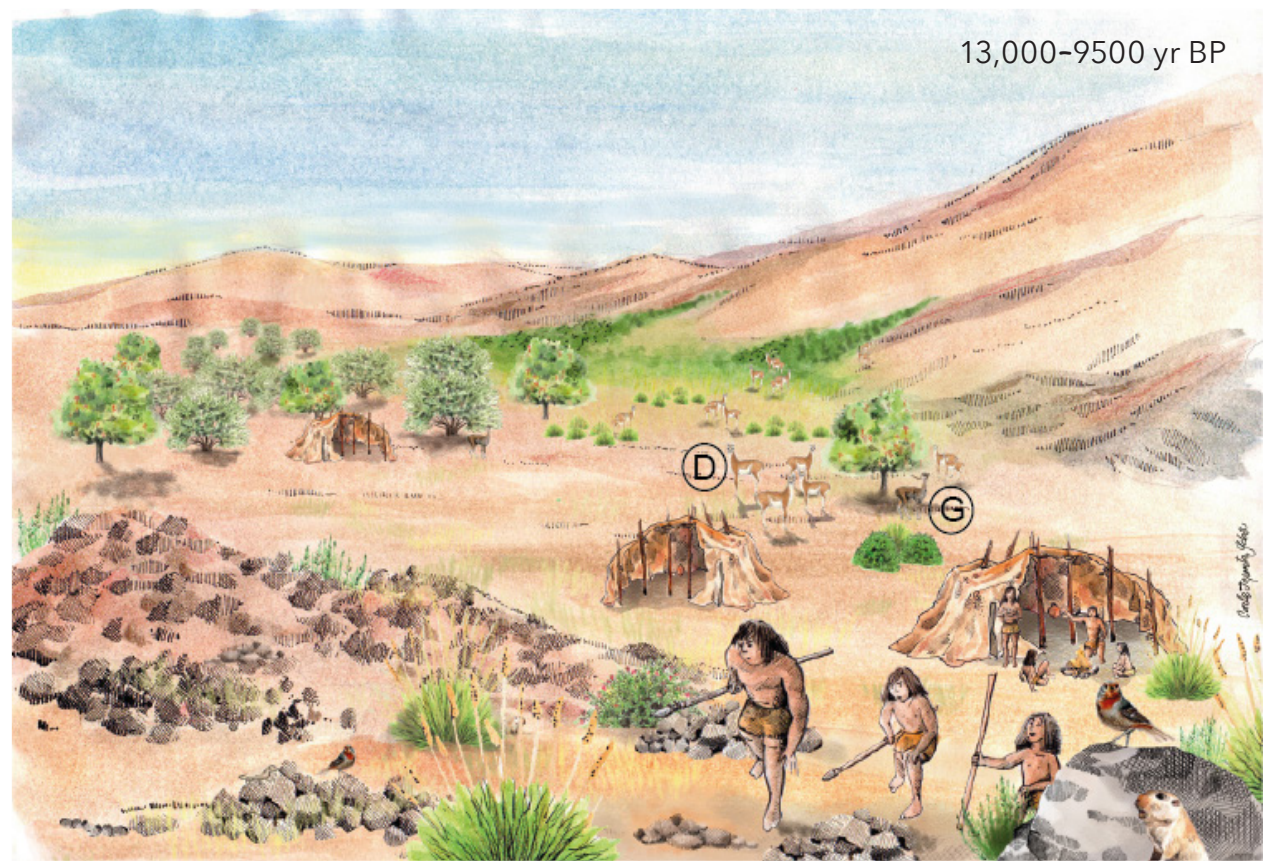

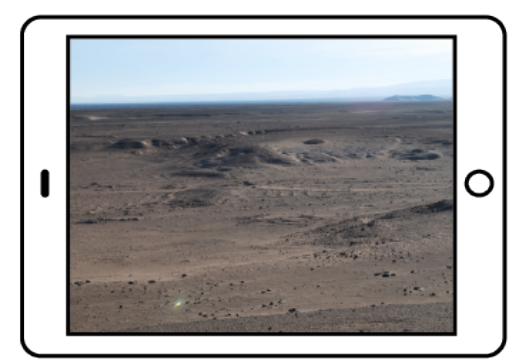

Earliest human sites at present

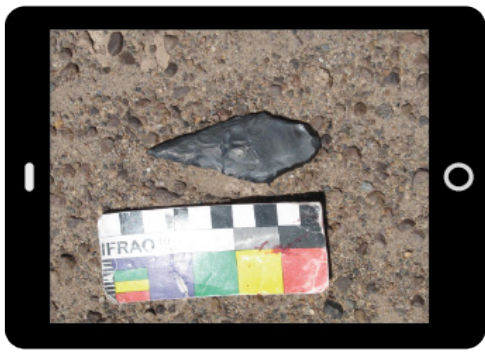

Projectile point
About 13,000 years ago, the desert once again became wet (Central Andean Pluvial Event 2), and freshwater oases with herbaceous vegetation and trees took root across the lowlands of the Atacama Desert. 1,3,4 The megafauna was no longer part of the story, but small rodents, birds, and camelids such as guanacos ${ }^{\mathrm{D}}$ and vicuñas ${ }^{G}$ became commonplace in these ecosystems. Humans also entered the scene during this period:

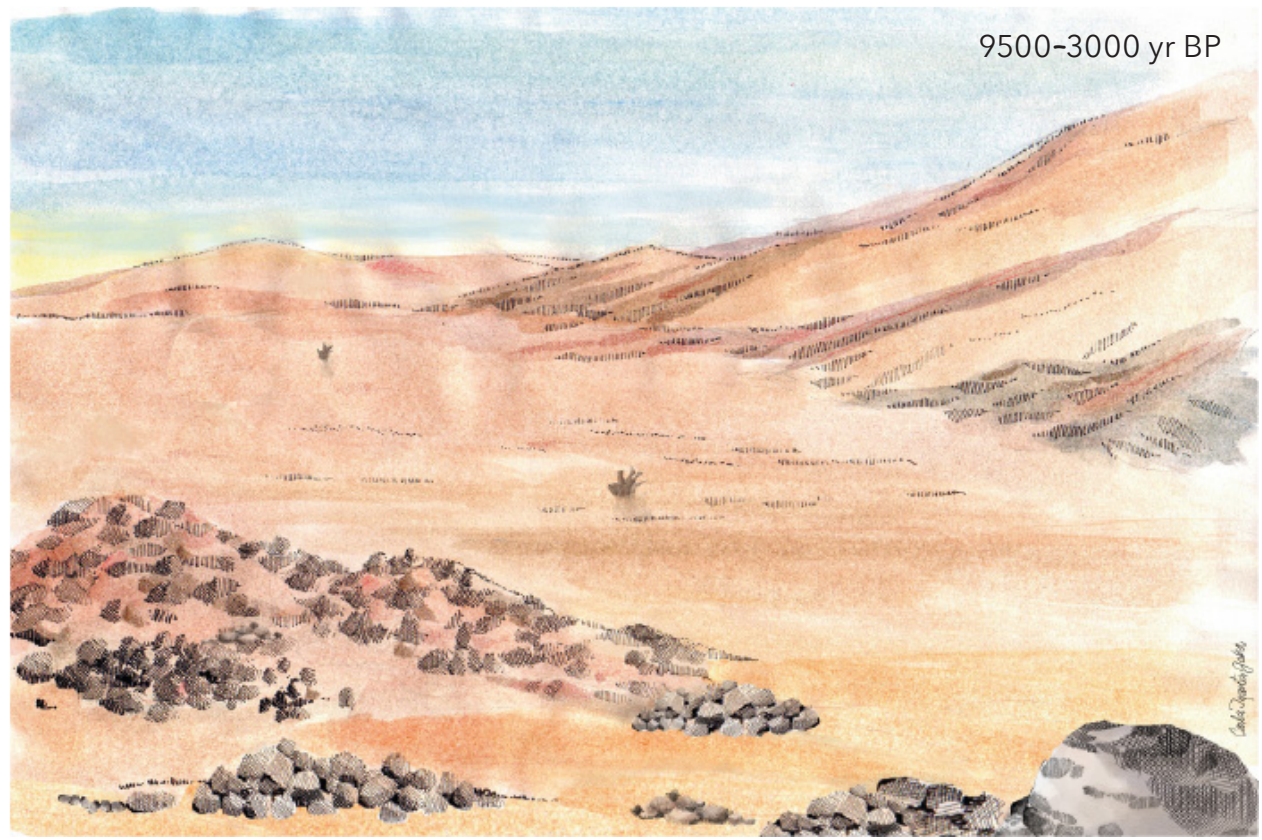

evidence indicates that the first settlers in the desert arrived about 12,800 years ago. ${ }^{3,4}$ Attracted by the availability of biotic and water resources, these huntergatherers established camps around wetlands and riparian areas. However, such residential bases were only intermittently occupied as environmental and ecological conditions varied, making a nomadic lifestyle necessary during various periods in the extreme inland Atacama. ${ }^{3,4}$

The lack of paleoenvironmental and archaeological records dating between 9500 and 3000 years ago has led paleoecologists and archaeologists to infer that a huge 6000-year drought took place in the Atacama Desert core due to a decrease in rainfall over the Andes. ${ }^{1,3,4}$ The heavy decrease in water availability was hard for hunter-gatherer groups, who disappeared from the landscape. In fact, the previous environment full of water and biotic resources vanished, leaving a harsh habitat resembling the modern desert.

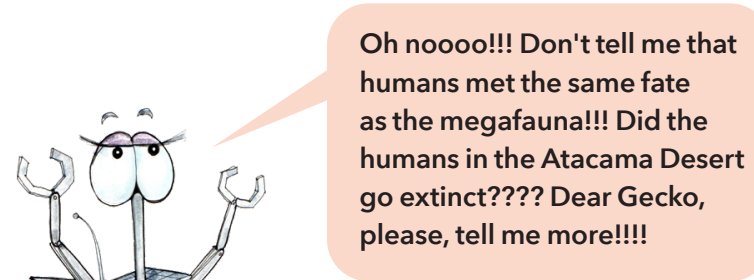

Fortunately they didn't! Archaeologists have found evidence that people moved to the few canyons within the desert that still had permanent water, or towards the Pacific coast and towards the Andean highlands. ${ }^{3,4}$

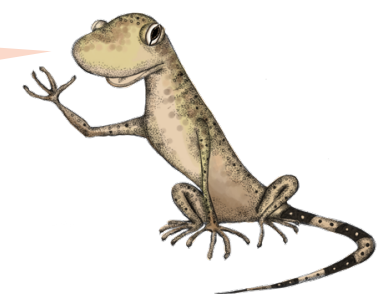


Wet phases returned to the area about 3000 years ago, but these were only moderate in comparison to what had occurred before. Paleoenvironmental evidence indicates that two wet periods at 25002000 and $1600-1100$ years ago led to increased runoff and local water-table levels across the Atacama Desert core. However, these were not enough to activate springs or wetlands, and the vegetation cover of native herbaceous and woody plants was scarce and mostly restricted to ravines. ${ }^{3,4}$ Humans re-occupied the low-elevation desert around 2800 years ago. ${ }^{5}$ Since then, people gradually adapted their traditional hunting and gathering system to an agricultural lifestyle, despite still foraging some wild resources (plants and animals). Population sizes increased when largely dispersed but concentrated villages with monumental public spaces (squares) and cemeteries were built, incorporating new forms of social organization with different economic and ritual activities. Local communities developed sophisticated technologies to manage surface water, including dams and irrigation canals for maintaining large and well-drained

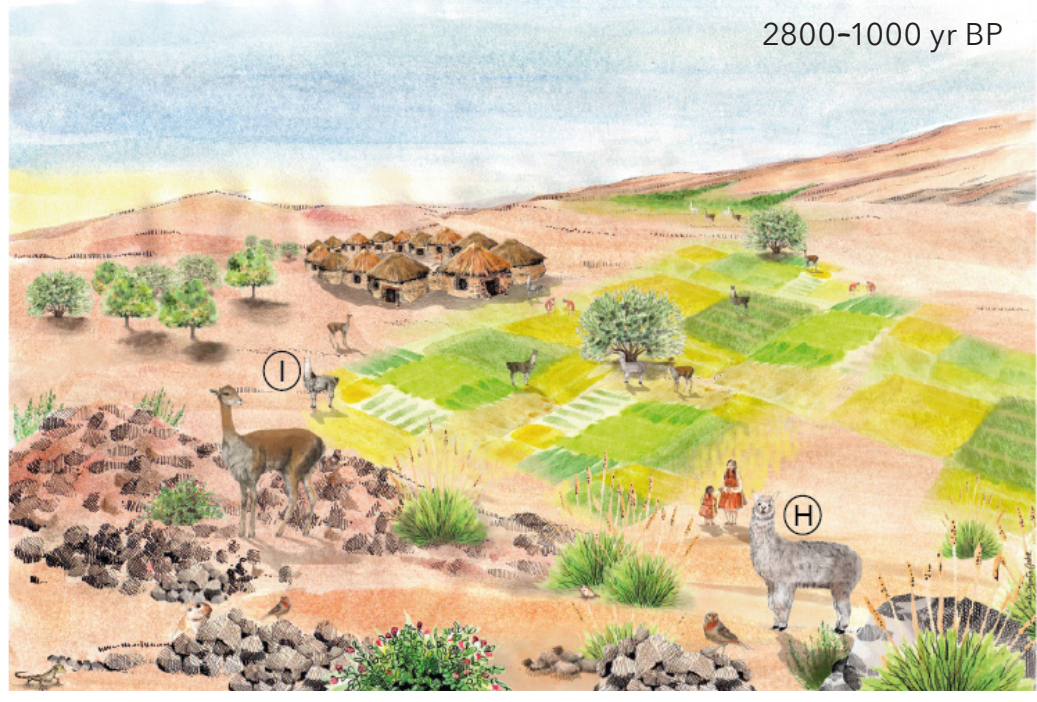

cultivation plots on what are now arid floodplains. Domestic South American camelids (alpacas ${ }^{H}$ and Ilamas') usually hung around and herded around these fields where quinoa, gourd, and maize were cultivated, as well as algarrobos or mesquite trees (Prosopis). ${ }^{3,4,5}$

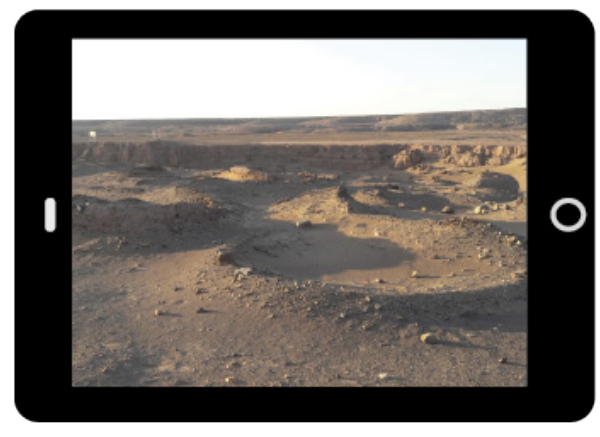

Abandoned village with circular-shaped buildings

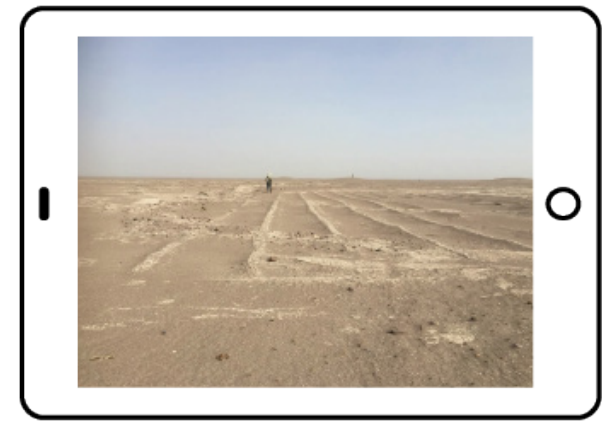

Ancient cultivation plots in the desert

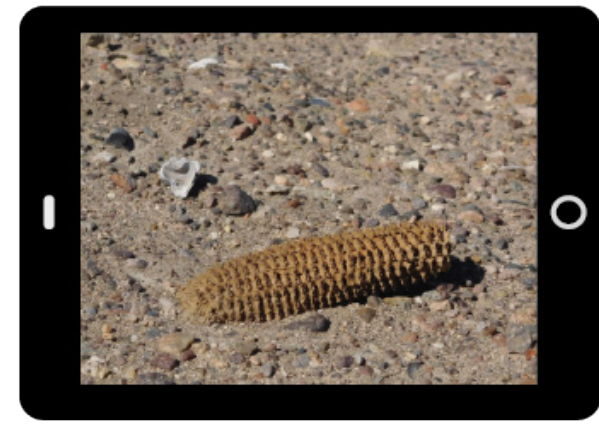

Cob associated with a cultivation plot
Arid conditions set into the area 1000 years ago. ${ }^{3,4} \mathrm{In}$ order to face this scenario, people moved from the desert core to the Pacific coast or higher elevations (above $2400 \mathrm{~m} / 7900 \mathrm{ft}$ above sea level), where water

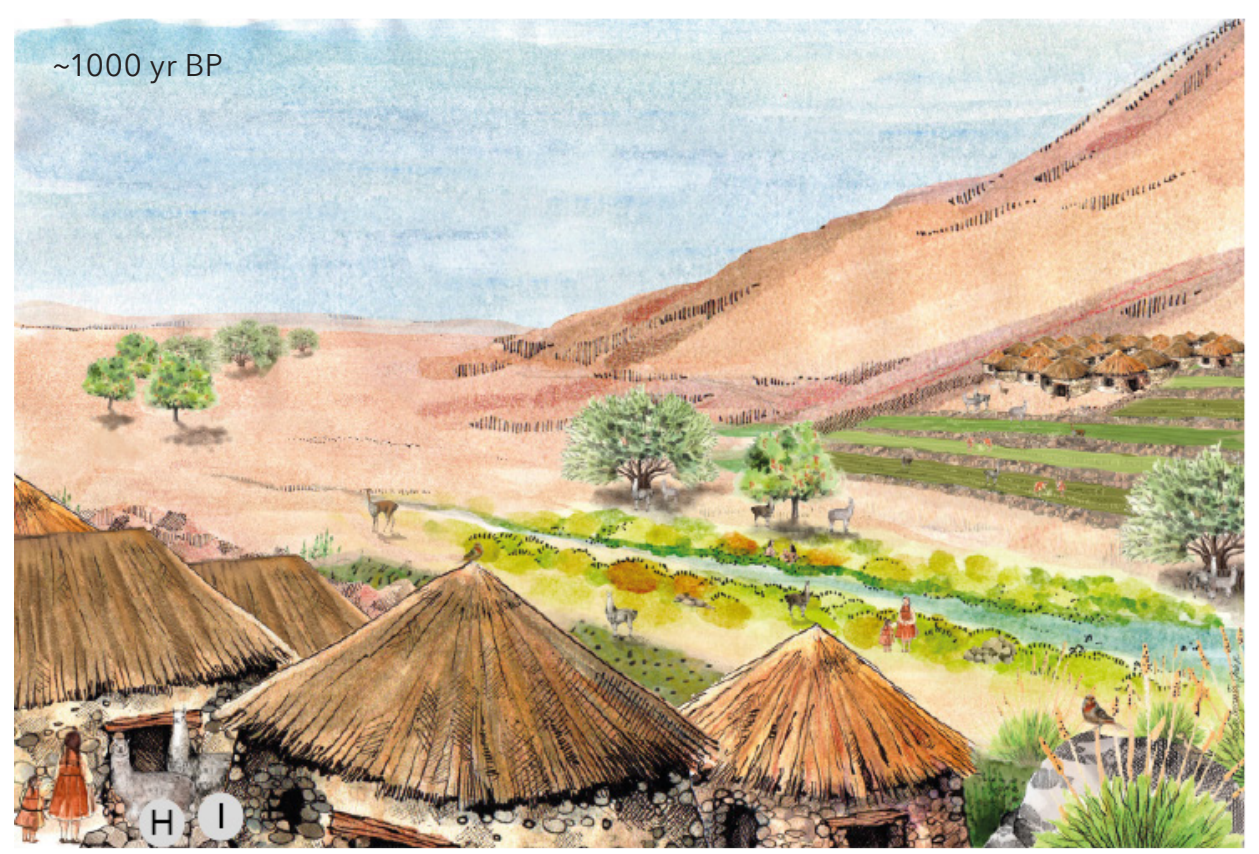

was much more abundant. That is, villages were now built following a vertical arrangement at upstream oases (canyons, wetlands) or in the Altiplano. ${ }^{6}$ Public spaces were separated from residential areas, located within or outside the villages. New systems of agriculture (arranged as terraced fields), defensive infrastructures (locally known as Pukaras) and landuse patterns emerged. Since this phase, the number of villages and the population density started to increase, and local communities intensified agricultural activities and the husbandry of alpacas ${ }^{H}$ and llamas' within these circumscribed territories at high elevations. ${ }^{6}$ The Atacama lowlands become a space that served as a place for communication and exchange between people from Andean highlands and the Pacific coast (an internodal territory). Still, archaeologists have suggested that this landscape was used opportunistically by farmers after flashflood episodes that temporarily inundated the Atacama Desert core. 


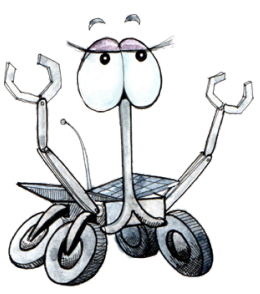

During the last 700 years, climate has remained similar to present, even during very short (but decadelong) wet pulses. 3,4 Despite this hostile environment, humans have continuously inhabited the core of the Atacama Desert since the European colonization (starting in 1533 CE). ${ }^{3,4,7}$ This has been achieved by a flexible lifestyle that involves the incorporation of new technologies and the large-scale exploitation of non-renewable natural resources. For example, modern urban centers have relied heavily on the groundwater stored within underground aquifers (fossil water) during past wet phases. $3,4,7$ The first profitable mining industry conducted between the 19th and 20th centuries in the Atacama Desert depended not only on the extraction of saltpeter but also on the use of logs of trees that grew in the core of the desert during both Central Andean Pluvial Events. Today, the Atacama Desert is the world's top producer of copper, which is a key raw material to manufacture a diverse array of
Hmmm ... I'm afraid not. They have actually inhabited this landscape since the 15th century, but in a quite different way ...

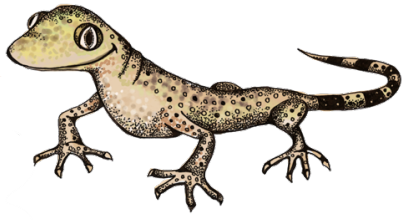

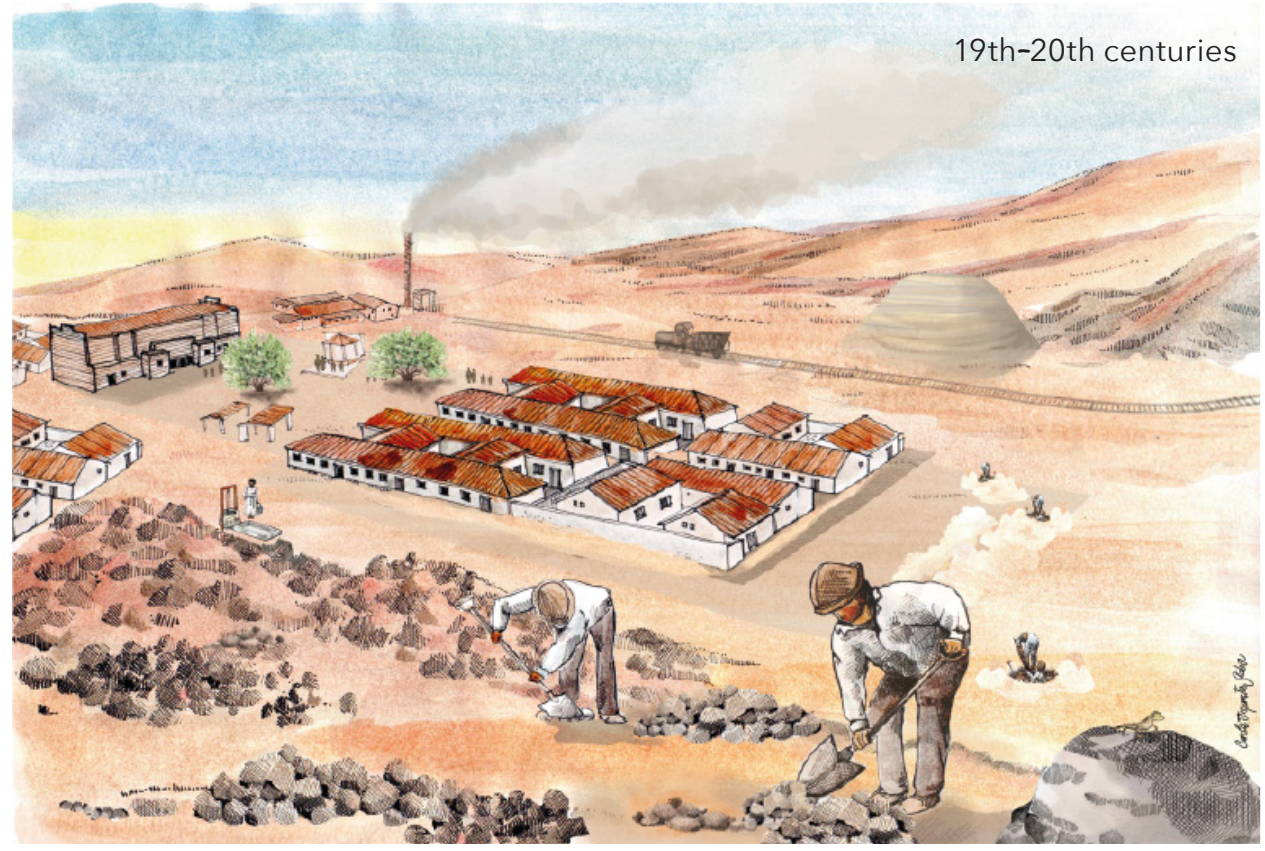

devices that are part of our day-to-day life (e.g. computers, batteries, pipes, clothes, cars, electrical wires, and coins). Nevertheless, such extensive copper extraction to supply global technological needs will soon consume either the entire mineral reserve or a large volume of fossil water.

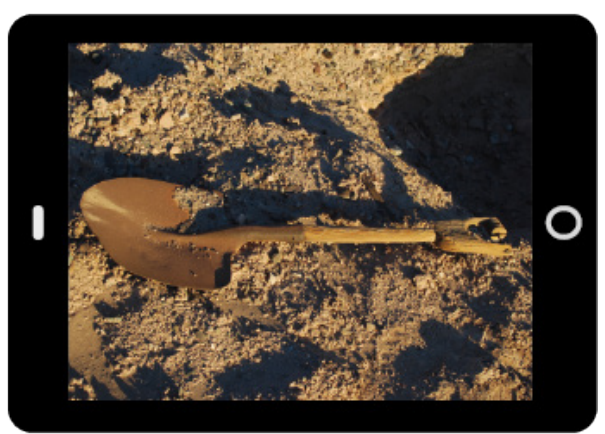

Old shovel used for saltpeter and fossil wood extraction

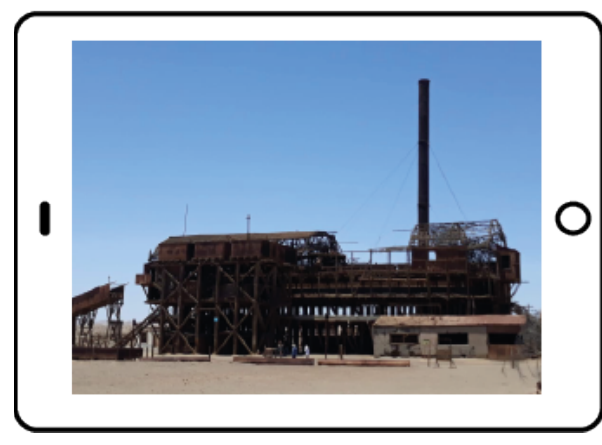

Ancient saltpeter/"caliche" processing plant

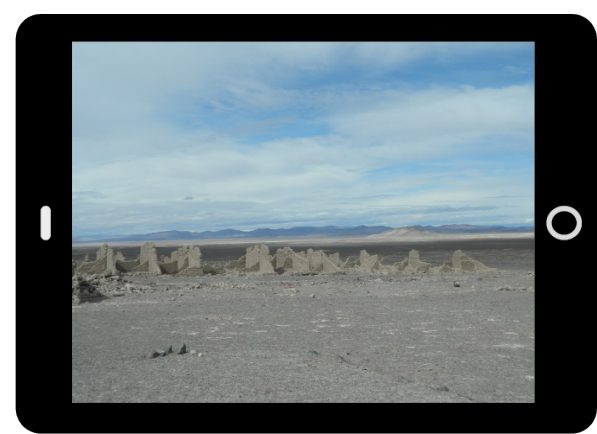

Saltpeter village ruins at present

Major paleontological, archaeological, and environmental changes recorded in the Atacama Desert over the last 18,000 years

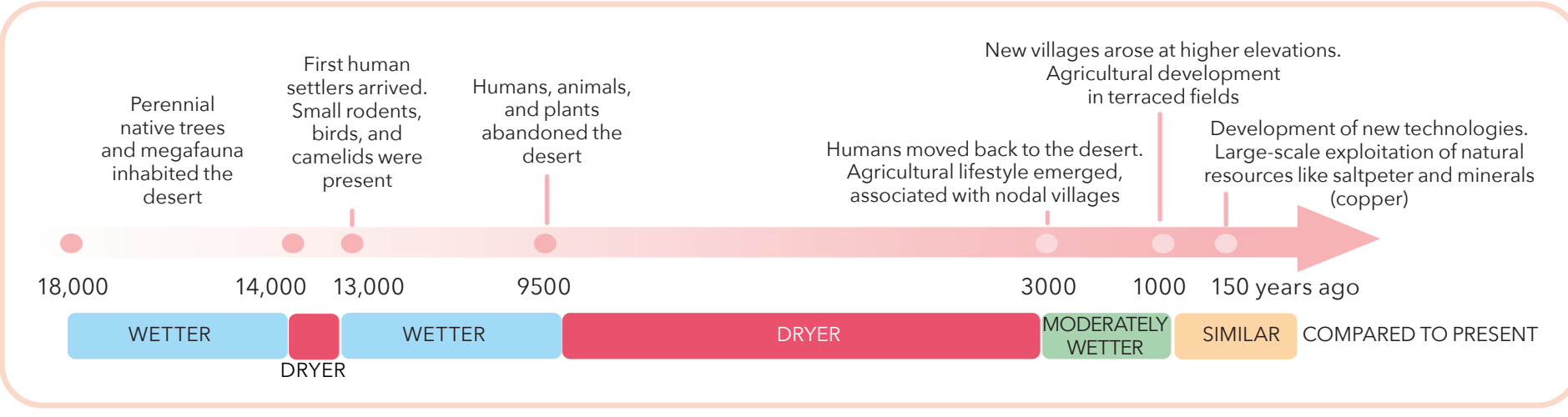




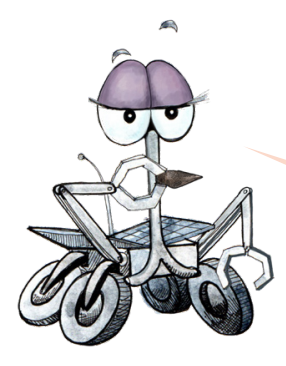

As you see, my dear Zoë, the Atacama Desert has a fascinating environmental history, and people have maintained a delicate balance for over 12,000 years, but the modern lifestyle has affected the balanced relationship that native societies used to have with the fragile Atacama Desert ecosystem ...

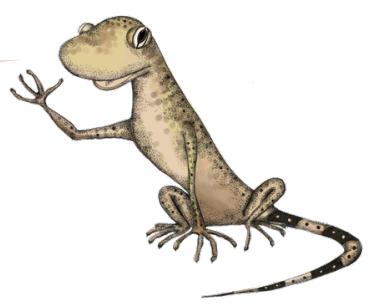

Absolutely! Now I feel a little bit ashamed since my circuits are made with Chilean copper ... building me consumed a lot of fossil water! Now I understand that the Atacama Desert is not a barren landscape ... its present ecosystems and archaeological heritage deserve to be protected and the extraction of fossil resources needs to be managed sustainably. I hope it is not too late..

\section{GLOSSARY}

Extraction of saltpeter: Ancient, extensive economic activity performed during the 19th and 20th centuries to extract potassium nitrate (saltpeter/caliche) from the surface of the Atacama Desert to be used to cure meat and to produce fireworks, fertilizers, and toothpastes.

Ground sloth: Extinct large mammal directly related to modern sloths. It was an herbivore that lived in and around the riparian and wetland oases of the Atacama Desert.

Oases: Isolated areas in the desert where water is available.
Paleoenvironmental: Related to a certain environment of the geologic past.

Perennial rivers: Streams where water is found throughout the year.

Water-table level: Shallowest depth of the groundwater below the Earth's surface. This depth can change through time.

Wetlands: Areas in the desert where water reaches the surface most of the year, allowing plants to grow there or in the surrounding areas. 
Past farmers and the environment: Insights from Sub-Saharan Africa

\section{Jerry Olatoyan}

Sub-Saharan Africa is an exciting place to investigate the interaction between past farmers and the environment. More than $\mathbf{4 0 0 0}$ years ago, early farmers in this region started planting indigenous crops like pearl millet, sorghum, yam, and Bambara groundnut before introducing crops like maize and cassava around $\mathbf{5 0 0}$ years ago. In the process, farmers interacted with many elements of the environment such as the landscape, vegetation, climate, and soils, and with time, humans began to have an ever-increasing effect on the environment. While some farmers managed to use sustainable methods of farming, the clearing of vegetation before planting crops often destroyed a lot of trees and changed the face of the landscapes, and as a result, some plants became extinct. Also, forests were destroyed and, in many cases, grasses and scanty trees regrew in their place (Fig. 1). A present-day example is from Mpumalanga in South Africa, where about $36 \%$ of the grassland and savanna biomes have disappeared mainly due to farming. ${ }^{1}$
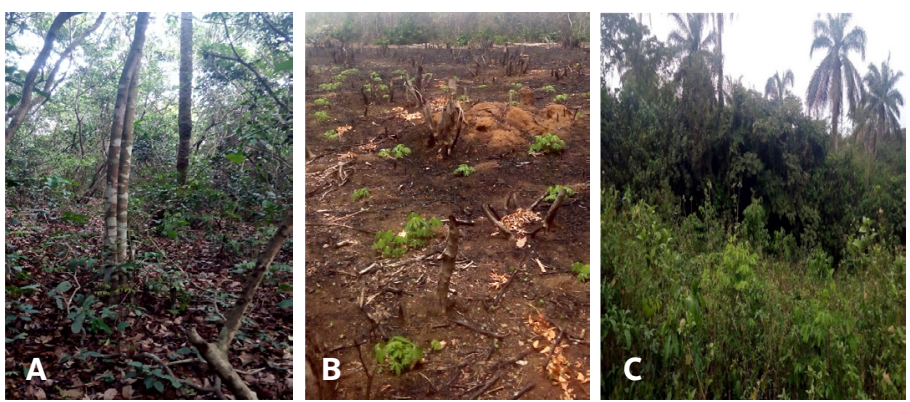

Figure 1: Example of changing landscapes in Ogun State, southwestern Nigeria: (A) A relatively undisturbed forest; (B) Removal of trees by cutting; (C) Regrowth of forest with scanty trees and grasses (Image credit: Jerry Olatoyan).

The transition to crop farming that took place about 4000-5000 years ago was a remarkable event in the history of Sub-Saharan Africa and gave rise to a new economy and livelihood. Prior to this, humans had been hunters and/ or gatherers for a long time (Fig. 2). This transition occurred at different times in different parts of this region due to migration, available wild resources, dominant vegetation types, climatic conditions, and a settled way of life. These factors were often responsible for the early or later beginning of crop farming as they either facilitated, hindered, or delayed the process. For example, while the direct evidence
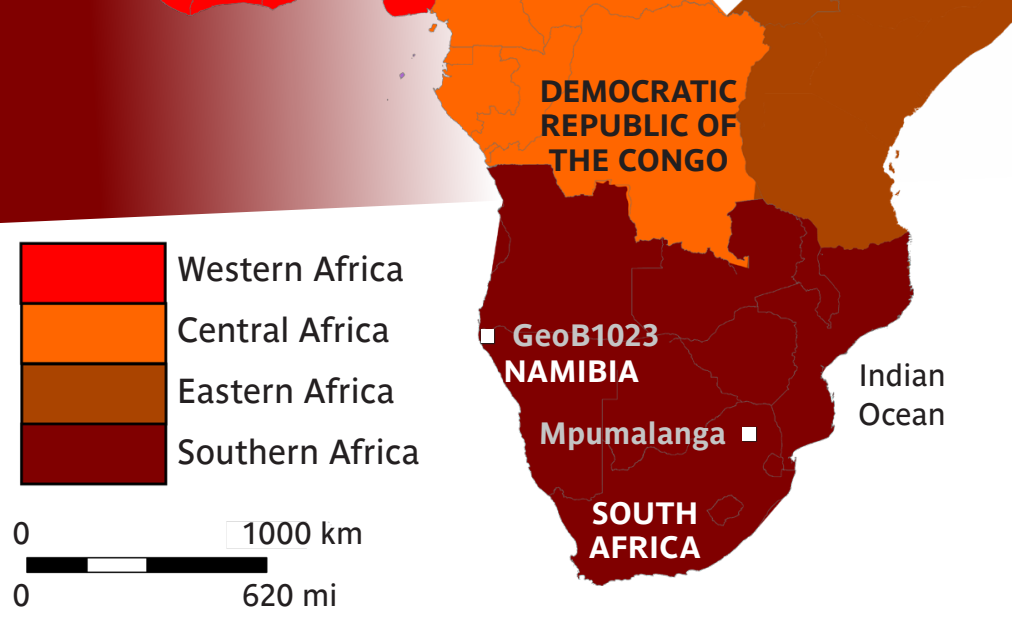

of the first sowing of tuber and root crops is still missing in the records, current evidence shows that cereal farming started around 2500 BCE in western Africa, 700 BCE in central Africa, and not until after $200 \mathrm{CE}$ in eastern and southern Africa. ${ }^{2,3,4}$ Since humans then had to wait for the harvest, they became less mobile, built semi-permanent or permanent settlements, and the population began to increase.

Also, around this time, iron and copper production became widespread, and this technological development is often associated with crop farming. With this technology, humans were able to produce tools like hoes and sickles to improve farming, as well as weapons such as spears to conquer territories and expand their kingdoms. However, the processes of producing these tools and weapons often led to the destruction of forests because they required enormous amounts of wood for charcoal (Fig. 3). An experiment in 2007 showed that approximately $228 \mathrm{~kg}$ (503 lbs) of charcoal from wood were required to process $40 \mathrm{~kg}$ (90 lbs) of ore in one furnace. ${ }^{5}$
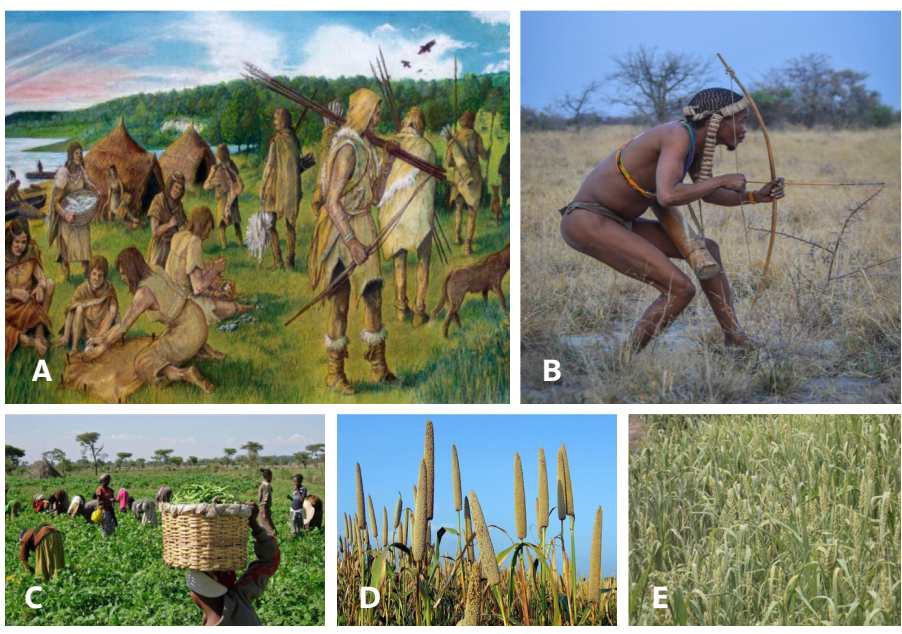

Figure 2: (A) A typical hunting and gathering ceremony (Ethelene Bailey, dualdove.com); (B) Use of the bow and arrow for hunting by a present-day San hunter from southern Africa (Andy Maano); (C) A typical crop farming economy (Ummaimah Dikko, fmic.gov.ng/agricultural-in); (D) Cultivation of pearl millet; (E) Cultivation of sorghum (Saranyanithi). 
Figure 3:

Steps involved in charcoal and iron production:

(A) Stacked wooden logs;

(B) Slow combustion of the wood;

(C) Charcoal produced by combustion;

(D) Iron ore reduction using a traditional furnace; (E) Spongy iron (bloom).
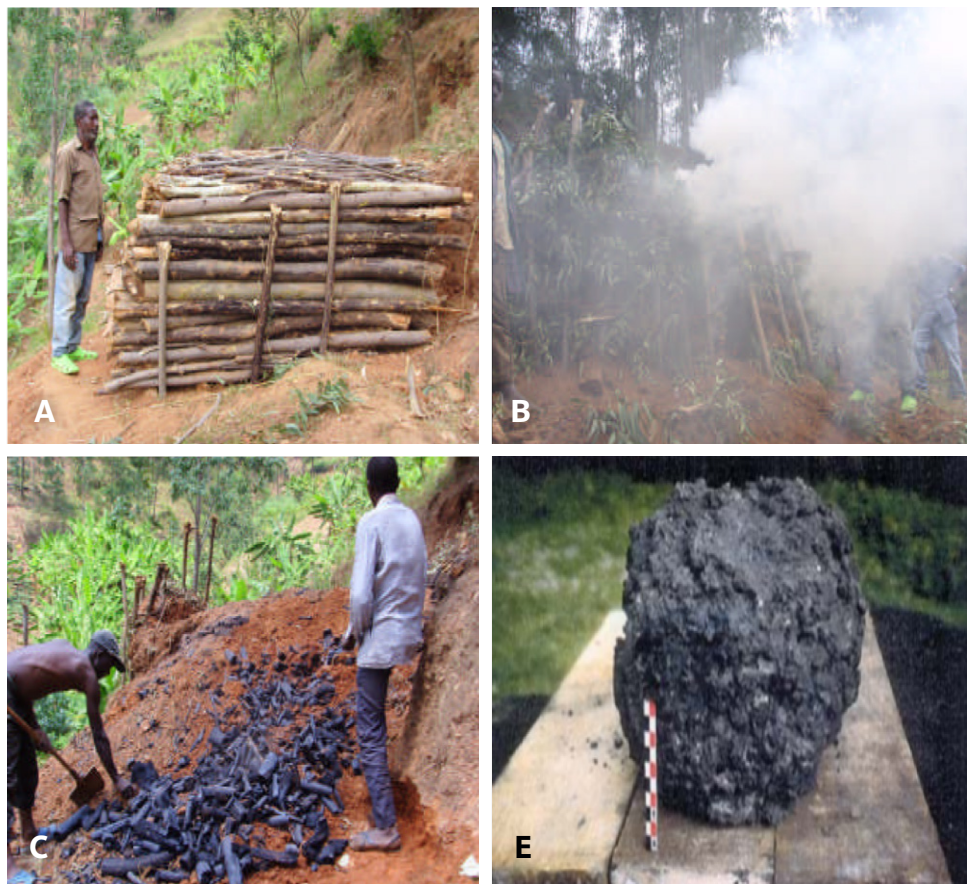

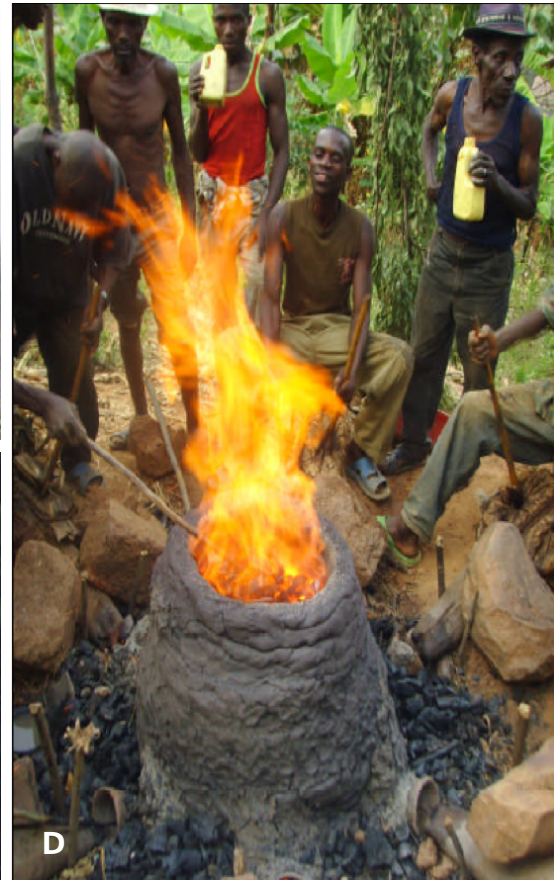

youtube.com/watch?v=SPU8Uwa-jBQ
Let's now look at how we study the impacts and changes on the environment caused by humans. The information about the environment is accumulated in layers over time that are found in natural archives such as lakes, peats, bogs, springs, swamps, and speleothems. These archives serve as the memory of nature, which must be protected. This is why studying paleosciences is important, as it promotes discovery and preservation of the hidden stories in these archives.

To retrieve the information from these archives, we use drilling equipment (e.g. a corer; Fig. 4) to collect sediments, which are then transported to the laboratory for analysis of pollen and charcoal. The sediments collected are sliced into chunks at specific intervals (Fig. 4), followed by physical (i.e. sieving), mechanical (i.e. centrifugation), and chemical (i.e. using $\mathrm{HCl}, \mathrm{HF}, \mathrm{KOH}$, acetolysis mixture) treatments. These allow us to extract the residue, containing microscopic pollen grains and bits of charcoal to be analyzed under the light microscope. After careful study,

Figure 4: (A) This researcher is using a Russian corer to bore into the fen and recover the layered sediments (core); (B) The recovered core with its layers visible; (C) How we slice the core into chunks before processing (University of Melbourne Palaeoecology-Palaeoclimatology).
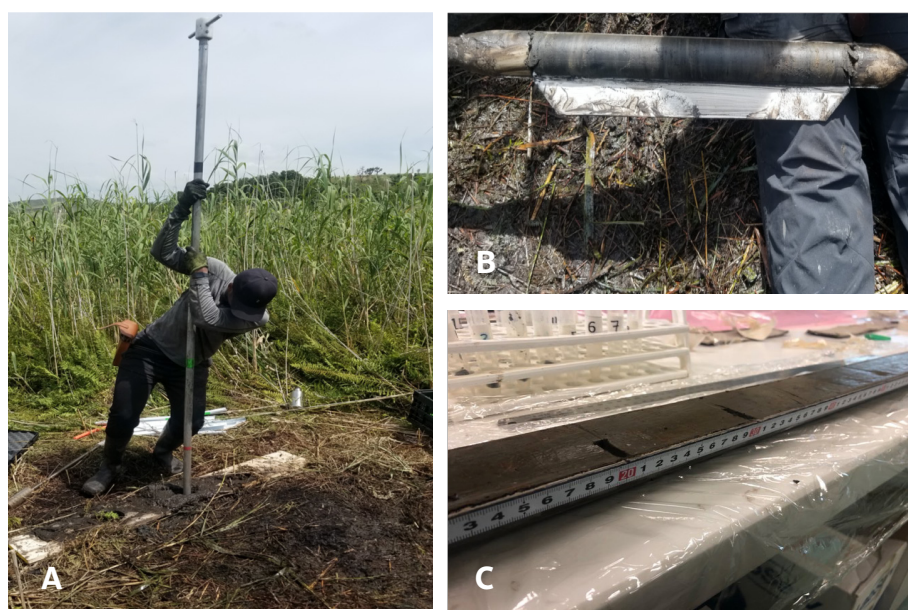

\section{Activity}

Remains of 500 furnaces were found at a site in Ogun State, southwestern Nigeria. Using the data from the above experiment where $40 \mathrm{~kg}$ (90 lbs) of ore in one furnace required $228 \mathrm{~kg}$ (503 lbs) of charcoal, try to estimate the amount of wood that would have been used for the 500 furnaces to each produce $40 \mathrm{~kg}$ ( $90 \mathrm{lbs}$ ) of ore, given that $150 \mathrm{~kg}$ (330 lbs) of charcoal are produced from $600 \mathrm{~kg}$ (1320 lbs) of firewood. ${ }^{6}$

Now estimate the number of acres of forest that would have been destroyed to produce this amount of wood, given that 1 ha $(2.5 \mathrm{ac})$ in tropical rain forests produces an average of $21,250 \mathrm{~kg}(46,850 \mathrm{lbs})$ of wood. ${ }^{7}$

we can identify the cultivated crops and weeds in the region of the core which enables us to have a better idea of the changes in vegetation caused by humans. Also, we can differentiate between the changes caused by climate and those driven by humans by combining two or more data sources that reflect human influence over a given period. For example, the analysis of pollen and charcoal in samples from the GeoB1023 site in Namibia, showed the disappearance of Afromontane forest (e.g. Podocarpus), increase of weed pollen (e.g. Tribulus), and charcoal particles (Fig. 5) beginning from $200 \mathrm{CE}$, which suggests that the inhabitants of this region were transitioning to crop farming around 2000 years ago. ${ }^{8}$
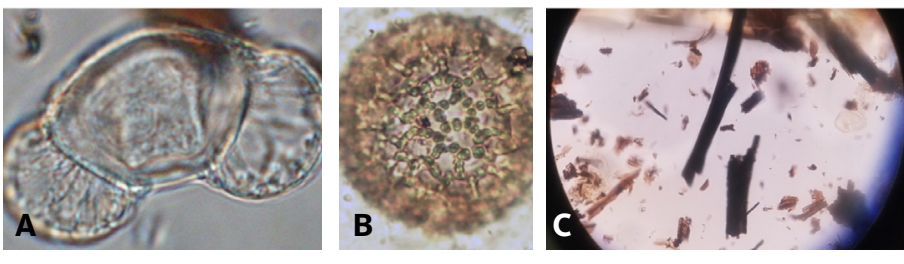

Figure 5: (A) Podocarpus pollen; (B) Tribulus pollen; 9 (C) Microcharcoal particles. 
Finally, as humans continue to practice farming over time, the climate also experiences tremendous changes that in turn affect the production yields of crops. However, farmers have learned how to modify the landscape in order to adapt to the effects of these changes. In northeastern South Africa, for example, farmers that lived between the 16th and 19th centuries used stones to build terraces (raised areas; Fig. 6), to reduce soil and water erosion while conserving the available soil nutrients and soil moisture for maximum use..$^{10}$ This is indeed one of the sustainable ways to adapt to changing environmental conditions locally and further indicate clear evidence of an advanced farming system practiced in pre-colonial times.

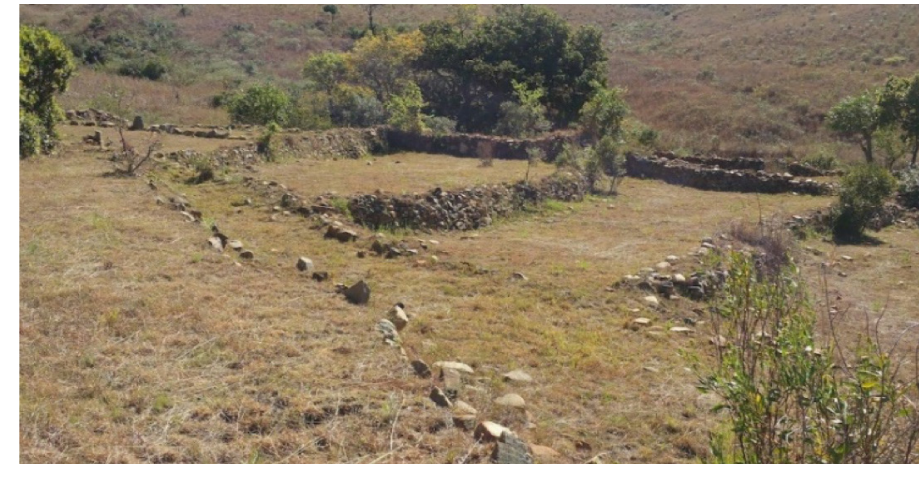

Figure 6: Farming terracing (James Ball, The Heritage Portal, theheritageportal.co.za).

\section{PAST FARMERS and the ENVIRONMENT: INSIGHTS FROM SUB-SAHARAN AFRICA}

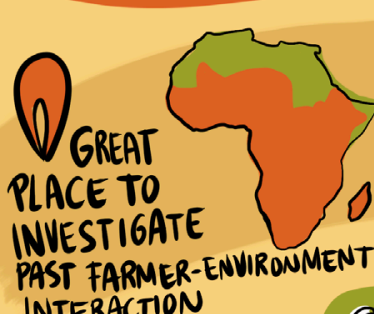
INTERACTION

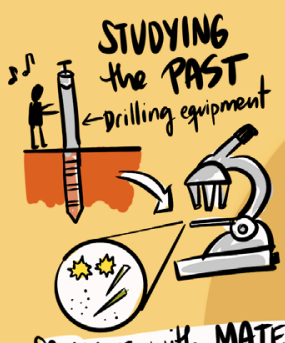

SAMPLES with MATERIALS to RECONSTRUCT EVENTS (pollen, charwal, etc)

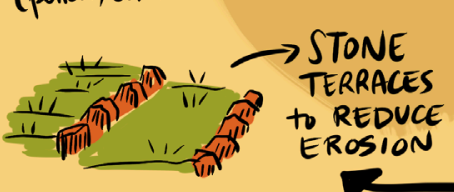

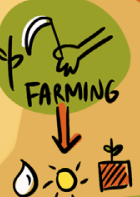
O. ENUIRONMENT
CHANGES but PAST
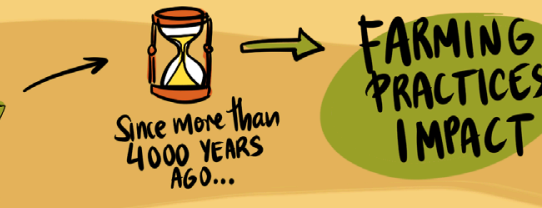
IMPACT
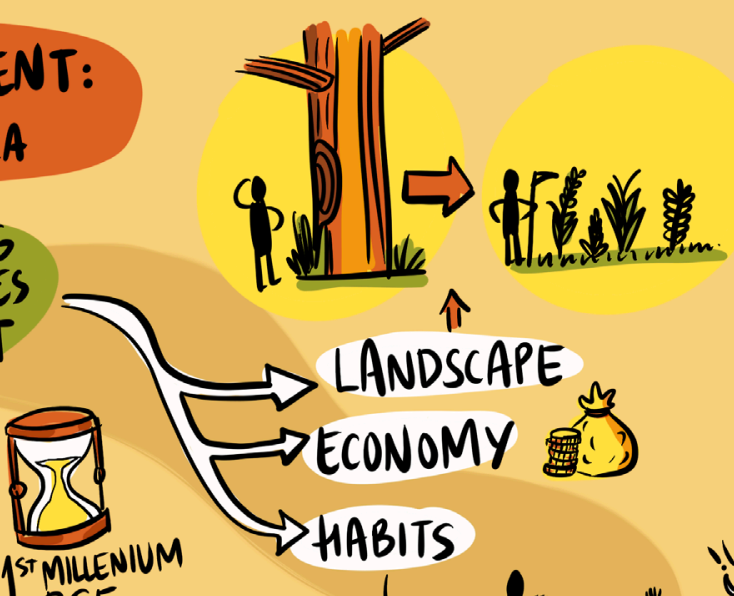

介 LANDSCAPE ? LOTS OF WOOD

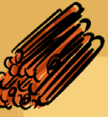
- Giron RODUCTON BCE
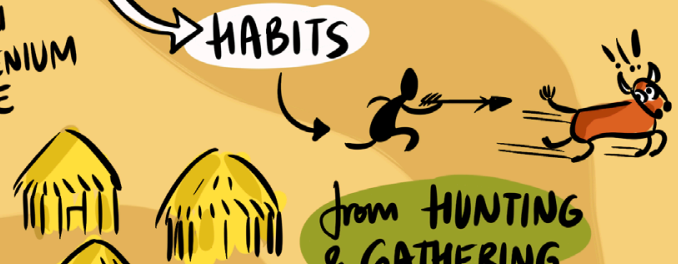
FARMING
TOOSS FARMERS also used

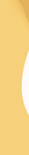
\& conaVer-TERRITORY CONaVER-TERTI
TDOLS ADVANCED\&SUSTAINABLE SYSTENS TO ADAPT to the ENVIRONMENT MiIilithen SETIL to FARM

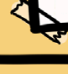
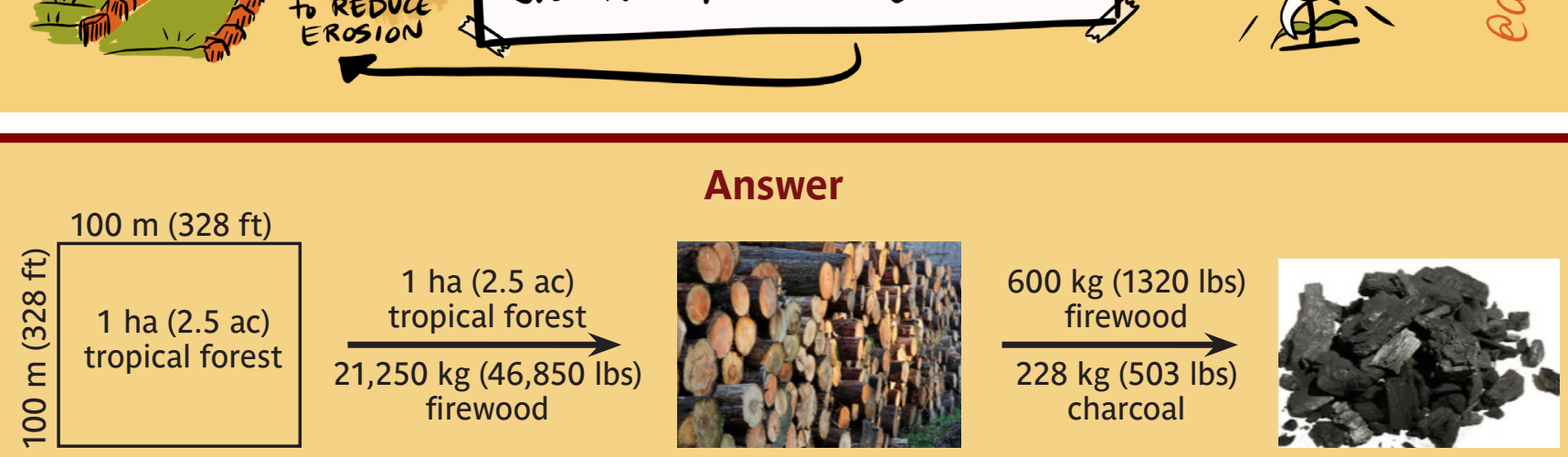

To approximate the amount of firewood that 500 furnaces would have required, we can calculate:

500 furnaces $\times 228 \mathrm{~kg}$ charcoal $/$ furnace $\times 600 \mathrm{~kg}$ firewood $/ 150 \mathrm{~kg}$ charcoal $=456,000 \mathrm{~kg}$ firewood 500 furnaces $\times 503 \mathrm{lbs}$ charcoal/furnace $\times 1320 \mathrm{lbs}$ firewood $/ 330 \mathrm{lbs}$ charcoal $=1,006,000 \mathrm{lbs}$ firewood

This can be used to calculate the area of tropical forest that would have been required:

$456,000 \mathrm{~kg}$ firewood $\times 1$ ha forest $/ 21,250 \mathrm{~kg}$ firewood $=\mathbf{2 1 . 5}$ ha forest

$1,006,000 \mathrm{lbs}$ firewood $\times 2.5 \mathrm{ac}$ forest $/ 46,850 \mathrm{lbs}$ firewood $=\mathbf{5 3 . 7}$ ac forest

That's about the size of 40 football fields! 

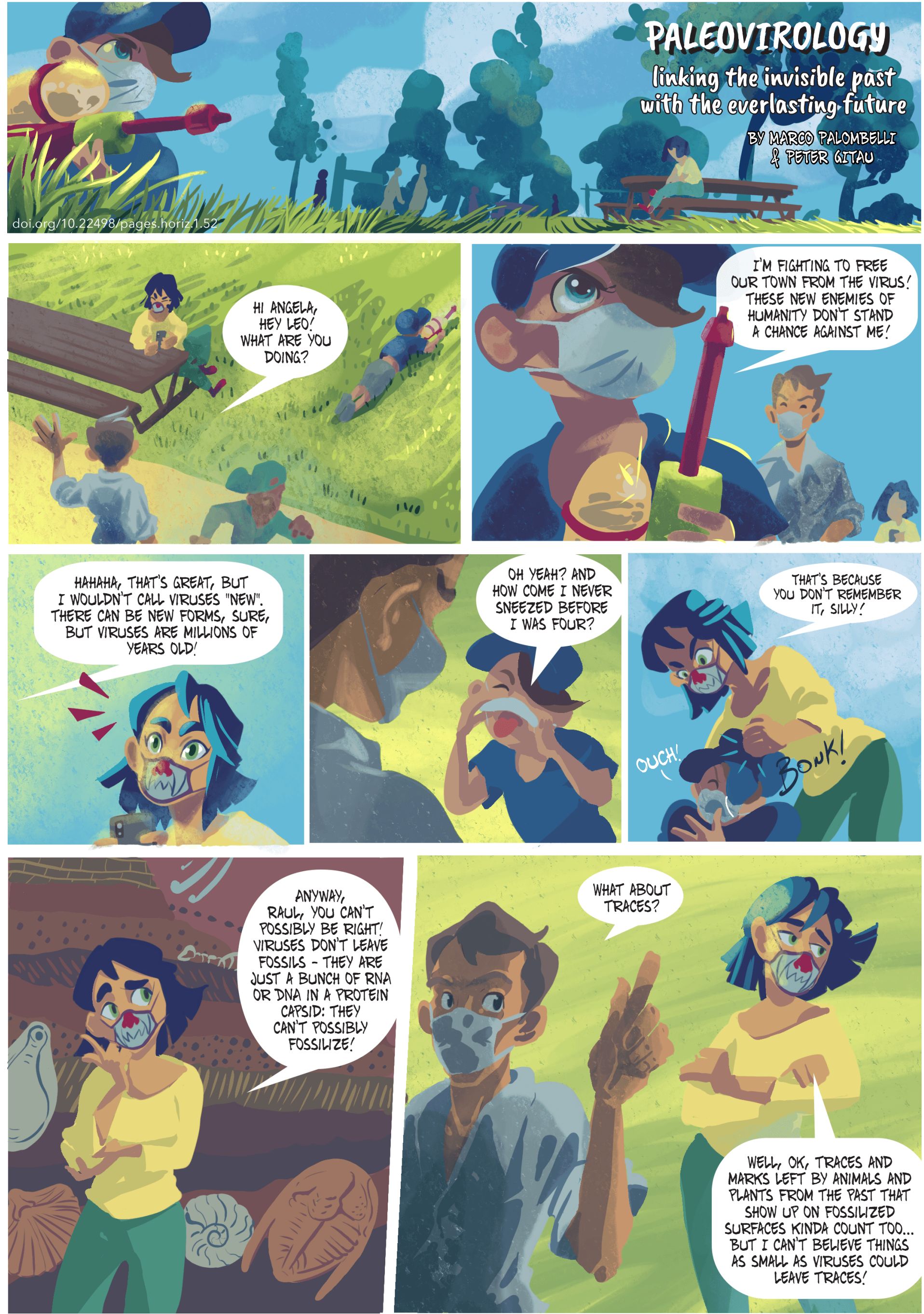

OH YEAH? AND HOW COME I NEVER SNEEZED BEFORE I WAS FOUR?

HERE CAN BE NEW FORMS, SURE,
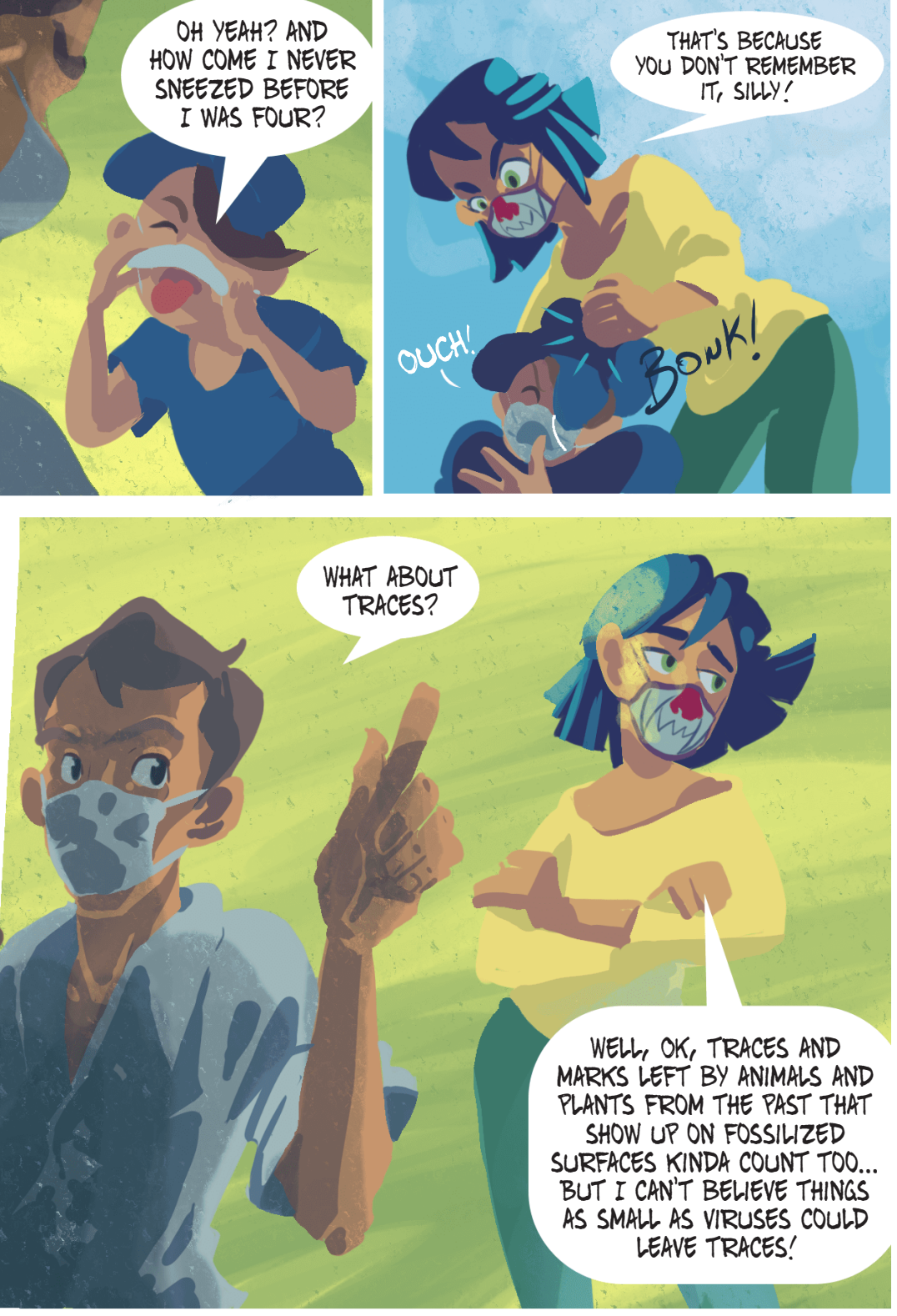


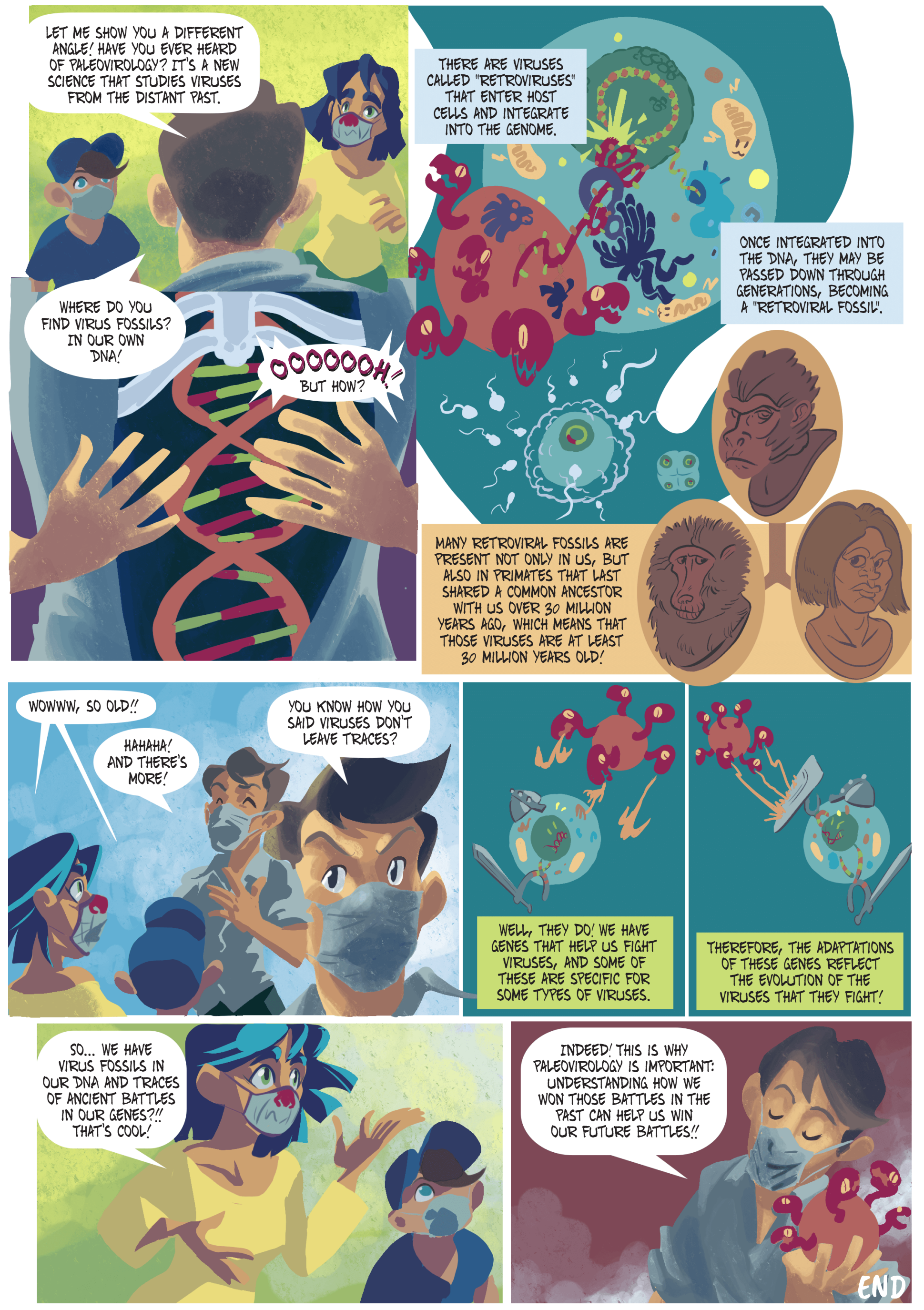




\section{Robyn Granger and Graciela Gil-Romera}

\section{Sediment cores}

Reconstructing the past using the archives of the Earth is like reading books from our planet's libraries. There are many different types of natural archives that act as libraries: ice, lakes, oceans, stalagmites from caves, tree rings, fossilized dunes, or dried lakes (you have seen some of these already in this issue!). Researchers need to check out one of those books to read about the Earth's past. One example of an Earth archive is sediment cores - long cylinders of mud recovered from an ocean or lake floor. In these cores, the deeper you go, the older the sediment.

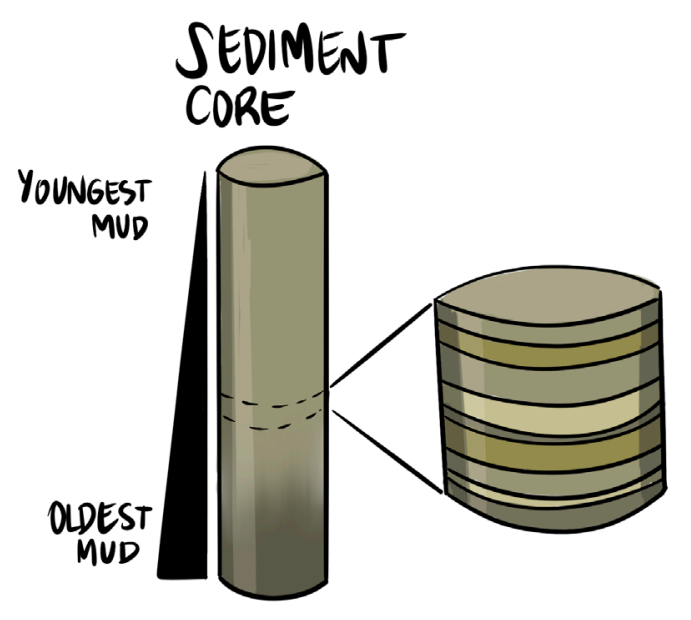

Chronology and age models

Scientists working with archives of the past need to be sure about when particular events or changes actually happened, i.e. they need to place these along a timeline. This timeline is called a chronology or an age model. Determining the date (usually the year, but nothing as precise as day and month - sometimes we can only figure out how many centuries or millennia ago!) at which something happened in the past can be done using different methods, depending on the type of archive we need to date.

Dating techniques can offer a quantitative value: for example, we may find that something happened 25,000 years ago. However, dates can also be interpreted relative to other events. If we find fossils from organisms that we know lived within a particular time period (for instance, trilobites lived between 520 and 250 million years ago), this gives us a clue that the sediment in which they were found, and anything else that sediment might contain, is about that old too. One common dating method which provides trusted quantitative values is radiometric techniques. These compare the abundance of a naturally occurring radioactive isotope with the abundance of its disintegration products, which form at a known constant rate of decay. A well-known example of this is radiocarbon dating, a technique that measures the decay of ${ }^{14} \mathrm{C}$ atoms.
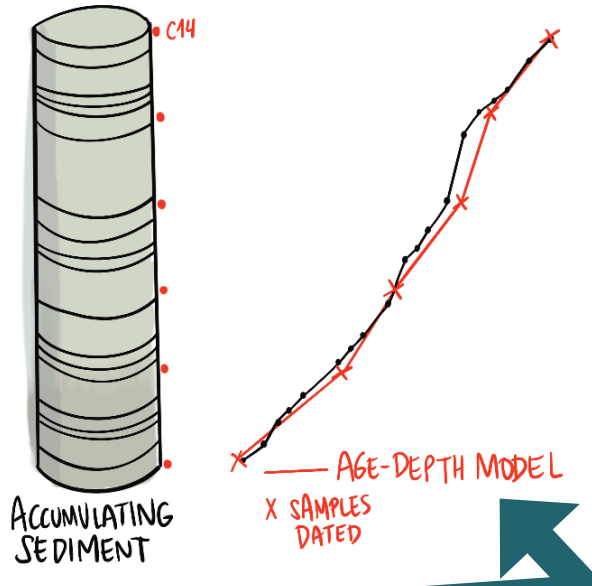

The red line tells you how scientists build models line shows how fast the sediment really accumulated. For an animation of this, check out Maarten Blaauw's website: chrono.qub.ac.uk/ blaauw/wiggles/agemodel.html

Reconstructing the timeline of events usually requires more than one date. Take for instance the cores that are shown in "Lake mud detectives" on page 36. If we want to understand how fast diatoms changed over time, we need to determine several dates within a single sediment core. Dating every centimeter of the whole core is costly and difficult, so, quite often, researchers have to build a model to interpret the sections of the core that are not dated. This model, as with any other we have in science, has some degree of uncertainty. Keep reading for more about models and confidence.

\section{Models}

In paleoclimate climate research, scientists use the term model to refer to a simple, small-scale representation of the Earth and its climate. These models are based on mathematical equations that describe our planet's physical, chemical, and biological laws. The equations are solved (approximately) by powerful computers, and unknown variables in the equations are assigned values based on modern observed data. "Can we tell how climate will change in the future?" on page 6 of this issue provides a good example of how models work.

Because interactions between the atmosphere, oceans, land, and cryosphere (all of the ice found on the Earth) in models mimic real-world processes, they can be used to predict how average climate or ecological conditions may change in the near future. These predictions are sometimes also called "projections". In addition, scientists can set different conditions in their model (more $\mathrm{CO}_{2}$ in the atmosphere, for example) to test hypotheses, explore different scenarios, and experiment freely without real-life consequences. Although large-scale climate modeling can involve large amounts of data, a model doesn't have to be complicated!

\section{Climate projection.}

A climate projection is what might happen in the future and how we might get there. Projections use the results generated by models to best reflect the most likely outcome of a situation; for instance a prediction about sea level 100 years in the future based on rising temperatures and melting of ice sheets on Antarctica. 


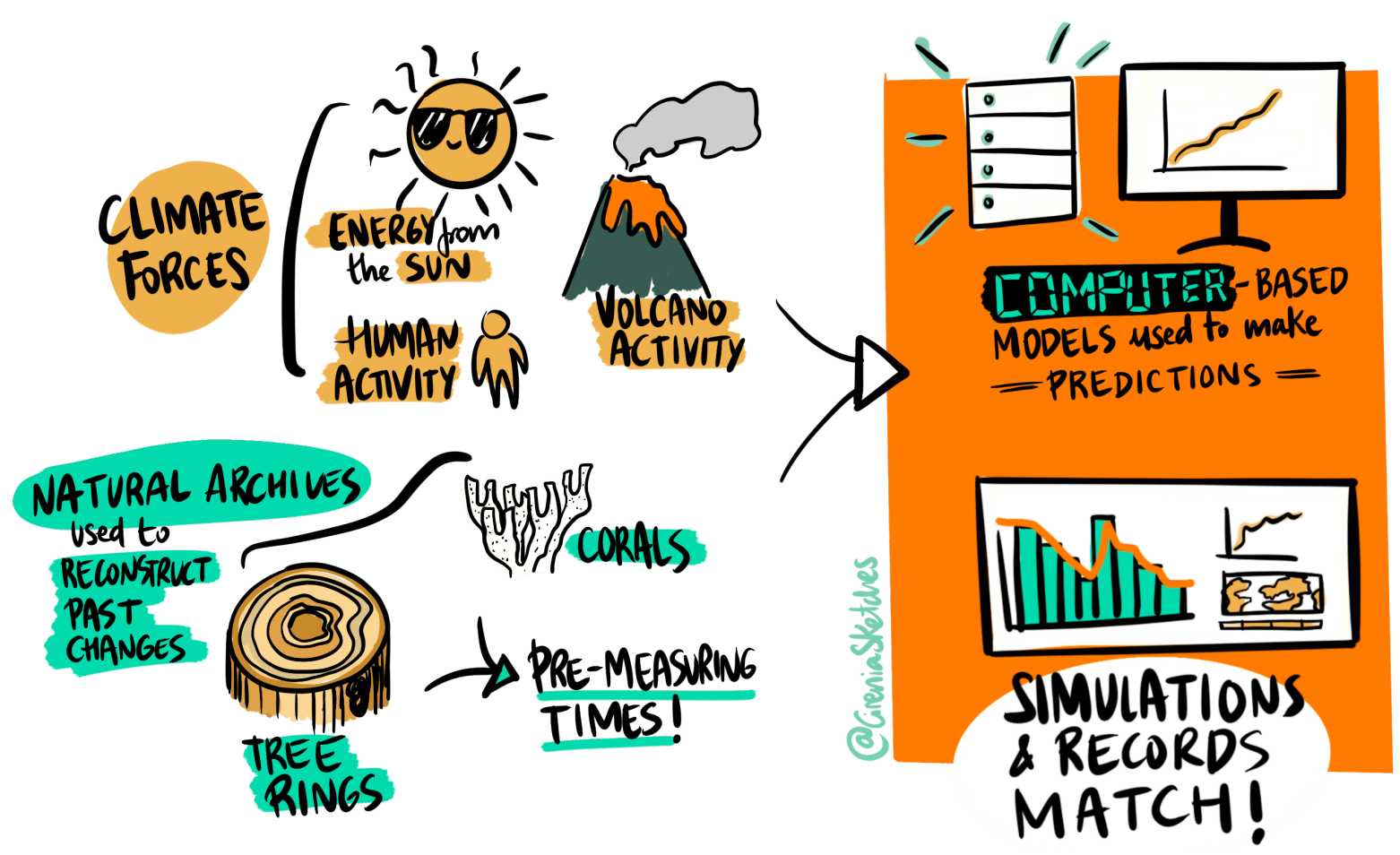

A key element of projections is determining what the climate was like in the past, using the same model data that determines the future. In this way, we can get an idea of the limits of climatic change even during times when the climate was extremely different from today, and to check the similarity of the projection to actual observed data. If your projection for the past looks nothing like the observations from the present or past, then it's unlikely that you will have a lot of faith in your future projection!

Ongoing observational measurements are also a crucial element of developing more accurate future projections, as these can be compared to previously projected scenarios, improving new projections and the models that inform them.

\section{Uncertainty}

Uncertainty refers to the level of confidence we have in any given result, based on the type, quality, amount, and consistency of the data. A low degree of uncertainty will produce a result with a high confidence level. It's similar to how confident you feel when you've aced an exam. There's no question (uncertainty) about it - you rocked it! Scientists try to increase confidence in their data by reducing uncertainty as much as possible, narrowing down the wide range of possible outcomes. One way to achieve this is to increase the amount of data points in a study, as a larger sample size will provide a more robust average and/or a higher resolution. Other ways include focusing on a smaller area or shorter time frame, or by using several independent methods to research the same question.

Uncertainty can be referred to quantitatively (e.g. standard deviation) or stated in words. The International Panel for Climate Change (IPCC) uses qualitative language based on quantitative probability estimates when discussing confidence in their climate projections:

"Virtually certain" = 99-100\% probability "Likely" = 66-100\% probability

"About as likely as not" = 33-66\% probability "Unlikely" = 0-33\% probability
There is almost always a degree of uncertainty associated with scientific results, indicating a range of possible values. This does not mean the results of a study are wrong - instead, uncertainty is simply a way to quantify how much confidence we should place in our measurements. Any resulting decisions can be made taking the appropriate level of confidence into account. One example of this is how the IPCC takes into account several potential scenarios with different levels of uncertainty, when making decisions on how best to reduce atmospheric $\mathrm{CO}_{2}$ emissions.

An often quoted saying by statistician George Box was that "all models are approximations. Essentially, all models are wrong, but some are useful." In summary, all data possess uncertainty, but can still provide useful information.

You see that your friend has a sandwich, a cookie, and an apple in her lunchbox. You casually wonder which she will eat first, but take a guess that she will go for the sandwich. But after several days of studying her eating habits, you observe that she usually eats the apple first, and your predictions begin to favor the apple. Then, after several weeks, you notice that she tends to eat her apple first on Mondays, Wednesdays, and Fridays, but her sandwich first on Tuesdays and

Thursdays. The more days

you watch, the easier it becomes to predict which she will reach for first. This is how uncertainty works! You can become more confident in your predictions once you have more data, but you can never be completely certain that your guess will be correct.

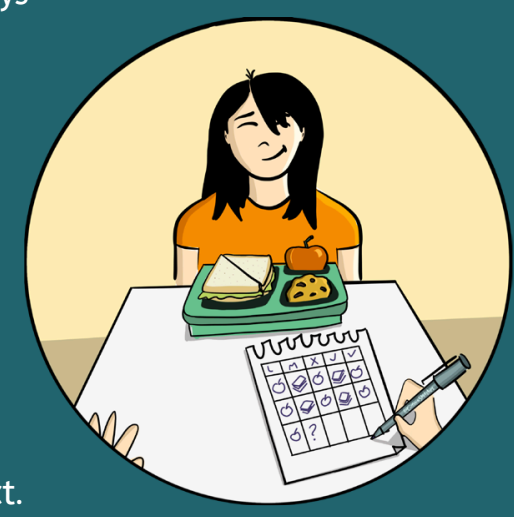




\section{MEET THE AUTHORS AND ILLUSTRATORS}

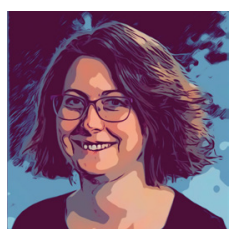

Keely Mills

British Geological Survey, Cambridge, UK

kmil@bgs.ac.uk, @KeelyMills

I love tiny microscopic plants called diatoms; these

tell me lots about how water quality has changed both today and in the past.

Paleoscience and the UN Sustainable Development Goals (p. 4)

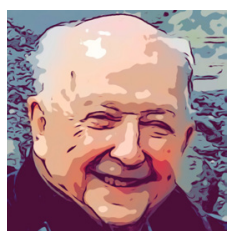

\section{Frank Oldfield}

University of Liverpool, UK

oldfield.f@gmail.com

For over 60 years I've used fossil plant remains, magnetism, and radioactivity to measure and date past environmental changes especially those driven by human activities.

Can we tell how climate will change in the future? (p. 6)

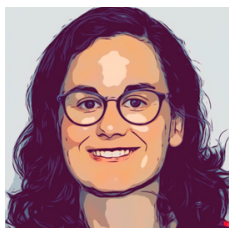

Mariem Saavedra-Pellitero

University of Birmingham, UK

p.m.saavedra-pellitero@bham.ac.uk

@MariemSaavedra

I am a micropaleontologist who uses a microscope to study beautiful, tiny algae called coccolithophores (pronounced "coc-co-lith-o-fours") to reconstruct the climate of the past.

How green were the oceans in the past? (p. 9)

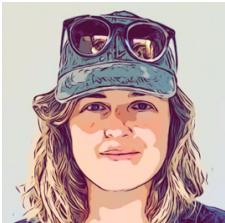

\section{Juliet Sefton}

Tufts University, Medford, MA, USA

Juliet.Sefton@tufts.edu, @SeftonGeo

I am a sea-level scientist who loves collecting mud to

find out what it tells us about the ups and downs of past sea levels.

Why sea level is not level (p. 16)

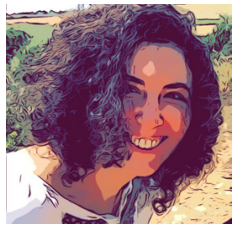

\section{Hadar Elyashiv}

MARUM, Germany, and The University of Haifa, Israel helyashiv@marum.de, @HadarElyashiv

I'm a marine sedimentologist, playing with mud and sand - studying how it is transported and influences the seafloor. Also a passionate science communicator. A message from the buried past (p. 20)

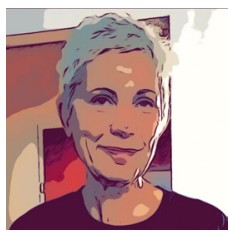

\section{Silvia Frisia}

University of Newcastle, Australia

silvia.frisia@newcastle.edu.au

I am a caver and a mineralogist. I look at crystals

through powerful microscopes and decipher how

they record the climate history of Earth.

The South Pacific and climate change (p. 30)

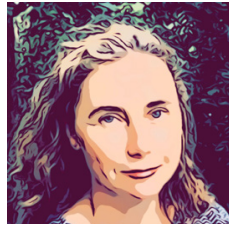

Pauline Treble

ANSTO, Lucas Heights, Australia

pauline.treble@ansto.gov.au

I am a paleoclimatologist. I turned my interest

in caving into a cool career - interpreting the

geochemical record in cave stalagmites to

understand how our climate changes.

The South Pacific and climate change (p. 30)

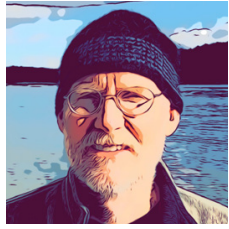

Joe McConnell

Desert Research Institute, Reno, NV, USA

Joe.McConnell@dri.edu

I use ice-core chemistry records to study how past human activities have impacted the environment, and how the environment has effected human societies. Linking lead pollution in ice cores to ancient history (p. 34)

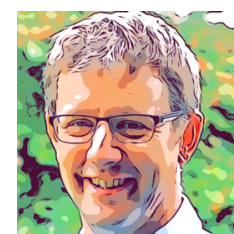

Matthew Jones

University of Nottingham, UK

matthew.jones@nottingham.ac.uk, @drmattjones Analyzing mud allows me to understand how water availability has changed through time. I'm a big fan of oxygen isotopes!

Paleoscience and the UN Sustainable Development Goals (p. 4)

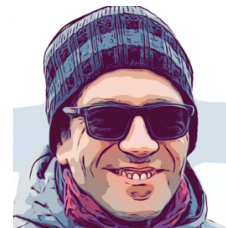

\section{ván Hernández-Almeida}

ETH Zürich, Switzerland

ivan.hernandez@erdw.ethz.ch

I work to understand climate's fingerprint buried in the seafloor. Sometimes science is too complex, so I write stories to help others to understand, remember, and imagine.

How green were the oceans in the past? (p. 9)

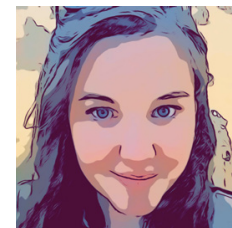

\section{Margot Courtillat}

University of Perpignan, France

margot.courtillat@univ-perp.fr, @MargotCourtill1

I'm a micropaleontologist. I am working with tiny marine fossils to reconstruct the climate of the past! From the depths of the Amundsen Sea (p. 12)

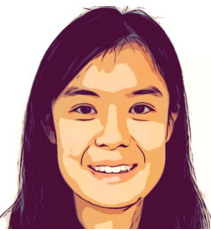

Fangyi Tan

Nanyang Technological University, Singapore FANGYI001@e.ntu.edu.sg, @fangyi2110 I use corals and mangrove sediments to study changes in sea level over the past $\sim 8000$ years. It's fun looking for clues from the past! Why sea level is not level (p. 16)

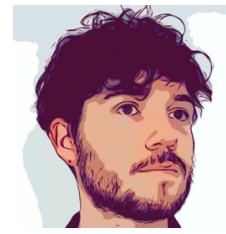

\section{Jérémie Moreau}

jeremie.morrow@googlemail.com,

@jeremiemoreaubd

I am a comic-strip author. I create stories and draw them - mainly stories about nature and living beings. Cover, The stone readers (p. 23)

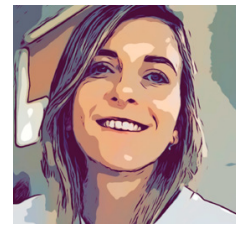

Nicole Pierce

University of Newcastle, Australia

nicole.pierce@uon.edu.au, @nikkipierceart I am a natural history illustrator and passionate about art-science collaboration. I specialize in fine art paintings, scientific illustrations and visual storytelling.

The South Pacific and climate change (p. 30)

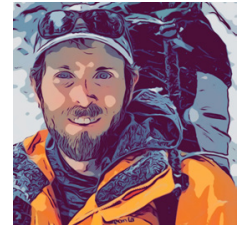

Nathan Chellman

Desert Research Institute, Reno, NV, USA

Nathan.Chellman@dri.edu

I study the chemistry of ice cores, tree rings, and lake sediments to look at how Earth's environment has changed over the past.

Linking lead pollution in ice cores to ancient history (p. 34)

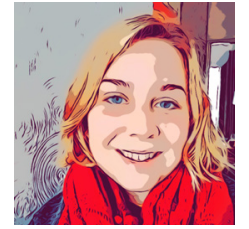

\section{Laura Hunt}

British Geological Survey and University of Nottingham, UK

Laura.Hunt@nottingham.ac.uk, @laura_hunt7 I'm a geoscientist who analyzes the stable isotope composition of mud (ew!) to understand how tropical lakes have been affected by past environmental change.

Lake mud detectives (p. 36) 


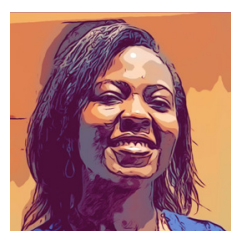

Angela Nankabirwa

National Fisheries Resources Research Institute, Jinja, Uganda

angelenankabirwa@gmail.com

I'm an algologist who studies functions and changes of algae communities in the environment to explain variations in fisheries and ecosystems as a whole. Lake mud detectives (p. 36)

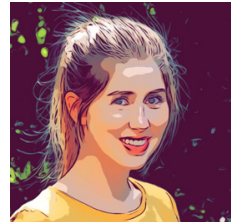

\section{Andrea Miebach}

University of Bonn, Germany

a.miebach@uni-bonn.de

I'm a paleoecologist studying how climate and people have changed the environment over thousands of years.

Pollen reveals the plant world of the past (p. 38)

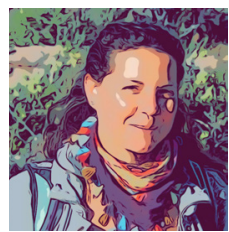

María Eugenia de Porras

IANIGLA, CONICET, Argentina

medeporras@mendoza-conicet.gob.ar, @eudepo1

I'm a paleoecologist in love with arid and semiarid lands, studying their changes in environment and climate during the last 20,000 years.

Humans and environments in the most arid place of the world (p. 44)

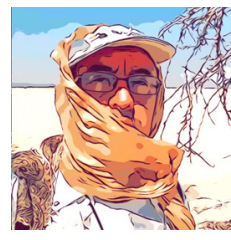

\section{Mauricio Uribe}

Universidad de Chile, Santiago, Chile

mur@uchile.cl

I'm an archaeologist studying past societies in the Atacama Desert. I look for Pre Columbian settlements and pottery to disentangle their lifestyle and social complexity.

Humans and environments in the most arid place of the world (p.44)

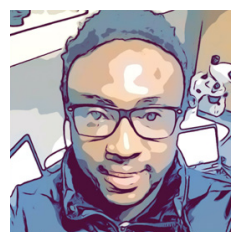

\section{Jerry Olatoyan}

University of the Witwatersrand,

Johannesburg, South Africa

2293675@students.wits.ac.za, @jerry_olu

I'm an archaeopalynologist - someone who finds it super cool to look at fossil pollen through a microscope, traveling back in time to assess environmental changes. Past farmers and the environment (p. 49)

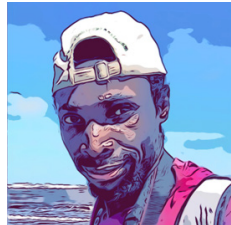

Peter Gitau

Sorbonne Université, Paris, France, and National Museums of Kenya

ngashpeter@gmail.com, @peterngangaG

I am an ecologist who travels back in time to find out how aquatic ecosystems respond to human and climate-driven changes.

Paleovirology (p. 52)

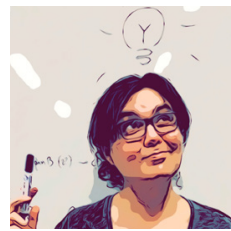

\section{Cirenia Arias Baldrich}

Oxford Brookes University, UK

cireniasketches@gmail.com, @CireniaSketches

I am a scientist and freelance illustrator in love with science communication. I help others to communicate their work using the power of images, keeping the rigor science demands.

Illustrations

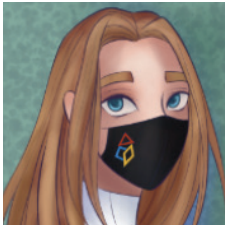

\section{Alice Favory}

alicefavory@icloud.com, @alixydrawing

I'm an illustrator who does digital as well as traditional drawing. I draw futuristic universes and original characters.

Editorial illustration (p. 3)

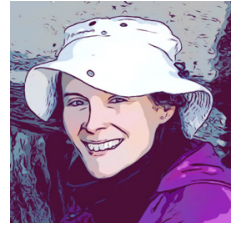

\section{Graciela Gil-Romera}

\section{CSIC, Zaragoza, Spain}

graciela.gil@ipe.csic.es

I'm a time-traveller who investigates how ecosystems coped with change in the past. I try to translate that knowledge to the present so we can have a better future.

Editor, Glossary (p. 54)

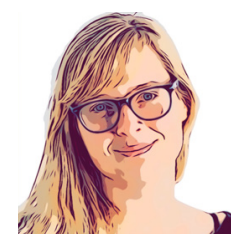

Tessa Driessen

Loughborough University, UK

t.d.driessen@lboro.ac.uk, @tessa_desi

I'm a paleoecologist - someone who studies the

ecology of the past - with a focus on diatoms and pollen in tropical crater lakes.

Lake mud detectives (p. 36)

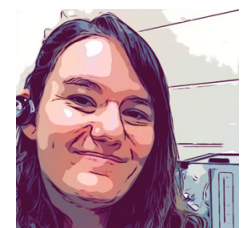

\section{Emma Rehn}

James Cook University, Cairns, Australia

emma.rehn@my.jcu.edu.au, @BlueRehn, @bluerehn

I'm a charcoal specialist - I look at tiny burnt pieces of plants under a microscope to see ancient bushfires. I also draw comics!

How to record fires that burned thousands of years ago (p. 41)

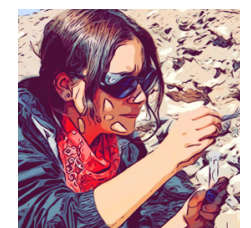

Eugenia M. Gayó

UPWELL, Santiago, Chile

emgayo@uc.cl, @kenagayoh

I'm a human ecologist. Most of the time I'm studying how societies and their environment have interacted over the last 18,000 years!

Humans and environments in the most arid place of the world (p. 44)

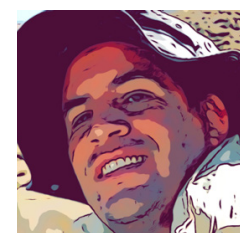

\section{Antonio Maldonado}

University of Perpignan, France

amaldonado@ceaza.cl, @AntonioMaldo5

I'm a palynologist; I investigate past climate changes aided by microscopic pollen grains preserved in fossi records from southern South America.

Humans and environments in the most arid place of the world (p. 44)

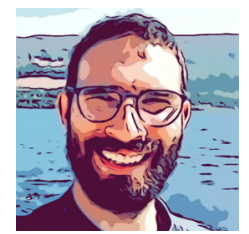

\section{Marco Palombell}

ink.mpalo@gmail.com, @ilcorvoblu, @ilcorvoblu I'm a comic artist-biologist using my expertise in both fields to weave stories about animals, people, and the wonderful planet they inhabit. Paleovirology (p. 52)

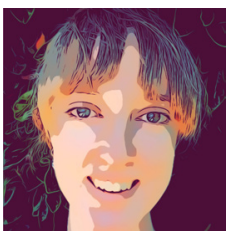

Robyn Granger

University of Cape Town, South Africa GRNROB016@myuct.ac.za, @RobsGranger

I am a paleoceanographer, and I use tiny marine fossils as clues to help unravel the mysteries of how the ocean works.

Glossary (p. 54)

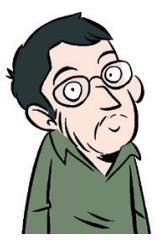

\section{Peb \& Fox}

peb.fox@laposte.net,

facebook.com/pebfox

We are two comic book authors who learn things about science by explaining them to others.

Paleotherapy (p. 60)
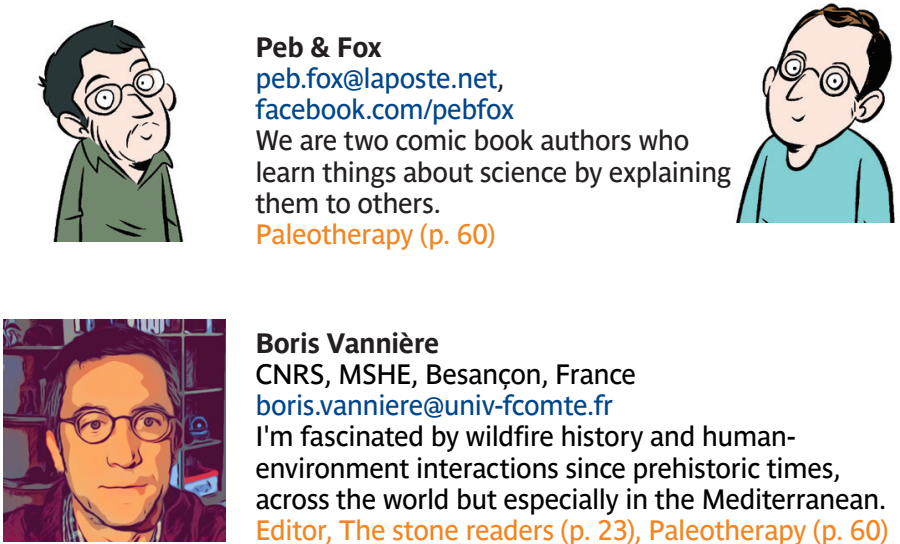

Boris Vannière

CNRS, MSHE, Besançon, France

boris.vanniere@univ-fcomte.fr

I'm fascinated by wildfire history and humanenvironment interactions since prehistoric times, across the world but especially in the Mediterranean. Editor, The stone readers (p. 23), Paleotherapy (p. 60)

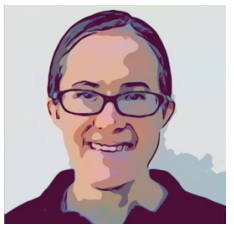

Sarah Eggleston

Past Global Changes, Bern, Switzerland

sarah.eggleston@pages.unibe.ch

I'm an ice-core scientist now at PAGES, where I assist other paleoresearchers with their work. Editor 


\section{RESOURCES AND REFERENCES}

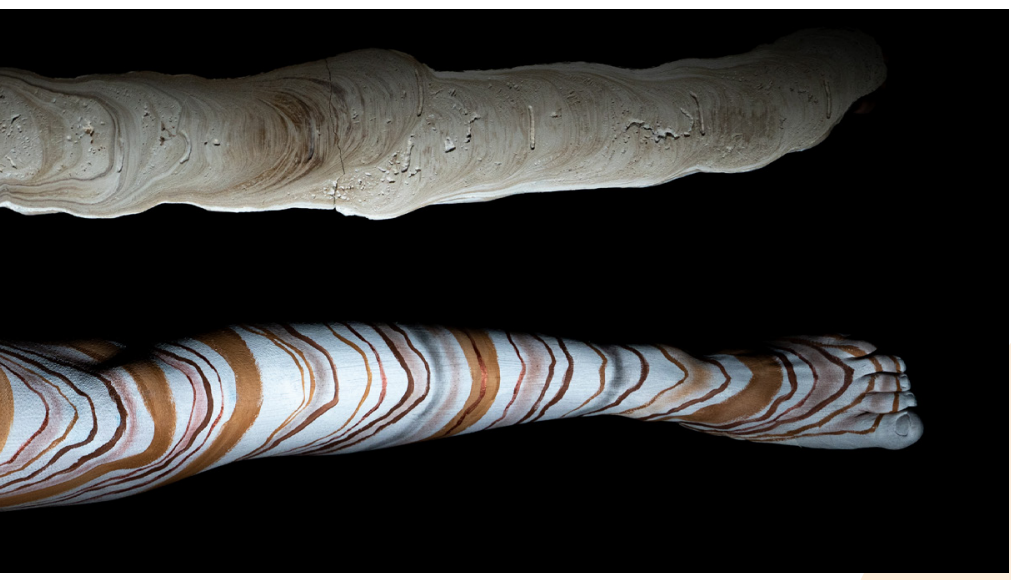

\section{Cambio a Flor de Piel}

which roughly translates from Spanish into English as "Changing the flower's skin", is a short movie explaining how the science of the past can help us achieve a better future. The movie uses a unique media format to transmit science - the mixture of bodypainting, music, and poetry transforming science into emotions and appealing to our artistic sides. The movie is directed by Graciela Gil-Romera (@gilromera) and Alejandra Vicente de Vera (@jani_vdv), part-time artists as well as scientists in the Palaeoenvironments and Global Change group at the Pyrenean Institute of Ecology (IPE-CSIC) (@PaleoIPE). Watch the video, with multilingual subtitles: youtube.com/watch?v=rnRfbOZ-ui0

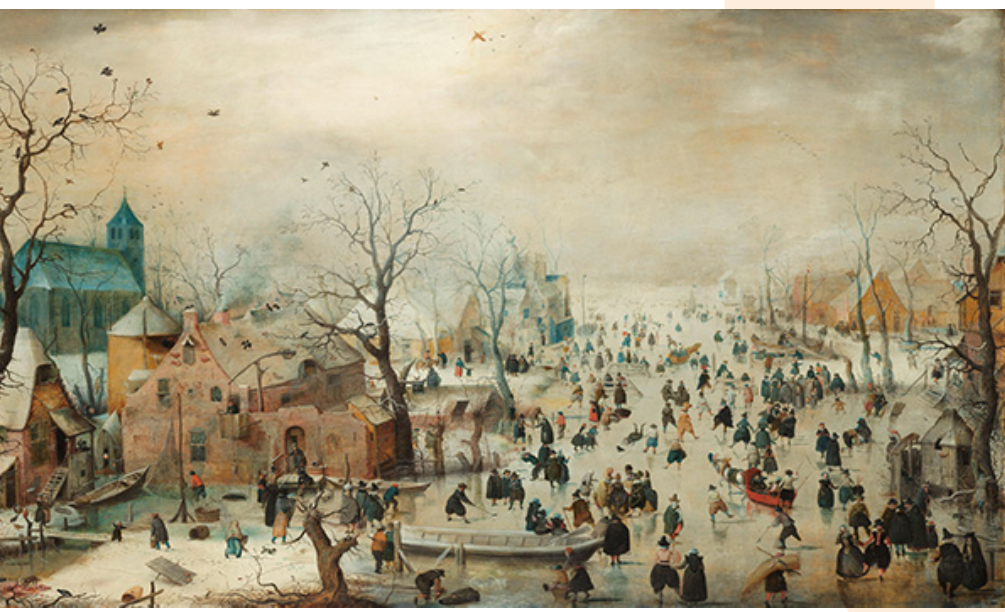

\section{Weathered History}

is a digital exhibition showing the matieral side of past climate change. Climate history is visualized using objects from 12,000 years of human history. On display are diverse testimonies from a wide range of countries, from cave paintings to sometimes curious technical inventions, such as the "dandy horse", and weather reports on cigarette packets from Hong Kong. The exhibition, which is available in German and English, was created by the Leibniz Institute for the History and Culture of Eastern Europe (GWZO), in cooperation with PAGES' Climate Reconstruction and Impacts from the Archives of Societies (CRIAS) working group: pastglobalchanges.org/ crias. Watch Weathered History: artsandculture.google.com/exhibit/ weathered-history/hwJiMeBlg6zDLg?hl=en

For further insights into some scientific research topics, exhibitions, books, and videos, go to the Outreach section of the Institut de recherche en sciences de l'environement (IPSL) website: ipsl.fr/en/Outreach

\section{Mills and Jones (pp. 4-5)}

1. UNSDGs

2. Intergovernmental Panel on Climate Change Assessment Reports

\section{Oldfield (pp. 6-8)}

1. IPCC (2013) Stocker TF et al. (Eds) Climate Change 2013: The Physical Science Basis. Cambridge University Press, 1535 pp.

2. Leedham C, Allen M (2021) Global Warming Index:

https://globalwarmingindex.org, accessed 17 March 2021

3. Real Climate: A useful and authoritative website covering all aspects of climate change, including modeling

4. Nature Climate Change: Up-to-date accounts from primary sources, often with more accessible editorial summaries of important issues. Original articles can also be accessed online

5. Intergovernmental Panel on Climate Change (IPCC): It is important to make yourself aware of the reports issued by the IPCC

6. NASA: Summaries of evidence for, and the nature of, climate change

7. Carbon Brief: A useful introduction to climate models is provided by the Q\&A "How do climate models work?"

8. Tree rings: A clear and relatively simple explanation of the use of tree rings to reconstruct climate (dendroclimatology)

\section{Hernández-Almeida and Saavedra-Pellitero (pp. 9-11)}

1. Florisphaera: Check out the original publication to learn about past ocean productivity using Florisphaera profunda

2. EarthLabs: Phytoplankton - The Ocean's Green Machines

3. ESA: Twenty years of ocean primary productivity, as seen from space

\section{Courtillat (pp. 12-15)}

1. Blog: The expedition describing day to day life on board with a lot of illustrations (in French)

2. Video: Made by Vivien Cumming during the expedition, this video explains the scientific project in detail (in English)

3. Video: Also made onboard, this report explains diatoms and their role in the reconstruction of Antarctic history (in English)

4. Website: Karen Romano Young was the artist on board during the expedition

5. Gohl K et al. (2019) Expedition 379 Preliminary Report: Amundsen Sea West Antarctic Ice Sheet History. International Ocean Discovery Program

6. Naish T et al. (2009) Nature 458: 322-328

7. IPCC (2018) Masson-Delmotte $V$ et al. (Eds) Global Warming of $1.5^{\circ} \mathrm{C}$. World Meteorological Organization, 32 pp.

\section{Sefton and Tan (pp. 16-19)}

1. IPCC: Pörtner H-O et al. (Eds) (2019) IPCC Special Report on the Ocean and Cryosphere in a Changing Climate

2. Kopp RE et al. (2016) Proc Natl Acad Sci USA 113: E1434-E1441

3. CSIRO (2016) Sea level data: www.cmar.csiro.au/sealevel/sl_data_ cmar.html, accessed 6 September 2020

4. NASA (2020) Understanding sea level: Global mean sea level: https:// sealevel.nasa.gov/understanding-sea-level/key-indicators/globalmean-sea-level/, accessed 6 September 2020

5. Galili E et al. (2019) PLoS One 14: e0222560

Hunt et al. (pp. 36-37)

1. Blog: Read about our recent fieldwork in Uganda

2. Video: Watch an interview with Tessa Driessen about her research and photography 


\section{Miebach (pp. 38-40)}

1. Litt et al. (2012) Quat Sci Rev 49: 95-105

2. Video: Tired of reading? Take a look at this short video about pollen

3. Video: Want to know more about pollen analysis? Here's an informative video

4. Video: Some nice images from the Dead Sea

\section{De Porras et al. (pp. 44-48)}

1. Workman TR et al. (2020) Quat Sci Rev 243: 106502

2. Villavicencio NA et al. (2019) In: Cartes L et al. (Eds) Avances en Paleontología Chilena. Instituto Antárctico Chileno, pp. 296-298

3. Maldonado A et al. (2016) PAGES Mag 24: 56-57

4. Santoro CM et al. (2017) J Anthropol Archaeol 46: 28-39

5. Uribe M et al. (2020) Lat Am Antiq 1: 81-102

6. Uribe M (2006) Estudios atacameños 31: 91-114

7. Gayo EM et al. (2019) Elem Sci Anth 7: 15

\section{Olatoyan (pp. 49-51)}

1. Ferrar AA, Lötter MC (2007) Mpumalanga biodiversity conservation plan handbook. Mpumalanga Tourism \& Parks Agency, pp 9-12

2. Huffman TN (2007) Handbook to the Iron Age: the archaeology of pre-colonial farming communities in southern Africa, pp 331

3. Manning K et al. (2011) J Archaeol Sci 38: 312-322

4. Crowther A et al. (2018) Quat Int 489: 101-120

5. Humphris JE (2010) An Archaeometallurgical Investigation of Iron Smelting Traditions in Southern Rwanda. PhD thesis, pp. 37-43

6. MIME/ADB (1996) Cambodian Energy Statistics; Sources of Energy Data and Methods of Estimation. United Nations, 69 pp

7. Food and Agriculture Organization (FAO) (2010) Forestry Paper, Ch. 2

8. Shi N et al. (1998) Veg Hist Archaeobot 7: 127-140

9. Willis KJ (2019) Tribulus terrestris (85.4.1 - 1). Digitized palynological slide. Obtained from: Martin AC, Harvey WJ (2017)

10.Widgren M et al. (2016) J Afr Archaeol 14: 33-53

\section{Glossary (pp. 54-55)}

1. Age models: On this website, under "Software and animations", you can see an animation of how fast sediments deposit and how the depth-age model is therefore built.

2. Radiocarbon: Here's an interesting article in The Conversation about how radiocarbon dating works

\section{ACKNOWLEDGMENTS}

The editors extend their sincere gratitude to Clara Aguilar, Yassine Ait Brahim, Stella Alexandroff, María Andrés, Asfawossen Asrat, Mindy Bell, Stephanie Borg, Ed Brook, Daniel Bruno, Emilie Capron, Cristiano M. Chiessi, Elisabeth Dietze, Mike Evans, Fátima Franco, Eva Fuentes, Carmen Galián-Barrueco, Eduardo García Prieto, Lindsey Gillson, Dai Grady, Alaia Herranz Franco, Darrell Kaufman, Christophe Le Gall, Quentin Lepiller, Nick Marriner, Erin Martin-Jones, Neil Roberts, Enrique Royuela, Deirdre Ryan, Willy Tinner, and Blas Valero-Garcés for lending their expertise in reviewing the articles in this issue.

Boris Vannière is supported by the Centre National de la Recherche Scientifique (CNRS) and the Maison des Sciences de l'Homme et de I'Environnement (MSHE), France.

Graciela Gil-Romera is supported by the Philipps-Märburg University, Germany, and the Spanish Research and Science Council (CSIC), Spain.

\section{Sefton and Tan (pp. 16-19)}

Symbols are attributed to Biorender, Canva and ian.umces.edu. Styling attributed to Canva.

\section{Frisia et al. (pp. 30-33)}

We are indebted to the Australian Research Council (ARCDP160101058) and the Australia Synchrotron for support. Thanks to Mohammadali Faraji who provided the Sr image for Fig. 5 and Andrea Borsato for the data used in Fig. 4 and 5.

\section{De Porras et al. (pp. 44-48)}

The authors are very thankful to Carla Infanta Gabor (Instagram: @carla_ilustraciones) for her dedication during the illustration process, and Delfina España and Zoë Fleming for their help with the design and language style, respectively. Project FONDECYT \#1181829 financially supported this publication.

\section{PA_ES PAST Global CHANGes PA—ES CEIEBRAINNG ZO YEARS}

\section{PAGES International Project Office}

Hochschulstrasse 4

CH-3012 Bern, Switzerland

\section{Series Editors}

Sarah Eggleston, Boris Vannière, Graciela Gil-Romera, Marie-France Loutre

\section{Text Editing}

Angela Wade

\section{Layout}

Sarah Eggleston

\section{Design}

sujata.design
Telephone

Email

Website

Twitter

Facebook

Find out more about PAGES Horizons at

pastglobalchanges.org/products/pages-horizons

\section{Parent program}

PAGES is a Global Research Project of Future Earth.

\section{Supporters}

The PAGES International Project Office and its publications are supported by the Swiss Academy of Sciences (SCNAT), the Chinese Academy of Sciences (CAS), and the University of Bern, Switzerland. 


\section{PALEOTHERAPY}

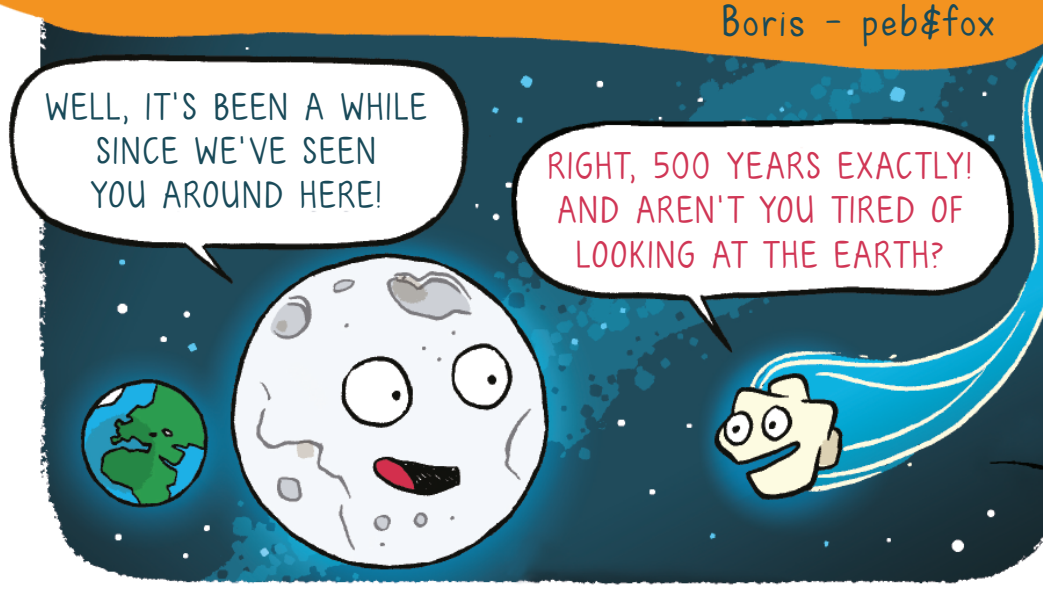

Actually, it's changing a lot at the moment!
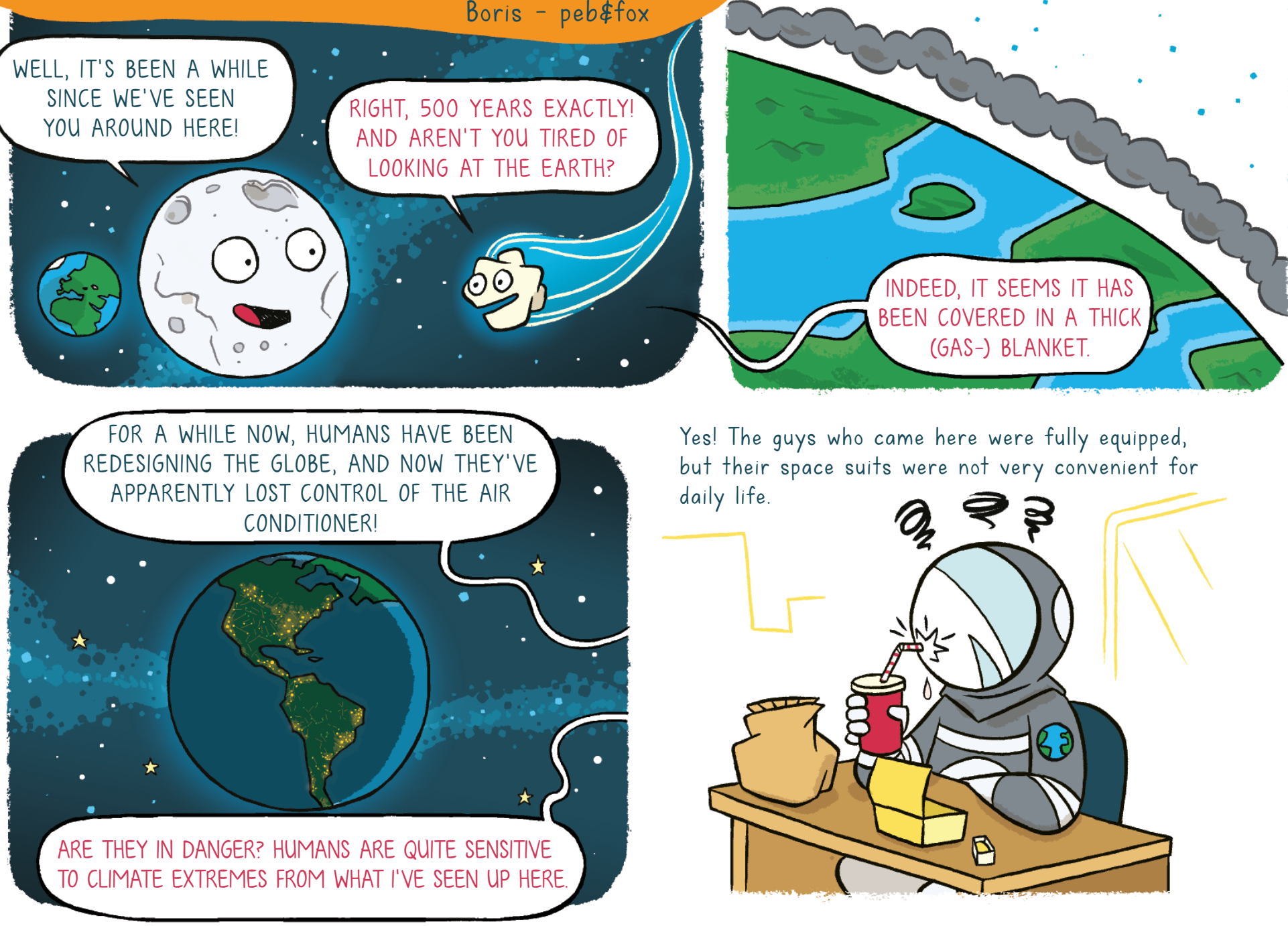

Yes! The guys who came here were fully equipped, but their space suits were not very convenient for

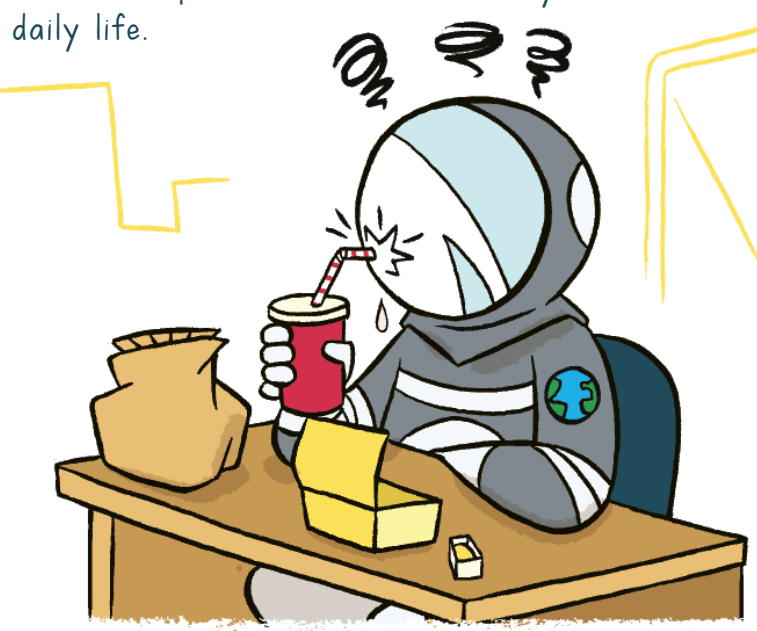

If I recall correctly, societies have been suffering from changes in weather for thousands of years.

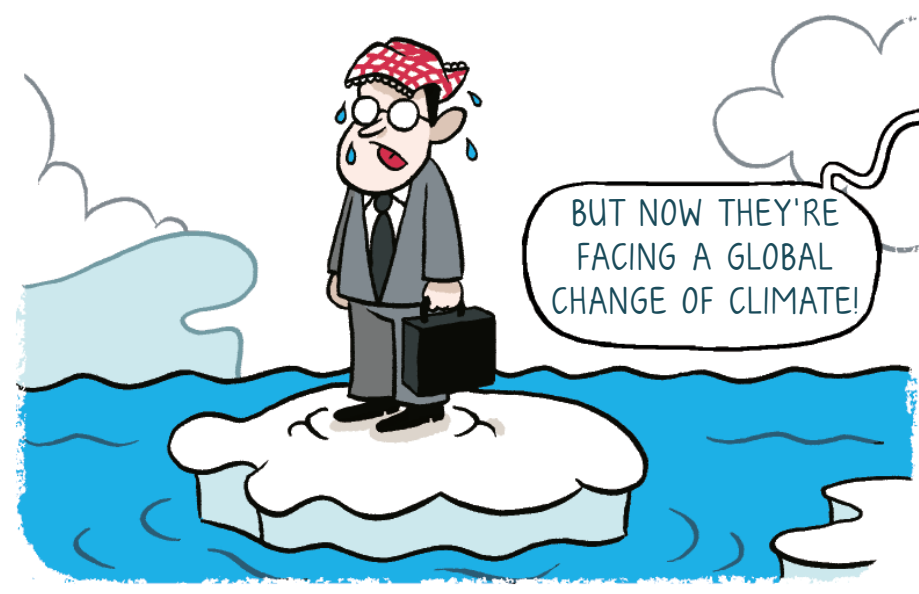

Have they forgotten what their ancestors went

through in the recent past?

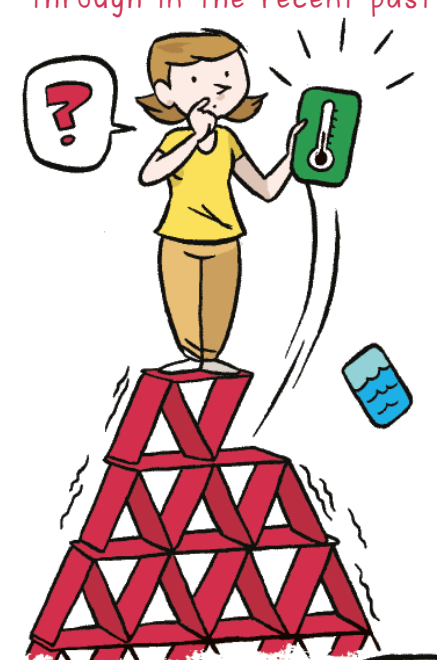

0
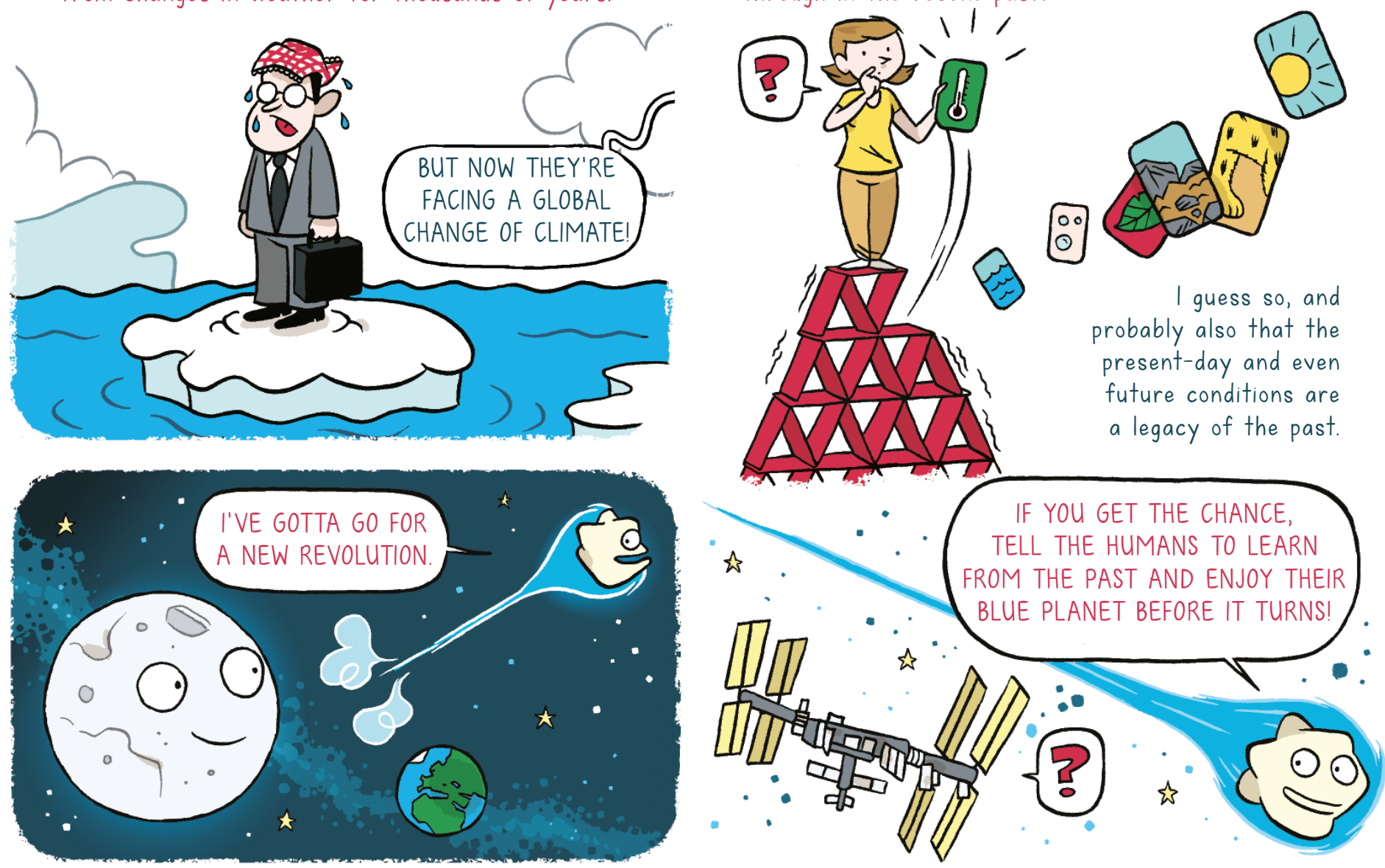